\title{
Protease activity as a prognostic factor for wound healing in venous leg ulcers (Review)
}

Westby MJ, Dumville JC, Stubbs N, Norman G, Wong JKF, Cullum N, Riley RD

Westby MJ, Dumville JC, Stubbs N, Norman G, Wong JKF, Cullum N, Riley RD.

Protease activity as a prognostic factor for wound healing in venous leg ulcers.

Cochrane Database of Systematic Reviews 2018, Issue 9. Art. No.: CD012841.

DOI: 10.1002/14651858.CD012841.pub2.

www.cochranelibrary.com 
TABLE OF CONTENTS

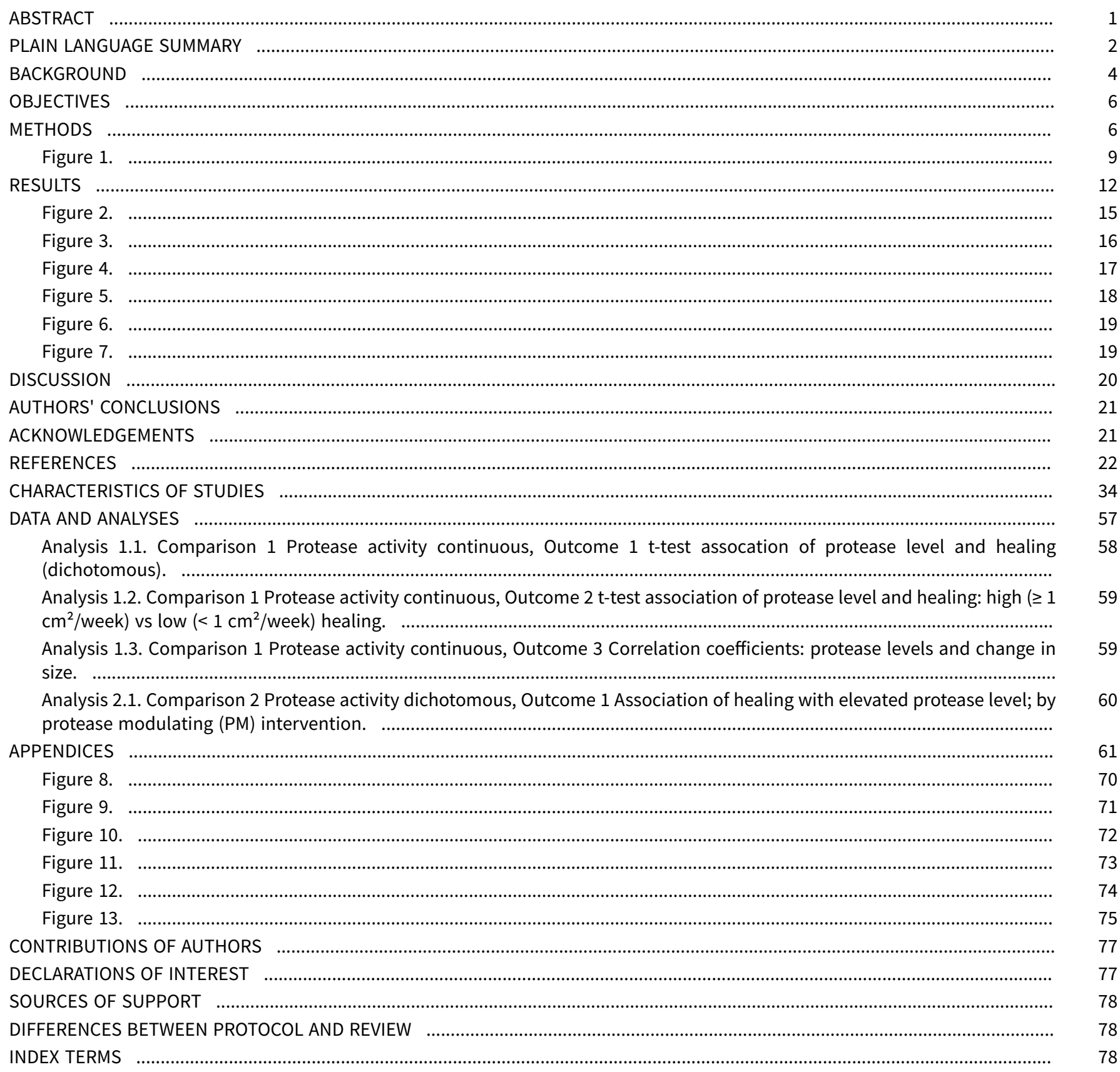


[Prognosis Review]

\section{Protease activity as a prognostic factor for wound healing in venous leg ulcers}

Maggie J Westby¹, Jo C Dumville¹, Nikki Stubbs², Gill Norman¹, Jason KF Wong³, Nicky Cullum¹, Richard D Riley ${ }^{4}$

1Division of Nursing, Midwifery and Social Work, School of Health Sciences, Faculty of Biology, Medicine and Health, University of Manchester, Manchester Academic Health Science Centre, Manchester, UK. 2 Leeds Community Healthcare NHS Trust, St Mary's Hospital, Leeds, UK. 3 Manchester Centre for Plastic Surgery and Burns, Wythenshawe Hospital, Manchester University NHS Foundation Trust, Manchester, UK. ${ }^{4}$ Research Institute for Primary Care and Health Sciences, Keele University, Keele, UK

Contact: Maggie J Westby, Division of Nursing, Midwifery and Social Work, School of Health Sciences, Faculty of Biology, Medicine and Health, University of Manchester, Manchester Academic Health Science Centre, Jean McFarlane Building, Oxford Road, Manchester, M13 9PL, UK. maggie.westby@manchester.ac.uk.

Editorial group: Cochrane Wounds Group.

Publication status and date: New, published in Issue 9, 2018.

Citation: Westby MJ, Dumville JC, Stubbs N, Norman G, Wong JKF, Cullum N, Riley RD. Protease activity as a prognostic factor for wound healing in venous leg ulcers. Cochrane Database of Systematic Reviews 2018, Issue 9. Art. No.: CD012841. DOI: 10.1002/14651858.CD012841.pub2.

Copyright @ 2018 The Cochrane Collaboration. Published by John Wiley \& Sons, Ltd.

\section{A B S T R A C T}

\section{Background}

Venous leg ulcers (VLUs) are a common type of complex wound that have a negative impact on people's lives and incur high costs for health services and society. It has been suggested that prolonged high levels of protease activity in the later stages of the healing of chronic wounds may be associated with delayed healing. Protease modulating treatments have been developed which seek to modulate protease activity and thereby promote healing in chronic wounds.

\section{Objectives}

To determine whether protease activity is an independent prognostic factor for the healing of venous leg ulcers.

\section{Search methods}

In February 2018, we searched the following databases: Cochrane Central Register of Controlled Trials (CENTRAL), Ovid MEDLINE, Ovid Embase and CINAHL.

\section{Selection criteria}

We included prospective and retrospective longitudinal studies with any follow-up period that recruited people with VLUs and investigated whether protease activity in wound fluid was associated with future healing of VLUs. We included randomised controlled trials (RCTs) analysed as cohort studies, provided interventions were taken into account in the analysis, and case-control studies if there were no available cohort studies. We also included prediction model studies provided they reported separately associations of individual prognostic factors (protease activity) with healing. Studies of any type of protease or combination of proteases were eligible, including proteases from bacteria, and the prognostic factor could be examined as a continuous or categorical variable; any cut-off point was permitted. The primary outcomes were time to healing (survival analysis) and the proportion of people with ulcers completely healed; the secondary outcome was change in ulcer size/rate of wound closure. We extracted unadjusted (simple) and adjusted (multivariable) associations between the prognostic factor and healing. 


\section{Data collection and analysis}

Two review authors independently assessed studies for inclusion at each stage, and undertook data extraction, assessment of risk of bias and GRADE assessment. We collected association statistics where available. No study reported adjusted analyses: instead we collected unadjusted results or calculated association measures from raw data. We calculated risk ratios when both outcome and prognostic factor were dichotomous variables. When the prognostic factor was reported as continuous data and healing outcomes were dichotomous, we either performed regression analysis or analysed the impact of healing on protease levels, analysing as the standardised mean difference. When both prognostic factor and outcome were continuous data, we reported correlation coefficients or calculated them from individual participant data.

We displayed all results on forest plots to give an overall visual representation. We planned to conduct meta-analyses where this was appropriate, otherwise we summarised narratively.

\section{Main results}

We included 19 studies comprising 21 cohorts involving 646 participants. Only 11 studies ( 13 cohorts, 522 participants) had data available for analysis. Of these, five were prospective cohort studies, four were RCTs and two had a type of case-control design. Follow-up time ranged from four to 36 weeks. Studies covered 10 different matrix metalloproteases (MMPs) and two serine proteases (human neutrophil elastase and urokinase-type plasminogen activators). Two studies recorded complete healing as an outcome; other studies recorded partial healing measures. There was clinical and methodological heterogeneity across studies; for example, in the definition of healing, the type of protease and its measurement, the distribution of active and bound protease species, the types of treatment and the reporting of results. Therefore, meta-analysis was not performed. No study had conducted multivariable analyses and all included evidence was of very low certainty because of the lack of adjustment for confounders, the high risk of bias for all studies except one, imprecision around the measures of association and inconsistency in the direction of association. Collectively the research indicated complete uncertainty as to the association between protease activity and VLU healing.

\section{Authors' conclusions}

This review identified very low validity evidence regarding any association between protease activity and VLU healing and there is complete uncertainty regarding the relationship. The review offers information for both future research and systematic review methodology.

\section{PLAIN LANGUAGE SUMMARY}

\section{Protease activity and its association with future healing of venous leg ulcers}

\section{What is the aim of this review?}

The aim of this Cochrane Review was to find out if there is a link between different levels of protease in venous leg ulcers (open skin wounds on the lower leg caused by problems with the way blood flows through the veins) now and the healing of wounds at some time in the future. Protease is an enzyme, a chemical naturally produced by the body that breaks down proteins and which may affect wound healing. We wanted to know whether having higher protease levels meant that wounds were less likely to heal or to heal more slowly. If so, this could help find the most useful treatments for each person with a leg ulcer. Review authors from Cochrane collected and analysed all relevant studies to answer this question and found 19 studies.

\section{Key messages}

At the moment, there is complete uncertainty about any association between protease activity and venous leg ulcer healing, but this review did give pointers on what may be important for future research on natural chemicals present in wounds and their effect on healing.

\section{What was studied in the review?}

Venous leg ulcers can last weeks, months or years. Leg ulcers can be painful, may become infected, and may affect mobility and quality of life. The usual treatment for venous leg ulcers is compression therapy (e.g. compression (elastic) bandages), but even this does not work for everyone (about a third of people still have wounds that have not healed after six months). We wanted to find out why these wounds often do not heal, and whether there are factors in the wound (called biomarkers) that can indicate which wounds are unlikely to heal. It has been suggested that wounds are slow to heal when there are high levels of protease. In this review, we investigated whether there was any evidence that higher protease levels at the start of a study were associated with slower healing leg ulcers or less healing at a future time point (such as six months).

In February 2018, we searched for relevant studies that had a reliable design and that investigated links between protease levels and future healing of venous leg ulcers. We found 19 studies involving 646 people. Not all studies reported the age and sex of participants. In those that did, the average age of the participants varied from 51 to 75 years. Eleven studies gave results we could use, involving 13 groups of people. Most people had wounds that had been there for at least three months.

\section{What were the main results of the review?}


There were many differences among the included studies: for example, how they defined healing, the type of proteases and how they measured them, the types of treatment and how they reported results. This lack of consistency meant we could not combine and compare the results, so we summarised the findings in a general way.

A bigger problem was that none of the studies had analysed the data appropriately as they did not take into account the impact of age or infection or treatments, and so we could not be sure that it was the protease levels that were important for healing, rather than age or other factors. Most studies were small and could have been better conducted, so it was difficult to be sure how meaningful the results were. Overall, the certainty of the evidence was very low. Further studies are needed to explore the importance of biomarkers for wound healing.

\section{How up to date is this review?}

We searched for studies that had been published up to February 2018. 


\section{B A C K G R O U N D}

\section{Description of the condition}

Venous leg ulcers (VLUs) are open skin ulcers (wounds) on the lower leg (from below the ankle up to mid-calf), that can last weeks, months or years, and are a consequence of problems in either the superficial or deep veins (or both) of the legs. Damage to the valves or vein blockages results in malfunctioning of the venous system, reducing the efficient return of blood to the heart and increasing the pressure in the leg veins (Ghauri 2010; Vlajinac 2014), which, if prolonged, may result in VLUs. The precise chain of events that links the high venous pressures with skin breakdown and a chronic wound is not fully understood (Coleridge Smith 1988; Valencia 2001). Leg ulcers are frequently associated with venous disease in combination with vascular disease, which impairs arterial blood supply, and such ulcers are said to have a 'mixed aetiology' (Marston 2011).

Accurate current estimates of leg ulcer prevalence are difficult to identify because most surveys do not differentiate between causes of leg ulceration, or do so per limb but not per participant (Moffatt 2004; Srinivasaiah 2007; Vowden 2009). One 2011 estimate suggested that venous ulceration has a point prevalence of 0.29 cases per 1000 in the UK, whilst mixed arterial/venous leg ulceration has a point prevalence of 0.11 per 1000 (Hall 2014). One systematic review also reported the point prevalence of leg ulcers in non-UK studies as: 0.39 per 1000 in New Zealand in 2004, 1.4 per 1000 in Portugal in 2005 and 2.4 per 1000 in Sweden in 2008 (Cullum 2016).

Venous disease is a chronic condition characterised by periods of ulceration (i.e. an open wound) followed by healing and then recurrence, though published contemporary data are lacking: one cross-sectional study from the 1980 s reported that half of current or recent ulcers had been open for up to nine months and that $35 \%$ of people with leg ulcers had experienced four or more episodes (Callam 1987). This picture was supported by a subsequent (1988) cross-sectional study (Nelzén 1994).

Several prognostic factors have been independently associated with slower or reduced healing of VLUs, for example, wound area, duration of ulcer, age, number of wounds, lack of mobility (especially ankle) and weight (Ashby 2014; Barwell 2000; Barwell 2001; Chaby 2013; Gohel 2005; Harrison 2011; Iglesias 2004; Lantis 2013; Margolis 1999; Margolis 2004; Milic 2009; Moffatt 2010; Scotton 2014).

The first-line treatment for VLUs is compression therapy in the form of bandages, stockings or mechanical devices (O'Meara 2012). This application of external pressure around the lower leg assists venous return and reduces the pooling of blood in the legs (venous reflux) (Fletcher 2013; O'Meara 2012). Alongside compression, dressings are almost always applied to open ulcers (O'Meara 2014). Other treatments for VLUs include venous surgery (removal of incompetent superficial veins) (SIGN 2010), and drugs such as pentoxifylline (Jull 2012).

Leg ulcers are associated with considerable cost to patients and to healthcare providers.

Two systematic reviews summarised the literature on healthrelated quality of life in people with leg ulcers (Herber
2007; Persoon 2004). Both included qualitative and quantitative evaluations, and reported that presence of leg ulceration was associated with pain, restriction of work and leisure activities, impaired mobility, sleep disturbance, reduced psychological wellbeing and social isolation. Ulcers can be painful, malodorous, prone to infection, and may severely affect people's mobility and quality of life (Dumville 2009; Herber 2007). In severe cases, ulceration can lead to limb amputation, though this is more likely in people who also have arterial insufficiency (Dumville 2009; Nelzén 2008; Valencia 2001), or even to a type of cancer known as Marjolin's ulcer (Choa 2015). Research suggested that people with complex wounds, including people with VLUs, commonly see complete ulcer healing as the most important outcome to them (Madden 2014).

The financial cost of treating a person with an open VLU in the UK was estimated at around GBP 1700 per year at 2012 prices: the largest component of ulcer treatment cost is nursing time (Ashby 2014). Another evaluation estimated the mean cost of treating a person with a VLU in Sweden as between EUR 1332 and EUR 2585 (based on costs for material for dressing changes) and in the UK as between EUR 814 and EUR 1994 (price year 2002), with higher costs associated with larger and more chronic wounds (Ragnarson Tennvall 2005). Data from one German study, which estimated total costs including those classified as indirect or intangible costs, estimated mean annual costs of treating leg ulcers as EUR 9060 per person (2006 evaluation). This figure was higher than other estimates because it included non-health service costs to the person and to society (Augustin 2012). One Australian cost-effectiveness study of 905 people estimated the mean cost per person per week for treatment of a chronic leg or foot ulcer below the knee for 24 weeks was AUD 53.31 (which corresponds to AUD 2772 per year); costs included consultations with healthcare professionals, compression bandaging, other dressings and treatments, and community care services, such as Meals-on-Wheels and home help (Graves 2014).

Research has shown that not all VLUs heal, even under trial conditions: one large study of 453 participants showed that about $30 \%$ of VLUs did not heal following first-line treatment with compression therapy over 12 months (Ashby 2014). There is interest in additional treatments that may improve wound healing, and one dressing option is the use of protease-modulating dressings, which are suggested to reduce the activity of a group of enzymes known as proteases. As discussed below, it is thought that prolonged and elevated activity of proteases may be a feature of non-healing wounds, such that appropriate use of proteasemodulating dressings could promote healing. However, evidence for the effectiveness of these dressings in VLUs is largely unclear (Westby 2016). Such dressings are a new development in wound care in that they are intended to be a 'targeted' treatment aimed at wounds with high protease activity. In this context, protease activity dictates subsequent treatment, but there is limited evidence supporting the use of a test-and-treat approach (Norman 2016). In fact, the prognostic nature of protease levels in relation to wound healing is unclear and this will be the focus of this Cochrane Review.

\section{Description of the prognostic factor}

A prognostic factor is any measure that, among people with a given health condition, is associated with a future clinical outcome; for example, in people with a VLU, lower body mass index (BMI) may be associated with less time to healing. The prognostic factor for this review was a biomarker, protease activity, 
which is sometimes elevated in open wounds. A biomarker is defined by the National Institutes of Health Biomarkers Definitions Working Group (1999) as "a characteristic that is objectively measured and evaluated as an indicator of normal biological processes, pathogenic processes, or pharmacologic responses to a therapeutic intervention" (Biomarkers Definitions Working Group 2001). Biomarkers are medical signs, as opposed to medical symptoms (which are indications of health or illness perceived by patients themselves) (Strimbu 2010). Biomarkers may predict health outcomes, but do not necessarily do so. However, there are still no accepted definitive biomarkers for making assessments of chronic wounds (Patel 2016; Yager 2007).

One possible biomarker type that has received some attention for wounds is proteases, which are enzymes that break down proteins into peptides and amino acids (Sittampalam 2017); in general, the various wound-related proteases break down different proteins. The principal proteases involved in the wound healing process are the matrix metalloproteinases (MMPs) and the serine proteases, which break down extracellular matrix (ECM) and connective tissue proteins such as collagen and elastin (Hahm 2011; Ladwig 2002; McCarty 2013; Nwomeh 1999; Velnar 2009). This protein breakdown is thought to be important in the early stages of the healing process because it facilitates movement of inflammatory cells into the injury site, which aids removal of unwanted material and bacteria. However, in the later stages of wound healing, protein breakdown is believed to be undesirable because the proteases damage newly formed tissue, preventing completion of healing (McCarty 2013; Velnar 2009).

Proteases are produced by an inflammatory process, which also inhibits the synthesis of chemicals that inhibit the action of metalloproteinases (tissue inhibitors of metalloproteinases; TIMPs). Some studies have measured the ratio of MMPs and TIMPs as a biomarker (McCarty 2013; Muller 2008), and it may be more valuable to consider the balance of proteases and their inhibitors as a biomarker (Löffek 2011; Yager 2007).

MMPs are divided into seven subtypes on the basis of their substrates and their domain structure (chemical components) (Lazaro 2016; Löffek 2011; Vihinen 2002): gelatinases (MMP-2 and MMP-9); collagenases (MMP-1, MMP-8, MMP-13); stromelysins (MMP-3, MMP-10, MMP-11); metalloelastase (MMP-12); matrilysins (MMP-7, MMP-26); membrane-type MMPs (MMP-14, MMP-15, MMP-16, MMP-17, MMP-24, MMP-25); and other MMPs (MMP-19, MMP-20, MMP-23, MMP-28). The main serine proteases are mast cell tryptase and chymase, plasmin, human neutrophil elastase (HNE), cathepsin G, urokinase-type plasminogen activators (UPA) and tissue-type plasminogen activators (t-PA) (Grøndahl-Hansen 1988). Other protease biomarkers include modular proteins that combine proteases with other biological species: for example, the families of $A$ disintegrin and metalloproteinase (ADAMs) (Duffy 2009; Edwards 2008), and A disintegrin and metalloproteinase with thrombospondin motifs (ADAMTSs) (Kelwick 2015). Chronic wounds also contain proteases associated with several types of bacteria (McCarty 2012; McCarty 2013; Percival 2012; Sibbald 2007; Suleman 2016). The activity level for each protease may be elevated at different stages of healing and there may also be different levels of activity in infected wounds (Serra 2016a), but there is currently insufficient evidence to differentiate proteases according to their function in the unhealed wound (Amato 2015; Lazaro 2016; Raffetto 2016; Serra 2017).
Protease activity can be measured in wound fluid using various biochemical tests. Laboratory-based scientific studies have used several different techniques, including approaches that primarily detect MMP-2 and MMP-9 (gelatin zymography), and methods that detect enzyme activity using either chemical (e.g. quenched fluorescence substrate hydrolysis) or biological antibody-based methods (enzyme-linked immunosorbent assays (ELISAs)) (Harding 2011; McCarty 2013; Sittampalam 2017). A range of methods of obtaining wound fluid has been used and these vary with the type of protease measured (Cullen 2006; Quirk 2003; Trengove 1999; Yager 2007). There is also a commercial colorimetric indicator available, which is said to determine protease activity, giving a colour change if activity is elevated above a threshold; the test uses a weighted average of the activity of elastase and one or more MMPs (Gibson 2014; NICE 2016).

\section{How the prognostic factor may be related to health outcomes}

It has been suggested that, in chronic ulcers generally, non-healing may be associated with prolonged high activity of proteases in the wound in the later stages of the wound healing process (Harding 2011; Hart 2002; McCarty 2013; Palolahti 1993).

Proteases are active in all phases of wound healing (haemostasis, inflammation, proliferation and remodelling) and are therefore thought to have a number of roles in the normal wound healing process (Patel 2016; Trengove 1999; Velnar 2009). It is thought that there is a burst of protease activity at the start of acute wound healing, and that in normally healing wounds, the activity peaks in the first few days and then declines to very low levels by one week, as healing progresses (Harding 2011; Nwomeh 1998).

However, in non-healing wounds, it is thought that high protease activity may arise through two main routes (involving different types of proteases): relating to both the host cells (human) and to bacteria in the wound. It is thought that the two types of protease activity may reinforce each other (have a synergistic mechanism) (McCarty 2012; McCarty 2013; Percival 2012; Sibbald 2007; Suleman 2016). In the host, complex inflammatory mechanisms may result in proteases reaching higher levels and persisting for longer than in normally healing wounds (McCarty 2013; Trengove 1999). As previously noted, this persistent breakdown of proteins (proteolytic activity) is thought to damage newly formed tissue and to degrade growth factors, leading to non-healing wounds (Cullen 2002a; Harding 2011; Wlaschek 1997; Yager 1997). Most chronic wounds are colonised with bacteria, though they are not necessarily infected. Bacterial proliferation and their formation into film-like material (biofilms) in non-healing wounds has been linked to chronic inflammation and then elevated protease levels. Infection refers to invasion of tissue by bacteria, leading to a clinically evident pathogenic inflammatory response and tissue damage (Percival 2012; Pugliese 2016; Sibbald 2007; Suleman 2016).

Limited evidence suggests correlations between elevated levels of MMPs and delayed healing in people with pressure ulcers (Ladwig 2002), or in foot ulcers of people with diabetes (Liu 2009), as well as in people with VLUs (Mwaura 2006; Serra 2013). It is possible that association of MMP level with delayed wound healing may be a general wound phenomenon, however differences between wound types have also been observed (Lazaro 2016; McCarty 2013). 
For VLUs in particular, studies of protease activity in wound fluid have suggested that there are significantly higher levels of proteases in ulcer tissue compared with healthy tissue, and that these levels decrease following compression treatment in wounds that heal (Beidler 2008); other studies have reported higher levels in chronic wounds compared with acute wounds (Lazaro 2016; Trengove 1999; Wysocki 1993).

However, association between protease activity and non-healing is not clear cut. Limited data from two industry-sponsored studies found that only $28 \%$ of 162 (Serena 2011) and 23\% of 139 (Gibson 2013) non-healing wounds of mixed aetiology had high protease activity; one of these studies reported that $22 \%$ of 101 leg ulcers had elevated protease activity (Gibson 2013).

Wound fluid is a useful source of biomarkers, and its composition is broadly assumed to reflect the current clinical condition of a wound (Löffler 2013). Wound fluid can be obtained in a largely noninvasive way, but to give reproducible and accurate measurement of biomarkers, the wound fluid has to be collected and processed reliably. There are several techniques for wound fluid sampling, including the use of occlusive dressings, entrapment of fluid in dressings, swabs, other techniques and devices. The duration of fluid collection can also be important (Löffler 2013).

\section{Importance of evidence about prognostic factors}

Biomarkers of this type may potentially be implicated in, or mediate, particular pathways to non-healing. Studying the prognosis associated with protease biomarkers has a three-fold purpose: first, it can help us understand mechanisms related to healing, including investigating the true causes of non-healing. Second, it can allow identification of wounds at increased risk of non-healing, which could allow selective treatment of these wounds according to the specific biomarker type and level. Third, biomarkers can be used to monitor a response to therapy (Riley 2013).

Targeted treatment of this type (the 'test-and-treat' or 'stratified medicine' approach) is important, especially if treatments are costly or have adverse effects, so that they are not used where they will not be effective (Hingorani 2013). It is likely that there is more than one pathway to non-healing and other pathways will probably be represented by other biomarkers. The best approach may be to determine a set of biomarkers and treat selectively according to their activity levels.

A commercial test for protease activity is now available (Gibson 2014), and is intended for use at the point of care, in conjunction with protease-modulating treatments (Barrett 2011; Harding 2011; Snyder 2011; Snyder 2013). This approach has mainly found application in diabetic foot ulcers (NICE 2016). A Cochrane Review on test-and-treat for healing in VLUs did not identify any studies (Norman 2016).

\section{Why it is important to do this review?}

VLUs are a common type of complex wound that have a negative impact on people's lives and incur high costs for health services and society. Leg ulcers are painful, sometimes malodorous, prone to infection and may severely affect the person's mobility and quality of life; in severe cases, there is a risk of limb amputation. There are a number of treatments for VLUs, but many ulcers prove hard to heal.

Two Cochrane Reviews investigated protease-modulating matrix (PMM) dressings, but there was insufficient evidence on the modulation of protease activity. Westby 2016 examined the effects of PMM dressings for healing VLUs, and found it was unclear whether PMM dressings increased the probability of healing at 12 weeks, in comparison with non-PMM dressings (risk ratio (RR) $1.28,95 \%$ confidence interval $(\mathrm{Cl}) 0.95$ to 1.71 ; 4 trials; 192 participants). The study populations typically comprised people with difficult-to-heal wounds, but only one study reported the level of protease. A second review searched for evidence on 'test-and-treat' approaches for healing VLUs; for example, PMM treatment given selectively to wounds with elevated protease activity (Norman 2016). It found no eligible studies. This current review is the third part of this set of Cochrane Reviews on protease activity-related treatment.

It is important to investigate whether elevated protease activity is a prognostic factor for healing. For practical use, the biomarker should be robust to adjustment for other factors such as age. This Cochrane Review was mainly exploratory in nature and its focus was on protease activity in general; it did not address associations of specific proteases, although we reported the actual proteases measured.

One literature review summarised clinical evidence on MMPs in chronic wound healing (Lazaro 2016). The authors reported studies that found correlations between MMP levels and various measures of healing, but did not give full quantitative data. They identified some studies investigating MMP thresholds for healing but these were in people with diabetic foot ulcers. The review did not examine the literature on proteases other than MMPs.

\section{O B JECT IVES}

To determine whether protease activity is an independent prognostic factor for wound healing in people with venous leg ulcers.

\section{METHODS}

The methods used in this review have two underlying assumptions: first, that biomarkers are representative of wound processes and can be used to monitor wound healing. Second, that the removal of wound fluid does not interfere with the healing processes (Yager 2007). It is unclear how robust these assumptions are.

\section{PICOTS system for this review (population, index, comparator, outcome(s), timing, setting)}

The PICOTS summary for this review was:

\begin{tabular}{llll}
\hline Population & $\begin{array}{l}\text { Index (prognos- } \\
\text { tic factor under } \\
\text { study) }\end{array}$ & Timing & Setting \\
\hline
\end{tabular}


People with venous leg ulcers
Protease activity Healing:

- time to healing (survival analysis)

- proportion of people with ulcers completely healed
Prognosis:

Any

- any follow-up period for outcome measurement (predicted 8-24 weeks)

- prognostic factor measured at baseline, representing time of wound assessment
We used the PICOTS system to formulate the review question, the objective and the inclusion criteria for the review (Debray 2017; Moons 2014), the comparator was not relevant in our review. Further details are given below.

\section{Criteria for considering studies for this review Types of studies}

We included reports of prospective and retrospective longitudinal studies that investigated whether the prognostic factor, protease activity, was associated with healing of VLUs, as such studies can produce valid odds or hazard ratios of prognostic factors. We did not include studies that solely examined the validation of prediction models, but we did include prediction model development studies when they also reported associations of individual prognostic factors (protease activity) with the outcome under study (healing). We included randomised controlled trials (RCTs) analysed as cohort studies, provided interventions were taken into account in the analysis. We included case-control studies only if there were no relevant eligible cohort studies for specific proteases. We included case-control studies because the design can provide valid estimates of associations between a prognostic factor and outcomes provided that the follow-up time is not too long. However, we acknowledge that case-control studies often suffer from other deficiencies (Altman 2001): these were assessed in our risk of bias assessment. We did not include cross-sectional studies or case reports because the association under study is inherently longitudinal. We included studies with any follow-up period, given the prognostic nature of our objective.

We planned to consider evidence separately within the different phases of prognostic factor investigation: phase 1 (exploratory), and phase 2 (confirmatory) studies, which provide different levels of evidence (Hayden 2008; Riley 2013). Exploratory studies identify associations of many potential prognostic factors and outcomes. These studies measure associations between single factors and the outcome ('univariable' or 'univariate' associations), and provide the least conclusive information regarding the independence of a variable as a valid prognostic factor. Confirmatory studies aim to measure the independent effect of a prognostic factor on the relevant outcome while controlling for other factors. We planned to include all eligible studies in the review and, if possible, planned to restrict the results summary and any meta-analyses to results from multivariable analyses. Where this was not possible, we included the results of univariable analyses, taking into account the phase of investigation in both the risk of bias assessment and GRADE rating on certainty of the summary estimates.

\section{Targeted population}

We included studies of people with a VLU, who were managed in any care setting and receiving any type of treatment. We expected the method of diagnosis of venous ulceration to vary, so accepted definitions as used in the included studies.

We included studies in people with VLUs alongside people with other types of wounds (e.g. arterial ulcers, pressure ulcers, diabetic foot ulcers) provided the results for people with venous ulcers were presented separately, or if most participants (at least 75\%) had leg ulcers of venous aetiology. Where wounds were described only as leg ulcers without information as to aetiology, we assumed they were venous in origin because this is the most common type of leg ulcer.

We included studies that involved participants at any stage in their treatment pathway, and we recorded, where available, baseline data on the time since diagnosis and treatments previously given, together with ongoing treatments. We included studies that involved participants with any infection status at baseline and recorded any available data on this.

We excluded studies conducted solely in vitro and animal studies.

\section{Types of prognostic factor}

The prognostic factor was protease activity. Any type of protease or combination of proteases was eligible, either from the host or from bacteria, including:

- MMPs: gelatinases (MMP-2 and MMP-9); collagenases (MMP-1, MMP-8 and MMP-13); stromelysins (MMP-3, MMP-10 and MMP-11); metalloelastase (MMP-12); matrilysins (MMP-7 and MMP-26); membrane-type MMPs (MMP-14, MMP-15, MMP-16, MMP-17, MMP-24 and MMP-25); and other MMPs (MMP-19, MMP-20, MMP-23 and MMP-28);

- serine proteases: mast cell tryptases and chymases; human nucleophil elastase; cathepsin G; plasmin; uPA; t-PA;

- proteases combined with other biological species: ADAM; ADAMTS.

Where possible, we combined these three major categories in the analyses, taking into consideration cut-off points used (see 'Data synthesis' section below).

We planned to include and report separately studies that investigated as biomarkers the ratio of proteases and their respective inhibitors (e.g. MMP-2 (protease) and TIMP-2 (inhibitor)).

The prognostic factor could be examined as a continuous or categorical variable and any cut-off point was permitted.

We permitted any approach to obtaining samples from wounds, and any method of measurement of protease activity. We did not include measures of proteases in the blood or in tissue samples (biopsies). 
We reported all unadjusted (simple) associations between the prognostic factor and healing and planned to report adjusted (multivariable) associations between the prognostic factor and healing, with details on any adjustment factors used, especially taking into consideration key adjustment factors of age and infection. No studies conducted multivariable analyses, and for some studies, we calculated unadjusted associations from raw data (e.g. mean and standard deviations of protease levels for healed and non-healed wounds).

\section{Types of outcomes}

\section{Primary outcomes}

We planned to include the following primary outcomes:

- time to healing (analysed by survival analysis);

- proportion of people with ulcers completely healed, at any follow-up duration.

We planned to consider subgroup analyses to explore the impact of follow-up time. We accepted study authors' definitions of what constituted a healed wound.

We recorded study-reported associations and extracted raw data to calculate univariate associations. Binary outcomes would preferably have been reported as time-to-event measures (survival), but failing that, we considered dichotomous summary data at the longest time point or the key time point specified in the study's methods section.

\section{Secondary outcomes}

- Change in size of ulcer/rate of wound closure (e.g. centimetres squared per day).

If there were no ulcer healing data for a particular association, we planned to use data on the change (and percentage change) in ulcer size, with adjustment for baseline size. We did not contact study authors to request adjusted means when not presented. Where studies reported change in ulcer size without adjustment for baseline size, we analysed the results and assigned high risk of bias to the outcome measurement domain.

For continuous outcomes, we reported either continuous summary data or dichotomous data with any cut-off point.

\section{Search methods for identification of studies}

We developed a search strategy based only on population terms and protease terms. We considered adding prognosis filters, but this review concerned only one type of biomarker and the number of records identified was manageable without the use of filters. Therefore, we followed the procedure recommended by Geersing 2012.

We searched the following databases:

- Cochrane Central Register of Controlled Trials (CENTRAL) (2018, Issue 2);

- Ovid MEDLINE (1946 to February 2018);

- Ovid Embase (1974 to February 2018);

- CINAHL (1982 to February 2018).

The search strategies are in Appendix 1.

In addition, we handsearched the bibliographies of all included studies and of identified relevant systematic reviews.

\section{Data collection}

We collected and analysed data according to methods stated in the published protocol (Westby 2017), which were based on the Cochrane Handbook for Systematic Reviews of Interventions (Higgins 2011) and guidance from the Cochrane Prognosis Methods Group (Cochrane Prognosis Methods Group 2018; Riley 2007).

\section{Selection of studies}

Two review authors independently assessed the titles and abstracts of retrieved records against the inclusion criteria. We obtained all potentially relevant studies in full and two review authors independently assessed these for eligibility. We resolved any disagreements at each stage through discussion and, where appropriate, we consulted a third review author. We did not contact the study authors to resolve the uncertainty. Where studies were reported in multiple publications/reports, we obtained all publications. Whilst we included a study only once in the review, we extracted data from all reports to ensure we obtained all available relevant data. We collated multiple reports of the same study, so that each study rather than each report was the unit of interest in the review. The study selection process is illustrated in a PRISMA diagram, see Figure 1. All studies excluded after full-text assessment are listed in a Characteristics of excluded studies table with their reasons for exclusion. 
Figure 1. Study flow diagram.

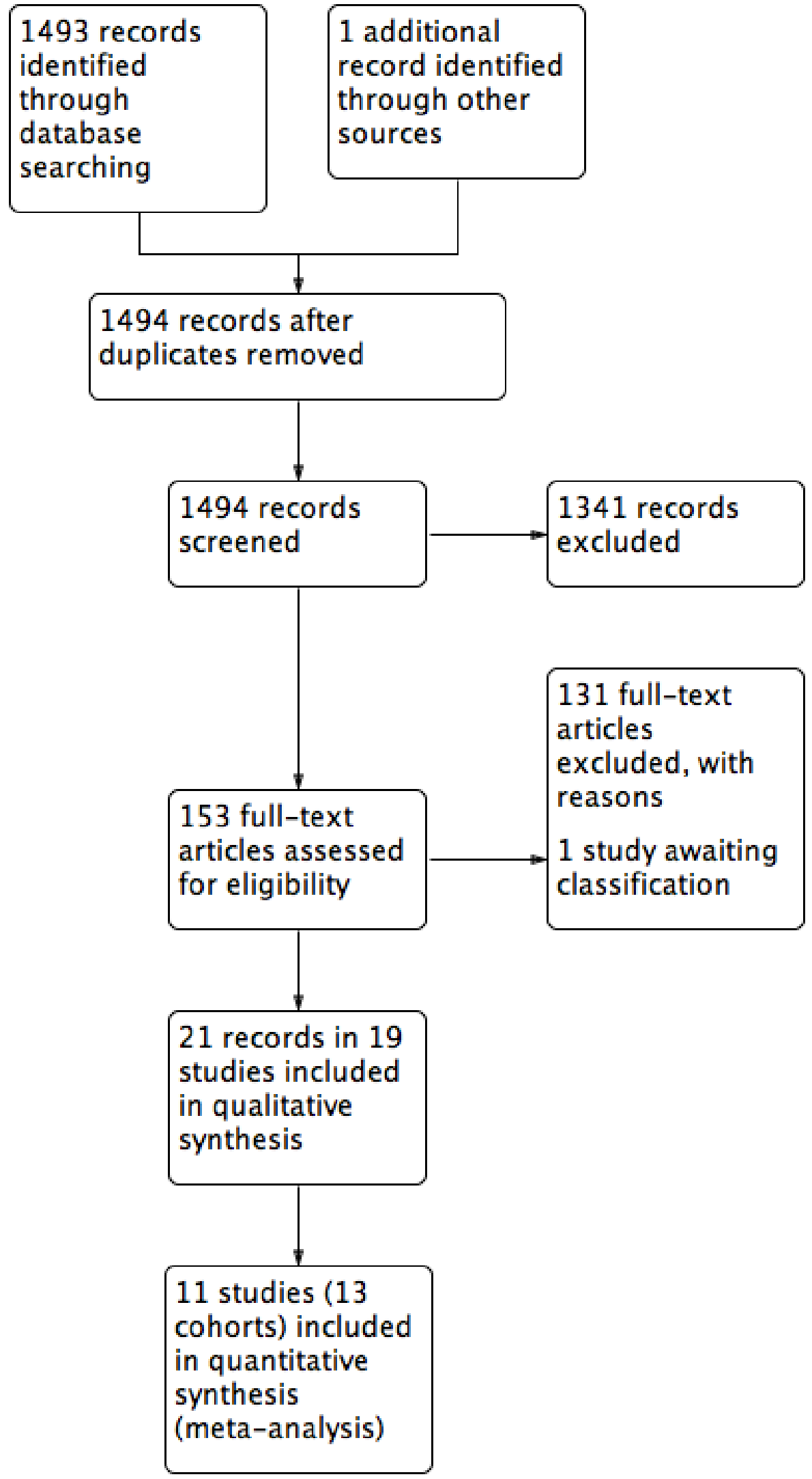




\section{Data extraction and management}

We collected all association data reported between the prognostic factor and outcomes, with details on any adjustment factors used. Where necessary, we extracted raw data that would allow calculation of association measures.

We extracted and recorded data from included studies using an Excel-based data extraction sheet, which we piloted initially on a few studies. We based the Items extracted on the CHARMS guidance (Moons 2014). One review author extracted data, which was then checked by a second review author. We did not contact the study authors if key data were missing from reports, because the overall risk of bias was too high.

We extracted the following data for the prespecified prognostic factors and outcomes in this review. We collected outcome data as described in the 'Types of outcome measures' section:

- country and setting in which study was conducted;

- study design;

- eligibility criteria;

- participant details;

- ulcer details, including duration of ulcer, ulcer size, number of ulcers and ulcer history, and ulcer severity (with the system used to classify this) as reported by the study authors;

- treatment details, including compression and debridement (including type and frequency);

- method of obtaining wound fluid for prognostic factor measurement, including duration of collection;

- method of measurement of protease activity (e.g. Gelatin zymography);

- details of each prognostic factor: type of protease/combination of factors, measurement of prognostic factor (including time of measurement), type of data (e.g. continuous/any cut-off points and if so, whether they were predefined and what the justification was for that cut-off point);

- details of each outcome: measurement, type of data (e.g. continuous/any cut-off points);

- duration of follow-up;

- type of analysis: explanatory/confirmatory (including the presence of a predefined protocol and study registration); logistic regression/Cox regression;

- any adjustment factors considered in the analysis;

- association statistics for each prognostic factor for primary and secondary outcomes (e.g. odds ratios (ORs), hazard ratios (HRs) and their $\mathrm{Cls} /$ variances/standard errors);

- loss to follow-up and reasons.

We extracted minimal data where there were no association data reported.

\section{Assessment of risk of bias in included studies}

Two review authors independently appraised the included studies using a standardised approach. In the case of discrepancies, the review authors attempted to reach consensus; if necessary, a third review author resolved any disagreements. The review authors were not blinded to study authors, institution or journal of publication because this was not feasible.
We planned to assess risk of bias using an approach based on the Quality In Prognosis Studies (QUIPS) tool, which is appropriate for prognostic factor review questions (Hayden 2013; Hayden 2014), also drawing on ROBINS I tool (ROBINS-I 2017), which assesses the risk of bias for non-randomised intervention studies (Sterne 2016). However, because of the absence of multivariable analyses in all studies. we modified the approach (see below).

\section{Original approach}

Our original approach to risk of bias assessment is described fully in Appendix 2. This approach assesses risk of bias per study for each prognostic factor-outcome combination, considering six domains: study participation (selection bias), study attrition, prognostic factor measurement, outcome measurement, adjustment, and statistical analysis and reporting. To assess the adjustment bias domain, we identified key adjustment factors, both from review of the literature and in discussion with clinicians (Appendix 3).

Each domain is rated as having high, moderate or low risk of bias. We defined an all-domain risk of bias per study for each prognostic factor-outcome combination, taking into account all the above domains, but especially focusing on the key domains of selection bias, study attrition, adjustment, and statistical analysis and reporting. As a guide, we assigned risk of bias as follows: low risk of bias if all (or all key) domains had low risk of bias; moderate risk of bias if there was high risk of bias for one key domain or moderate risk of bias for at least two key domains (with the rest as low risk of bias); high risk of bias if there was high risk of bias for at least two key domains. We planned to perform sensitivity analysis considering only studies at low all-domain risk of bias (Hayden 2013).

\section{Post-hoc modified approach}

In view of the lack of multivariable analysis in all the studies, we modified post-hoc the QUIPS risk of bias assessment for domain 6 (statistical analysis and reporting) to avoid 'triple-counting' the univariate features of the studies which are also addressed in the GRADE approach and in QUIPS domain 5 (adjustment factors) (see Appendix 2; Appendix 4). The GRADE approach to prognostic factor reviews assigns a moderate rating to phase 1 exploratory studies or other studies reporting univariable associations or having sufficient data to calculate associations. Domain 5 of QUIPS (adjustment) assigns high risk of bias if key adjustment factors were not taken into account in the design or the analysis. We modified the assessment of risk of bias for domain 6 so that if a well-designed, appropriately analysed and well-reported exploratory (univariate) study was described, a low risk of bias was assigned for this domain. For all other studies, we assigned moderate or high risk of bias to that domain, taking into account the aim of the study and the impact of interventions, as well as the other factors in Appendix 2.

\section{Measures of association}

We planned to extract all unadjusted and adjusted measures of association from included studies and to convert effect sizes, as necessary, to avoid possible selection bias, thus allowing us to use data from as many studies as possible.

We had anticipated that results from multivariable analyses would have been reported as ORs, RRs and HRs and, if so, we would have used ORs as the common measure of the association, using RRs and HRs to estimate ORs at a particular time point (Symons 2002). 
However, none of the included studies reported adjusted measures for binary healing outcomes, but some studies provided sufficient raw data to allow us to calculate associations.

- Where both the healing outcomes and prognostic factors were reported as dichotomous variables (e.g. elevated and nonelevated protease activities for complete healing), we formed 2 $\times 2$ tables and analysed these data as the RR.

- Where the prognostic factors were reported as continuous variables and individual participant data (IPD) were given and the outcome was dichotomous, we conducted a univariate regression analysis in STATA (STATA 2013).

- Where there were summary data, we extracted the mean and standard deviation protease activity for each healing outcome state. To obtain an indication of possible associations between protease activity and healing, we conducted a t-test to record associations between healing at the follow-up time (as an independent variable) and protease levels at baseline (as the dependent variable) (i.e. we investigated the reverse association).

Where the outcomes were reported as continuous measures (e.g. change in ulcer size) and the prognostic factor was a dichotomous variable, we planned to analyse the regression coefficients with their standard errors or to conduct a simple t-test. If both outcome and prognostic factor were continuous variables, we extracted (or calculated) Pearson correlation coefficients and $\mathrm{P}$ values and calculated Cls (Lowry 2018).

For consistency, we recalculated associations to be in the same direction, as necessary, with associations above 1 indicating better prognosis for positive binary outcomes (e.g. a healed wound). We did not contact study authors regarding missing or unusable data.

\section{Unit of analysis issues}

The prognostic factor (protease activity) and outcome (complete wound healing) were both considered at the ulcer level. A possible unit of analysis issue could have arisen when there was more than one ulcer per person and multivariable analysis was conducted with adjustment factors measured at the individual level (e.g. age). This represents clustered data and analyses should be conducted using hierarchical methods. Where studies included clustered data of this type, we planned to report this, noting whether data were analysed correctly, recording this as part of the risk of bias assessment. We planned to consider including such studies in any meta-analysis, taking into account the associated risk of bias. No studies clearly included more than one wound per participant.

\section{Dealing with missing data}

We included studies that investigated the relationship between protease activity and healing regardless of whether there were missing data and even if limited evidence was provided about the size of the effect (e.g. if the factor was mentioned only as being 'nonsignificant' in the analyses). We did not contact study authors to attempt to retrieve any missing information.

\section{Assessment of heterogeneity}

We considered the clinical heterogeneity of included studies based on the population, measure of the prognostic factor, cut-off points used, outcome measurement and methodological heterogeneity due to study design/potential biases. We planned to synthesise associations as appropriate within clinically relevant subgroups, grouping studies regardless of type of protease, duration of ulcer and presence of infection. We planned to examine the duration of ulcer and presence of infection in subgroup analyses where there was heterogeneity.

\section{Assessment of reporting deficiencies}

We planned to examine publication bias for each meta-analysis, provided there were 10 or more studies, by visually examining asymmetry on funnel plots and testing for asymmetry at the $10 \%$ level, using Egger's test for HRs, and Peters' test for ORs (Debray 2018; Sterne 2011).

\section{Data synthesis}

Synthesising data in prognostic factor studies requires us to recognise the many different ways of reporting and analysing results, and, where possible, to request alternative data or to transform results to a common format (see 'Measures of association' section). We planned to consider the impact of data transformations using sensitivity analyses.

We had expected that most studies would present data in the format of dichotomous outcome data and continuous prognostic factor data (e.g. protease activity), which may have been dichotomised or categorised using cut-off values .

After carrying out any appropriate transformations, where possible we grouped together studies with similar prognostic factor cutoff points/similar analytical approaches, and represented the data on forest plots. We had planned to conduct meta-analyses if valid data were available assessing associations between individual prognostic factors and an outcome of interest for sufficiently homogeneous subgroups of studies. We defined 'sufficiently homogeneous' subgroups according to population, measures of the prognostic factor and outcome measurement. However, we considered all data to be at too high a risk of bias to pool. We had planned to include in the forest plots details of any adjustment factors considered in the study analyses, but instead gave other relevant details in the footnotes.

We planned to combine the data for all proteases, regardless of the source or type of protease mainly because of a lack of evidence to inform stratification. For prognostic factors analysed as dichotomous measures, we planned additionally to take cutoff points into consideration as described above. We planned to analyse separately ratios of proteases and their inhibitors.

If meta-analysis had been conducted, we would have analysed HRs and ORs separately (at similar follow-up points). We also planned to transform the measures, where possible, so that a single analysis (OR) could have been conducted. We planned to conduct metaregression analysis if there were more than 10 studies providing sufficient data (Berkey 1995). We planned to conduct metaanalyses using STATA (StataCorp version 14) with a random-effects restricted maximum likelihood (REML) meta-analysis model, which accounts for any between-study heterogeneity in the prognostic effect (Cornell 2014; Riley 2010). Such heterogeneity is common in prognostic factor studies. Unless the heterogeneity (as assessed above) was too extensive for appropriate pooling, we planned to summarise the meta-analysis by the pooled estimate (the average prognostic factor effect), the Hartung-Knapp $95 \% \mathrm{Cl}$, the estimate 
of $\mathrm{Tau}^{2}$ (between-study variance) and a 95\% prediction interval for the prognostic effect in a single population (Riley 2011).

\section{'Summary of findings' table and GRADE assessment}

We used an approach modified from the GRADE framework (Guyatt 2011a) to assess the certainty of the summarised evidence for each prognostic factor-outcome combination (Hayden 2014; Huguet 2013; lorio 2015). We rated the overall strength of evidence as high, moderate, low or very low considering the phase of prognostic study (confirmatory/explanatory or exploratory), the within-study risk of bias, the directness of evidence, heterogeneity, precision of effect estimates and risk of publication bias (Iorio 2015; Schünemann 2011a). We also considered two 'upgrading' factors, large effect and dose effect, although we noted that high risk of bias may artificially lead to large effects (see Appendix 4 for further details).

We did not present the main results of the review in formal 'Summary of findings' tables because the vast majority of the evidence was at high risk of bias and this, together with the study design, meant that the evidence was of very low certainty throughout. Instead we summarised the findings in the text. 'Summary of findings' tables present key information concerning the certainty of the evidence, the magnitude of the associations examined and the sum of the available data (Schünemann 2011b), and include an overall grading of the evidence. This defines the certainty of a body of evidence as the extent to which one can be confident that an estimate of effect or association is close to the true quantity of specific interest.

If it was not appropriate to combine results using a meta-analysis (due to excess clinical heterogeneity), we planned to present the results qualitatively, considering the strength and consistency of results using the following schema:

- strong evidence of effect: consistent findings (defined as greater than $75 \%$ of studies showing the same direction of effect) in multiple low risk of bias studies;

- moderate evidence of effect: consistent findings in multiple high risk of bias or one study with low risk of bias (or both);

- limited evidence of effect: one study available;

- conflicting evidence of effect: inconsistent findings across studies;

- no effect: no association between participant expectations and the outcome of interest.

We planned to calculate absolute risk differences for the effect of the prognostic factor using estimates of baseline risk from the literature where possible.

\section{Subgroup and sensitivity analyses}

We planned to use sensitivity analyses to explore the impact of study level all-domain risk of bias, first restricting the analysis to studies rated as having low risk of bias, and if this was not feasible, to restrict to low or moderate risk of bias.

If there was heterogeneity, we planned to investigate it using the following prespecified subgroup analyses, provided there were at least two studies per subgroup:
- baseline duration of ulcer (up to 24 weeks; 24 weeks or greater); duration may be a proxy for a non-healing wound, in which protease activity may be associated differently with healing;

- presence or absence of infection.

We did not plan to conduct subgroup analyses by type of protease because this would have introduced too high a level of complexity for this review, but we recorded the type of protease measured.

We planned to consider subgroup or sensitivity analyses to explore the impact of types of measurement approaches for assessing prognostic factors.

This Methods section was based on the exemplar Cochrane prognosis review protocol for prognostic factors (Hayden 2014) and the general protocol template of the Cochrane Prognosis Methods Group (Cochrane Prognosis Methods Group 2018). In conducting the review, we carried out a number of modifications to the methods, as described above.

\section{RES U L T S}

\section{Description of studies}

\section{Results of the search}

The search generated 1493 records and one of the review authors identified an additional paper separately: we obtained 153 full papers (Figure 1); some of these were reviews ordered for bibliographic checks and background material; we excluded 110 studies with reasons (Characteristics of excluded studies table). We included 19 studies described in 21 reports (see 'Included studies' for explanation). One study was placed in the Characteristics of studies awaiting classification section (Cullen 2009); this was a conference abstract and gave too little information.

\section{Included studies}

Studies are described in detail in the Characteristics of included studies table. In this table, we report two studies twice because they were RCTs with different risks of bias for each treatment group: we report each trial arm as a separate cohort (Moffatt 2014a; Moffatt 2014b; Serra 2015a; Serra 2015b).

Nineteen studies (involving 21 cohorts), with 646 participants, met the inclusion criteria for the review (Ahmad 2015; Cullen 2012; Frankova 2013; Gohel 2008; Grzela 2014; Harris 1995; Hoffman 1999; James 2003; Litwiniuk 2012; McDaniel 2017; Moffatt 2014a; Moffatt 2014b; Mwaura 2006; Raffetto 2015; Serra 2013; Serra 2015a; Serra 2015b; Smeets 2008; Trengove 1999; Trøstrup 2011; Wysocki 1999). The size of the cohorts was small, with a median (range) of 30 (7 to 80) participants. Two studies were reported only as conference abstracts or posters (Cullen 2012; Raffetto 2015).

Most included studies had a cohort study design and two were a type of case-control study. Eleven studies reported a prospective longitudinal design (Ahmad 2015; Frankova 2013; Gohel 2008; Hoffman 1999; James 2003; Litwiniuk 2012; Mwaura 2006; Serra 2013; Trengove 1999; Trøstrup 2011; Wysocki 1999), of which three had 10 or fewer participants (Hoffman 1999; James 2003; Trøstrup 2011). There were six RCTs, two of which reported results separately for each arm (Moffatt 2014a; Moffatt 2014b; Serra 2015a; Serra 2015b); two of which reported relevant results for the study as a whole (Cullen 2012; McDaniel 2017); and two did not give 
any useable results (Grzela 2014; Smeets 2008). The remaining two studies had a type of case-control design nested in a crosssectional study (Harris 1995; Raffetto 2015): we have interpreted these studies as having a longitudinal component that occurred before the study started.

Eight included studies did not provide sufficient useable results data in the published report (Frankova 2013; Grzela 2014; James 2003; Litwiniuk 2012; Smeets 2008; Trengove 1999; Trøstrup 2011; Wysocki 1999). One study reported association statistics only for an intermediate biomarker for both the prognostic factor and the outcome (James 2003); the other studies reported both the prognostic factor and the outcome as continuous variables, generally giving summary statistics for each, but no association statistics. To have useable data for the review, we would have had to request further analyses from the authors. Therefore, we included these studies for completeness, noted the lack of useable results and only extracted data for a minimal set of characteristics (see Characteristics of included studies table). We did not formally conduct 'Risk of bias' assessments and did not include these studies in the 'Risk of bias' figures (see 'Risk of bias' section).

The remaining 11 studies involving 13 cohorts are summarised in this section and analysed in the results section (Ahmad 2015; Cullen 2012; Gohel 2008; Harris 1995; Hoffman 1999; McDaniel 2017; Moffatt 2014a; Moffatt 2014b; Mwaura 2006; Raffetto 2015; Serra 2013; Serra 2015a; Serra 2015b). There were 522 participants in these studies, with a median of 40 participants (range 7 to 80 ).

Six studies were conducted in the UK (Ahmad 2015; Cullen 2012; Gohel 2008; Harris 1995; Hoffman 1999; Moffatt 2014a/Moffatt 2014b); two in Italy (Serra 2013; Serra 2015a/Serra 2015b); one in the USA (McDaniel 2017); one in Ireland (Mwaura 2006); and one abstract did not report the country (Raffetto 2015).

Of the longitudinal studies, two had a follow-up time of substantially less than two months (four weeks: Cullen 2012; five weeks: Gohel 2008). The other studies ranged from eight weeks (Mwaura 2006; McDaniel 2017; Serra 2013) to 36 weeks (Hoffman 1999); one of these gave correlation coefficients between protease levels measured at four weeks and follow-up at eight weeks (McDaniel 2017).

\section{Participant characteristics}

In 10 studies, all the participants had VLUs. In the remaining study, $56 \%$ of participants had VLU and $44 \%$ had mixed arterial-venous leg ulcers (Moffatt 2014a/Moffatt 2014b). Three studies had similar numbers of males and females (Ahmad 2015; Gohel 2008; Moffatt 2014a/Moffatt 2014b); one was about two-thirds male (McDaniel 2017); three studies had about twice as many females as males (Mwaura 2006; Serra 2013; Serra 2015a/Serra 2015b); and four did not report on sex (Cullen 2012; Harris 1995; Hoffman 1999; Raffetto 2015). Where reported, mean ages ranged from 51 to 75 years. Two studies reported that wounds were not infected (Gohel 2008; Harris 1995). The mean/median duration of wounds ranged from three months (Gohel 2008) to 14 years (Harris 1995).

\section{Prognostic factors}

The studies investigated the following protease biomarkers; some studies examined more than one biomarker:

- MMP-1 (Raffetto 2015);
- MMP-2 (Gohel 2008; Mwaura 2006; Raffetto 2015);

- MMP-3 (Raffetto 2015);

- MMP-7 (Raffetto 2015);

- MMP-8 (McDaniel 2017; Raffetto 2015);

- MMP-9 (Gohel 2008; Raffetto 2015; Serra 2013; Serra 2015a/Serra 2015b);

- MMP-10 (Raffetto 2015);

- MMP-12 (Raffetto 2015);

- MMP-13 (Raffetto 2015);

- MMP-unspecified (Harris 1995; Moffatt 2014a/Moffatt 2014b);

- HNE (Cullen 2012; Hoffman 1999; McDaniel 2017);

- uPA (Ahmad 2015).

No study clearly measured bacteria-specific proteases and no studies reported ratios of biomarkers and their inhibitors.

Studies reported different methods for extracting wound fluid for analysis of protease activity: occlusive dressings (Ahmad 2015; Gohel 2008; Harris 1995; McDaniel 2017; Serra 2013); entrapment in dressings (Hoffman 1999; Mwaura 2006; Raffetto 2015), with two of these studies using dressings already used for treatment (Hoffman 1999; Mwaura 2006); swabs (Moffatt 2014a/Moffatt 2014b); and not stated (Cullen 2012; Serra 2015a/Serra 2015b).

Studies measured protease using ELISA techniques (Ahmad 2015; McDaniel 2017; Mwaura 2006; Raffetto 2015; Serra 2013; Serra 2015a/Serra 2015b); fluorogenic substrate assay (Cullen 2012); gelatin zymography (Gohel 2008); and other activity assays (Harris 1995; Hoffman 1999; McDaniel 2017; Moffatt 2014a/Moffatt 2014b). One study reported measurement only of pro-MMP (and this was not cleaved to give the active form; Gohel 2008); another study (Ahmad 2015) measured total UPA including bound and complexed forms, with the active form level being below the level of the bioassay; Harris 1995 separately reported total, active and latent forms of MMP; three studies reported 'activity' (Cullen 2012; Hoffman 1999; Moffatt 2014a/Moffatt 2014b); one study appeared to measure total MMP (Mwaura 2006); and the other studies reported concentrations (McDaniel 2017; Raffetto 2015; Serra 2013; Serra 2015a/Serra 2015b), but it was unclear whether this meant total MMPs (active and pro-MMP forms).

Two studies used a cut-off point for the prognostic factor: Cullen 2012 used greater than $25 \mathrm{mU} / 110 \mu \mathrm{L}$ for elastase (taken from their work in diagnostic studies (Serena 2011)) and Moffatt 2014a/Moffatt $2014 \mathrm{~b}$ used an activity score of 5 or more to define high activity on a scale of 0 to 10 for MMPs (unspecified). The other studies reported the prognostic factor as a continuous measure, sometimes in relation to a standard (Ahmad 2015; Gohel 2008; Hoffman 1999), or per total protein in the sample (McDaniel 2017; Serra 2013; Serra 2015a/Serra 2015b), or as a concentration (Grzela 2014; Mwaura 2006; Raffetto 2015).

This variability in sampling, measurement techniques and use of standards meant that analyses of continuous outcomes were conducted using standardised mean differences.

\section{Outcome measures}

Studies measured healing in several ways: only three studies reported complete healing as a dichotomous outcome (Ahmad 2015; Hoffman 1999; Moffatt 2014a/Moffatt 2014b). Five studies 
reported partial healing (other dichotomous measures of 'healing'), compared with 'no healing,' defined as follows:

- reduction in area of $30 \%$ or greater over four weeks versus no healing (Cullen 2012);

- decreased size (greater than 20\%), decrease in slough and development of healthy granulation tissue versus no healing (Mwaura 2006);

- categorical healing: high healing $\left(1 \mathrm{~cm}^{2} /\right.$ week or greater); low healing (less than $1 \mathrm{~cm}^{2} /$ week) and no healing (Serra 2013);

- granulating wounds versus non-granulating/inflammatory wounds (Harris 1995; Raffetto 2015).

Two studies compared different degrees of healing:

- high healing $\left(1 \mathrm{~cm}^{2} /\right.$ week or greater) versus low healing (less than $1 \mathrm{~cm}^{2} /$ week) (Serra 2013; Serra 2015a/Serra 2015b).

Three studies reported the outcome as a continuous measure: one measured the change in size (Gohel 2008), and the others the percentage change in size from baseline (Hoffman 1999; McDaniel 2017).

\section{Interventions}

Nine studies reported that the participants received compression therapy (Ahmad 2015; Cullen 2012; Gohel 2008; Hoffman 1999; McDaniel 2017; Moffatt 2014a/Moffatt 2014b; Mwaura 2006; Serra 2013; Serra 2015a/Serra 2015b). Two studies gave no information on compression interventions (Harris 1995; Raffetto 2015).

In addition to compression, two studies received vein surgery, as appropriate (Serra 2013; Serra 2015a/Serra 2015b). Six studies received other treatments, some of which were likely or possible protease-modulating dressings:

- likely protease modulating: Cullen 2012 (randomised to collagen/oxidised regenerated cellulose (ORC) matrix with or without silver);

- possible protease modulating: Moffatt 2014a (oxyzyme or iodozyme plus basic treatment); Serra 2015a (doxycycline); McDaniel 2017 (oral n-3 eicosapentaenoic acid (EPA) and docosahexaenoic acid (DHA) plus silver dressing);

- unlikely to be protease modulating: Gohel 2008 (non-adherent); Hoffman 1999 (non-adherent, wool padding, etc.); Moffatt 2014b (usual care continued); Serra 2015b ('most appropriate treatment' - basic treatment).

\section{Excluded studies}

We excluded 110 studies from the review for the following main reasons (see Characteristics of excluded studies table): 13 studies had an ineligible population (Budzyn-Napierala 2016; Cullen 2002b; Honda 2011; Huttunen 2005; Karatepe 2010; Kucukguven 2013; Mirastschijski 2002; Schultz 2004; Serra 2014; Shields 1994; Varelias 2002; Varelias 2006; Zamboni 2005); five did not assess a relevant prognostic factor (Cook 2009; Ibbotson 1994; Senet 2003; Stojadinovic 2014; Wlaschek 1997); 18 did not report an eligible healing outcome (Bernatchez 2012; Dalton 2005; Eming 2008; Failla 2008; Grinnell 1998; Huttunen 2000; Huttunen 2004; Impola 2005; Karim 2006; McInnes 2014; Moor 2009; Palolahti 1993; Rayment 2008; Schmid 1999; Schmidtchen 2000; Wysocki 1993; Wysocki 1996; Zillmer 2011); 38 studies where the study design was not longitudinal (Ahmad 2011; Amato 2015; Anon 2008; Ayuk 2016; Bogaczewicz 2004; Bohórquez-Sierra 2006; Clark 2001; Cook 2000; Da Silva 2014; Derbyshire 2003; Duffy 2005; Fisher 1998; Gordon 1975; Herouy 2000a; Herouy 2000b; Ivins 2014; Körber 2006; Kucharzewski 2005; Ligi 2016; Lim 2010; McCarty 2012; McCarty 2013; Moore 2007; Nwomeh 1999; Ovington 2001; Phillips 2007; Raffetto 2014; Rayment 2009; Rogers 1999; Schmidtchen 2003; Serena 2016; Serra 2015c; Serra 2016a; Singh 2010; Tarlton 1999; Vahlquist 2000; Weckroth 1996; Widgerow 2011); and 34 studies where the samples were not obtained from wound fluids or were not obtained by an eligible method (Alexewicz 2007; Barros 2012; Caimi 2015; Eming 2006; Fernandez 2008; Gacka 2004; Grinnell 1992; Hasmann 2011; He 1999; Herouy 2004; Herrick 1997; Hoffman 1998; Lantis 2011; Lotti 1995; Mirshahi 1995; Nielsen 1992; Norgauer 2002 Pirila 2007; Rechardt 2000; Saarialho-Kere 1998; Salgado 2017; Serra 2016b; Serra 2017; Stacey 1993; Stacey 2000; Tauzin 2014; Turio 2002; Ulrich 2005; Vaalamo 1996; Vaalamo 1997; Vaalamo 1999; Van Bergen 1996; Weckroth 2004; Zeegelaar 1997).

One excluded study, Serena 2016, had similarities with two of the included studies (Harris 1995; Raffetto 2015), in that healing trajectories were analysed within a cross-sectional study. However, the trajectories (healing and non-healing) were derived from measurements of healing rate before the start of the study, rather than clinical assessment of the phase of the wound in the study. Therefore, we considered the study to be cross-sectional and measuring diagnosis rather than prognosis. Additionally, Serena 2016 had only $32 \%$ VLUs and it would have been necessary to write to the authors.

\section{Studies awaiting classification}

We identified one study that is awaiting classification (Cullen 2009). This was a conference abstract and gave too little information.

\section{Ongoing studies}

We found no ongoing studies.

\section{Risk of bias in included studies}

No study conducted multivariable analyses, but all 11 studies (13 cohorts) with useable results either had sufficient data to calculate univariate associations or reported correlations between protease measurements and a measure of healing. We did not report risk of bias assessments for studies with non-useable results. However, all these studies were at high risk of bias due to inadequate analyses and lack of adjustment.

Figure 2 shows risk of bias judgements for each cohort. Judgements for each domain across studies are shown in Figure 3. These figures also included studies that did not have useable results and did not have risk of bias assessments, and these appear blank. 
Figure 2. Risk of bias graph: review authors' judgements about each risk of bias item presented as percentages across all included studies with results. Studies without useable results do not have risk of bias assessments, and these appear blank.

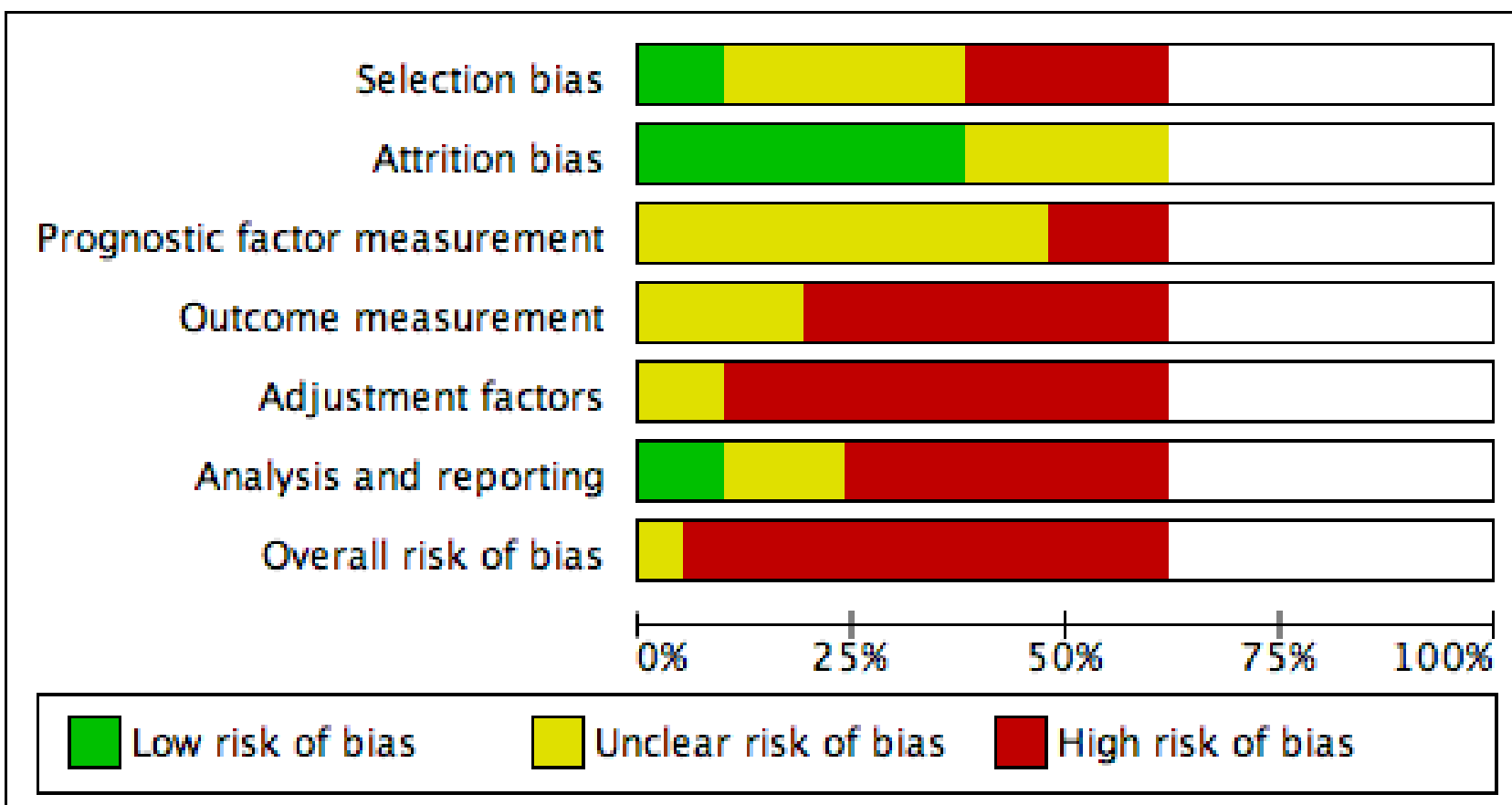


Figure 3. Risk of bias summary: review authors' judgements about each risk of bias item for each included study with results. Studies without useable results do not have risk of bias assessments, and these appear blank.

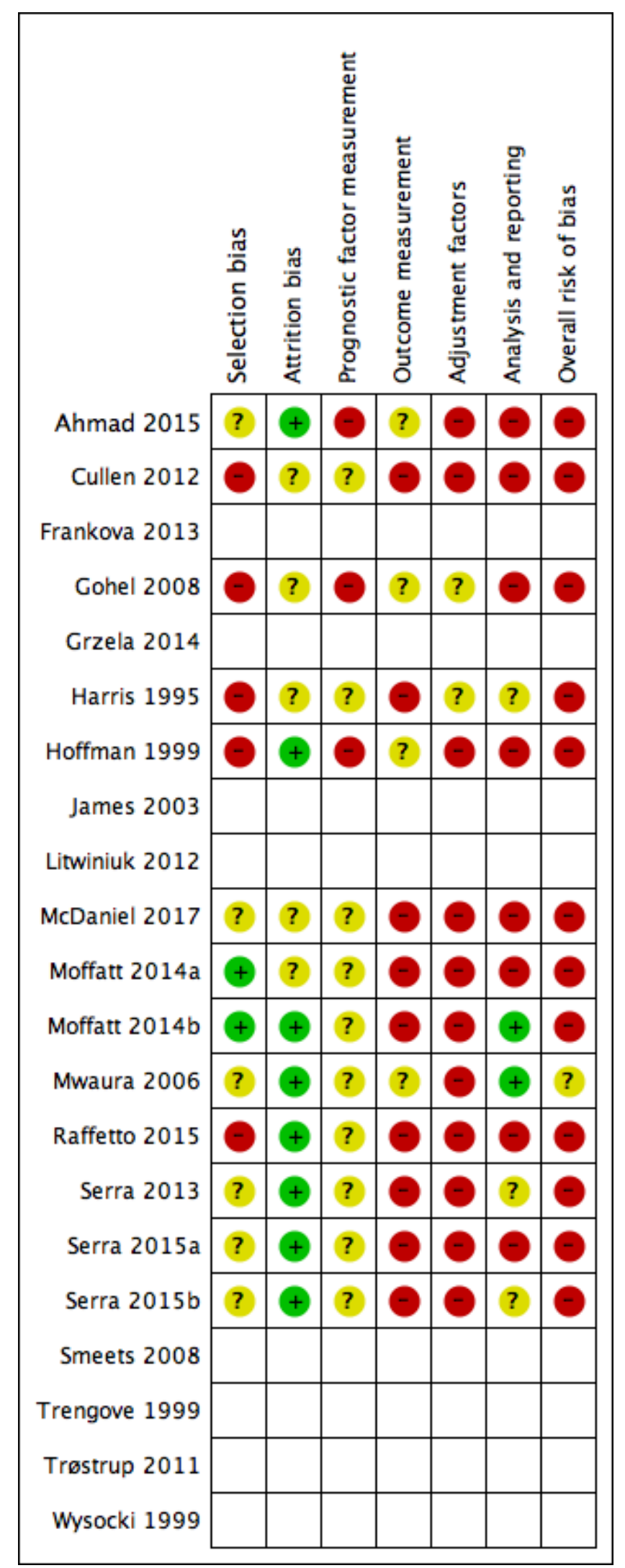


Overall, all studies (and all cohorts) except Mwaura 2006 were at high risk of bias (they had high risk of bias for at least two domains): this was commonly due to high risk of selection bias (five of 12 cohorts), outcome measurement bias (nine cohorts) and adjustment factor bias (11 cohorts). Mwaura 2006 was at moderate risk of bias overall.

\section{Results}

At the outset of this results section, we must stress that no reliable associations could be identified from the data presented here because all the evidence in this review was of very low certainty (see Certainty of the evidence section below). However, as this is a new type of review in the wounds field, we have presented the full set of (very low-certainty) results in order to indicate possible factors that should inform future research and systematic review methodology in this area. We have not generally reported the numerical findings in the main text, but these can be seen in the forest plots as indicated.

\section{Associations of protease activity (continuous data) with complete healing and partial healing}

\section{Healing as dichotomous data (versus no healing)}

We used individual participant data (IPD) from one study including seven participants to conduct a univariate logistic regression analysis (Hoffman 1999). The OR per unit increase in elastase activity at baseline was $0.96(95 \% \mathrm{Cl} 0.88$ to 1.04$)$. This was very lowcertainty evidence.

We used the data from each of six studies including 174 participants to carry out a 'reverse' t-test of associations between healing and protease activity (Ahmad 2015; Harris 1995; Hoffman 1999; Mwaura 2006; Raffetto 2015; Serra 2013). The (theoretical) interpretation of this was that a negative SMD indicated that lower baseline levels of protease were associated with higher proportions of healing wounds at follow-up (compared with non-healing).

Results from all studies are shown on the same forest plot to visually display the findings and to allow possible influencing factors to be considered (Analysis 1.1; Figure 4).

Figure 4. Forest plot of comparison: 1 Protease activity continuous, outcome: 1.1 t-test assocation of protease level and healing (dichotomous).

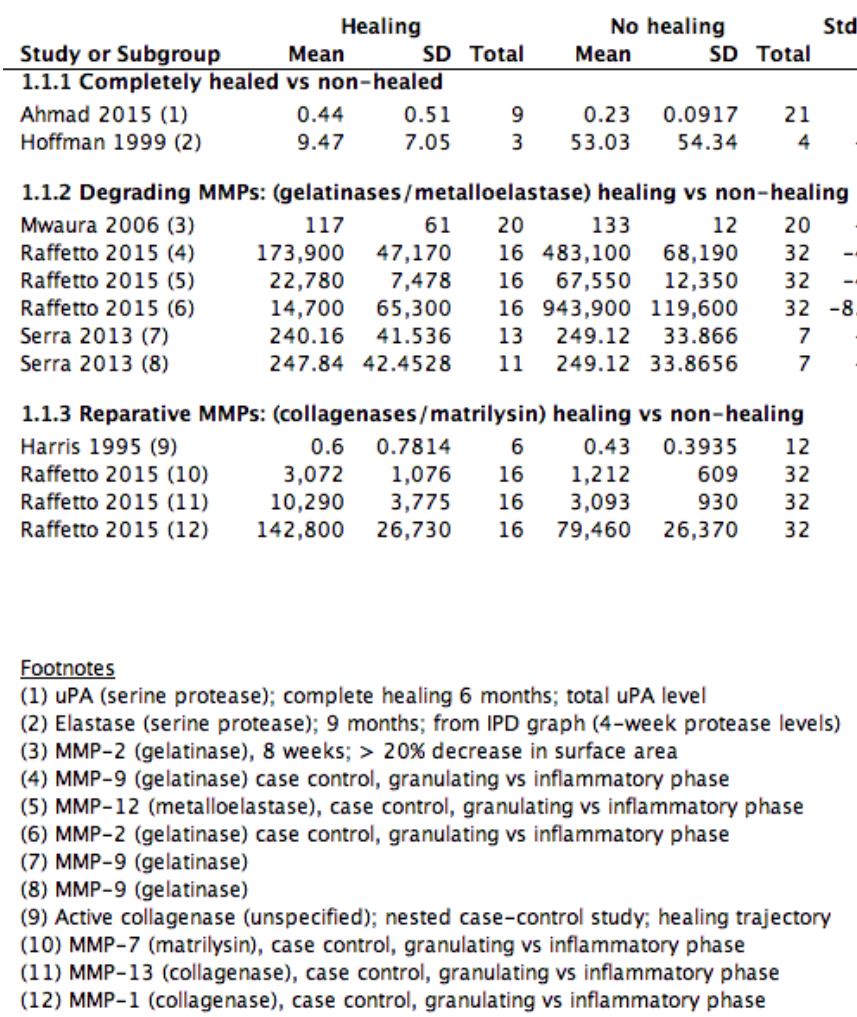
IV, Fixed, $95 \% \mathrm{CI} \quad$ IV, Fixed, $95 \% \mathrm{CI}$ A B C

$0.72[-0.08,1.53]$ $-0.87[-2.51,0.78]$

$-0.36[-0.98,0.27]$ $-4.90[-6.08,-3.71]$ $-4.00[-5.03,-2.97]$ $-8.70[-10.62,-6.79]$ $-0.22[-1.14,0.70]$ $-0.03[-0.98,0.92]$

$0.30[-0.69,1.28]$ $2.31[1.54,3.08$ $3.10[2.21,3.98]$ $2.35[1.58,3.13]$

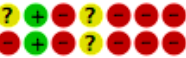
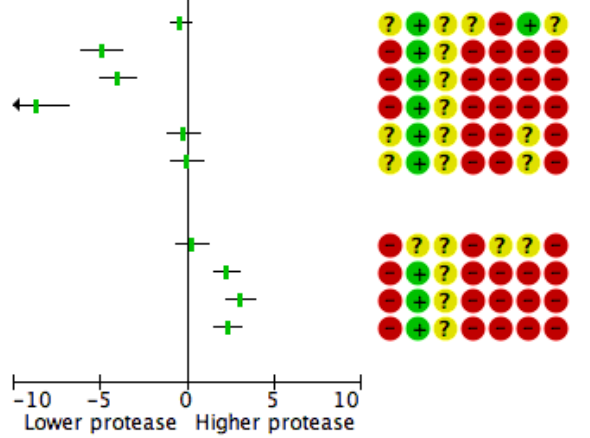

Risk of bias legend

(A) Selection bias

(B) Attrition bias

(C) Prognostic factor measurement

(D) Outcome measurement

(E) Adjustment factors

(F) Analysis and reporting

(G) Overall risk of bias

Four studies including 137 participants reported partial healing (versus no healing) (Harris 1995; Mwaura 2006; Raffetto 2015; Serra 2013), with Harris 1995 comparing granulating/epithelialising ('healing') wounds with non-granulating ('non-healing') wounds in a type of case-control study; Mwaura 2006 reporting a 'healing wound' as one with more than $20 \%$ decrease in wound size, decrease in slough and development of granulation tissue; and Serra 2013 comparing 'high healing' $\left(1 \mathrm{~cm}^{2} /\right.$ week or greater decrease in size) and 'low healing' (less than $1 \mathrm{~cm}^{2} /$ week) versus

Two studies including 37 participants reported complete hea (versus no healing) (Ahmad 2015; Hoffman 1999). Both studies investigated serine proteases. This very low-certainty evidence illustrated inconsistency in the point estimates regarding the direction of the association, high risk of bias and very wide Cls; in other words, it is completely unclear whether serine protease activity is associated with leg ulcer healing. Ahmad 2015 measured mainly bound and complexed forms of uPA protease and Hoffman 1999 appeared to measure the active form of neutrophil elastase. 
no healing. Raffetto 2015 reported protease levels for wounds in granulating versus inflammatory phases in a type of casecontrol study, with protease levels given for a number of different proteases.

Raffetto 2015 (a conference abstract) suggested there may be two types of protease involved in wound healing, which they described as 'degrading' MMPs and 'reparative' MMPs. We explored this proposed differentiation of proteases in Analysis 1.1 (Figure 4). The degrading and reparative MMPs in Raffetto 2015 appeared to have different directions of association with healing, and the other studies may have supported this interpretation (Harris 1995; Mwaura 2006; Serra 2013). However, this was very low-certainty evidence, dominated by a single study which identified healing and non-healing wounds in the same cohort, and there may well be confounding and bias (Raffetto 2015).

\section{Healing as dichotomous data ('high healing' versus 'low healing' chronic wounds)}

Two studies including 95 participants examined the association of protease levels with 'high healing' versus 'low healing' chronic wounds (Serra 2013; Serra 2015a/Serra 2015b). Both studies defined 'high healing' wounds as those that had a change in wound size of $1 \mathrm{~cm}^{2} /$ week or greater and 'low healing' wounds as those that had a change in wound size of less than $1 \mathrm{~cm}^{2} /$ week. Findings are shown on a forest plot (Analysis 1.2; Figure 5). It was very uncertain whether there was a difference in protease activity between high- and low-healing wounds.

Figure 5. Forest plot of comparison: 1 Protease activity continuous, outcome: $1.2 \mathrm{t}$-test association of protease level and healing: high ( $\geq 1 \mathrm{~cm}^{2} /$ week) versus low $\left(<1 \mathrm{~cm}^{2} /\right.$ week) healing.

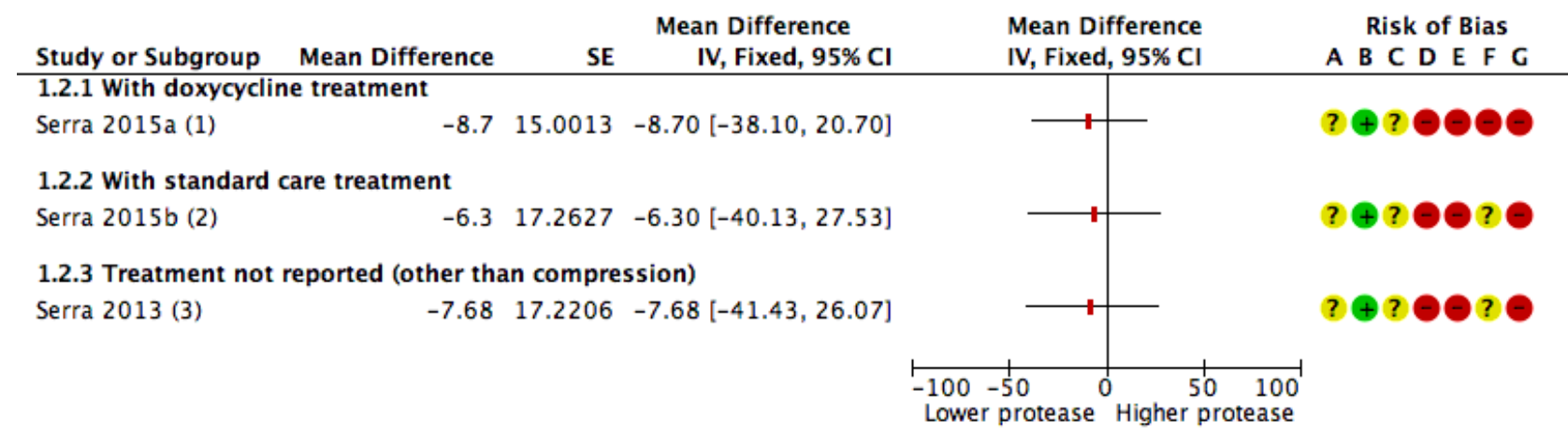

\section{Footnotes}

(1) MMP-9. 5 months' follow-up, randomised controlled trial (RCT)

(2) MMP-9. 5 months' follow-up RCT

(3) MMP-9, high healing vs low healing, 8 weeks' follow-up

Risk of bias legend
(A) Selection bias
(B) Attrition bias
(C) Prognostic factor measurement
(D) Outcome measurement
(E) Adjustment factors
(F) Analysis and reporting
(G) Overall risk of bias

A) Selection bias

(B) Attrition bias

(G) Overall risk of bias

\section{Healing as continuous data}

Three studies including 122 participants reported (or provided IPD to allow calculation of) correlation coefficients between protease levels and reduction or percentage reduction in ulcer size (i.e. healing); a positive correlation meant that as protease levels increased, the reduction in ulcer size increased (i.e. more healing) (Gohel 2008; Hoffman 1999; McDaniel 2017).

Results for all studies were represented on a forest plot, even though one had no numerical data (Analysis 1.3; Figure 6). Gohel 2008 reported narratively that there was "no relationship" between the initial levels (of proteases) and subsequent healing at five weeks (negative, but non-significant correlation coefficients were reported for the change in protease levels versus the change in ulcer size between zero and five weeks, but these were crosssectional data only and therefore ineligible). McDaniel 2017, although measuring protease levels at baseline, only reported correlations between protease levels at four weeks and the percentage reduction in ulcer size between baseline and eight weeks; this study reported results for both arms of the RCT combined. Hoffman 1999 reported IPD for the seven participants included (four-week protease levels and percentage reduction in size at 36 weeks). One of these data points appeared to be an outlier and we calculated the Pearson correlation coefficient and plotted a graph both with and without this outlier. This gave very different correlation coefficients (albeit with very wide $\mathrm{Cls}$ ), and was thus an unstable finding; results from both calculations are shown on the forest plot. The evidence across all studies was of very low certainty showing wide $\mathrm{Cls}$, high risk of bias and some inconsistency. Gohel 2008 also reported pro-MMP levels, so was likely to represent indirect evidence for protease activity and McDaniel 2017 had, in effect, a very short follow-up, and combined results for different intervention arms. It was possible that there was a difference in correlation coefficients for MMP-8 and HNE in one study (McDaniel 2017), negative for MMP-8 and no correlation for HNE, but the evidence was very uncertain. 
Figure 6. Forest plot of comparison: 1 Protease activity continuous, outcome: 1.3 Correlation coefficients: protease levels and change in size.

\begin{tabular}{|c|c|c|c|c|c|}
\hline \multirow[b]{2}{*}{ Study or Subgroup } & \multirow[b]{2}{*}{ Correlation coefficient } & \multicolumn{2}{|c|}{ Correlation coefficient } & \multirow{2}{*}{$\begin{array}{l}\text { Correlation coefficient } \\
\text { IV, Fixed, } 95 \% \mathrm{CI}\end{array}$} & Risk of Bias \\
\hline & & SE & IV, Fixed, $95 \% \mathrm{CI}$ & & A B C D E F G \\
\hline \multicolumn{4}{|c|}{ 1.3.1 Change in MMP-2 level vs reduction in ulcer size } & & \\
\hline Gohel 2008 (1) & 0 & 0 & Not estimable & & \\
\hline \multicolumn{4}{|c|}{ 1.3.2 Change in MMP-9 level vs reduction in ulcer size } & & \\
\hline Gohel $2008(2)$ & 0 & 0 & Not estimable & & \\
\hline
\end{tabular}

1.3.3 MMP- 8 level at 4 weeks vs \% reduction in size at 8 weeks
McDaniel 2017 (3)
$-0.360 .1995$
$-0.36[-0.75,0.03$

1.3.4 Elastase level at 4 weeks vs \% reduction in size at 8 weeks

McDaniel $2017(4) \quad-0.02 \quad 0.1709 \quad-0.02[-0.35,0.31]$

1.3.5 Elastase at 4 weeks vs \% change in size at 9 months

Hoffman 1999 (5)

$-0.78130 .4405$

$-0.78[-1.64,0.08]$

Hoffman 1999 (6)

$-0.00420 .3826 \quad-0.00[-0.75,0.75]$

]

Footnotes

(1) Pro-MMP-2; 5 weeks. "No relationship between initial levels and healing"

(2) Pro-MMP-9; 5 weeks. "No relationship between initial levels and healing"

(3) Combined intervention and placebo group; RCT, 4 weeks into trial

(4) Combined intervention and placebo group; RCT, 4 weeks into trial

(5) Elastase level calculated from IPD; 6 data points (without outlier);

(6) Elastase level calculated from IPD; 7 data points (with outlier)

\author{
Risk of bias legend \\ (A) Selection bias \\ (B) Attrition bias \\ (C) Prognostic factor measurement \\ (D) Outcome measurement \\ (E) Adjustment factors \\ (F) Analysis and reporting \\ (G) Overall risk of bias
}

\section{Associations of protease activity (dichotomous data) with healing and partial healing}

Two studies (three cohorts) including 164 participants allowed calculation of an RR for the univariate association of elevated protease activity with healing: Moffatt 2014a/Moffatt 2014b reported complete healing at 12 weeks and Cullen 2012 defined healing as at least $30 \%$ reduction in area over four weeks. We did not pool the data because of the difference in healing definition, but show the results on the forest plot (Analysis 2.1; Figure 7), grouped according to the interventions: Cullen 2012 gave all participants an 'established' protease modulating matrix dressing (collagen/ ORC with or without silver); in the intervention arm Moffatt 2014a participants received oxyzyme/iodozyme treatment, which was postulated to be protease modulating. In the control group of Moffatt 2014b the treatment was not protease modulating.

Figure 7. Forest plot of comparison: 2 Protease activity dichotomous, outcome: 2.1 Association of healing with elevated protease level; by protease modulating (PM) intervention.

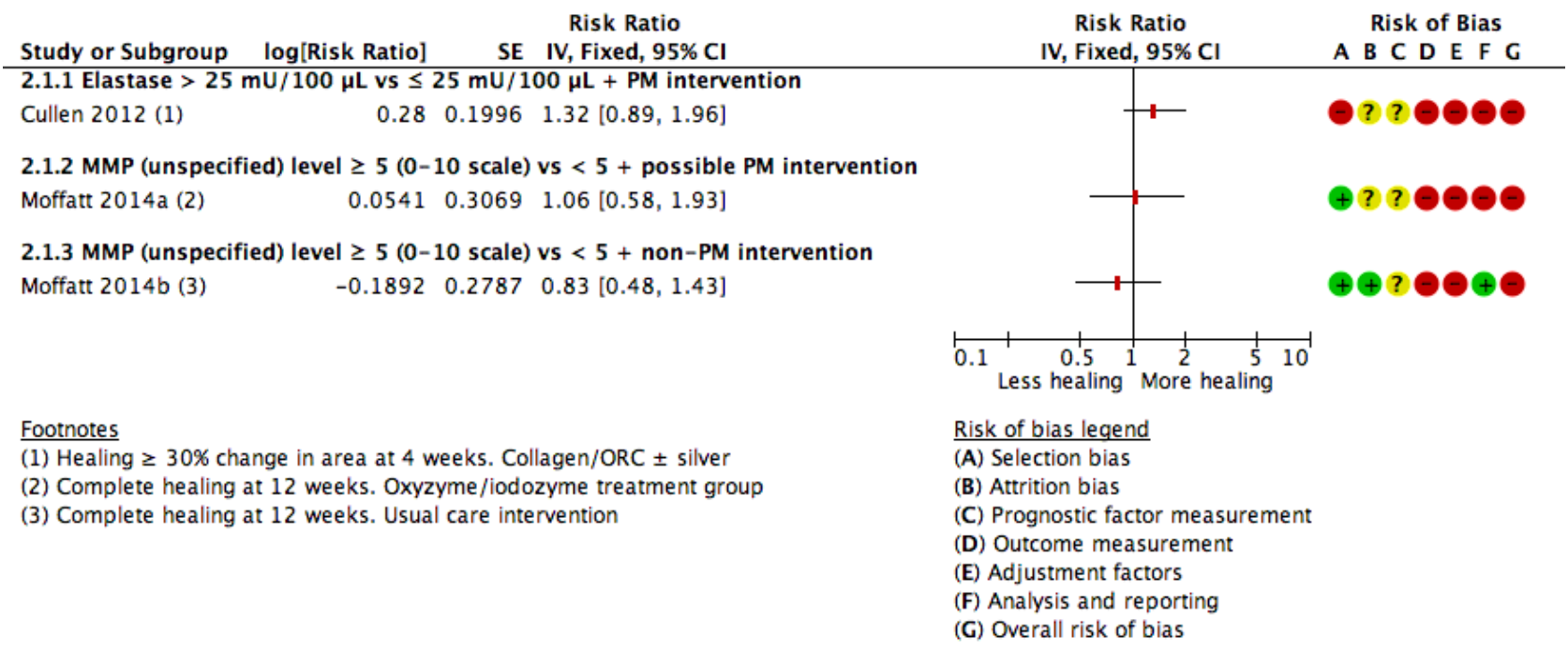


There was a positive association between elevated protease levels and healing in Cullen 2012 and an indication of a negative (expected) association in the usual care group of Moffatt 2014b. Such a trend might be explained by interactions between the protease-modulating treatment and protease levels. In nonhealing wounds with elevated protease levels, the proteasemodulating treatment may have selectively activated the healing process by removing excess protease, but in non-healing wounds with normal protease levels, the causes of non-healing will have been different and may not have been affected by proteasemodulating treatments. However, given the very low certainty of the evidence, there are other biases or confounding factors that may also explain any trend, including the nature and timing of action of the different proteases.

\section{Certainty of the evidence (GRADE)}

All the evidence was of very low certainty: the exploratory study design meant the GRADE rating started as moderate-certainty evidence (Appendix 4), and all studies except Mwaura 2006 were at overall high risk of bias (high risk of bias for at least two domains) and so the evidence certainty was downgraded by two more levels, taking the rating to very low certainty. There was also imprecision in the findings and some inconsistency. Furthermore, we considered it likely that in these small observational studies the possible biases and confounding factors would have a large impact on the results, so limiting their reliability even more.

\section{DISCUSSION}

\section{Summary of findings}

It was uncertain whether protease activity was a prognostic factor for wound healing in people with VLUs because the certainty of the evidence was very low. Of the 21 cohorts found from extensive searching, only 13 (522 participants) had data available for analysis. Of these 13 cohorts, none reported the time-to-healing outcome and only two recorded the proportion of people with ulcers completely healed, with other studies recording partial healing measures (such as $1 \mathrm{~cm}^{2} /$ week or greater decrease in size) or change in ulcer size. There was marked clinical and methodological heterogeneity across studies, which precluded meta-analysis and made narrative summary difficult. This heterogeneity included differences in the definition of healing, the type of protease and its measurement, the distribution of active and bound protease species, the types of treatment and the reporting of results. No study conducted multivariable analysis or provided IPD to allow us to do so, and all the included evidence was of very low certainty. This should be interpreted as complete uncertainty of the role of protease activity in venous ulcer healing rather than evidence of no association. No reliance can be placed on the validity of the findings.

However, this review can provide important insights for future research on the potential prognostic factors in wound healing generally and of the value of proteases for venous ulcer healing specifically. We also hope that this review presents an exemplar for future systematic reviews of biomarkers as prognostic factors in wound healing and allows reflection on the current clinical context of protease-modulating dressing use. We enlarge on these aspects below.

\section{Considerations for further prognosis research}

The review was unable to answer the question of whether protease activity was an independent prognostic factor for the healing of VLUs. The review highlighted the heterogeneous nature of protease activity reporting, a lack of standardisation of protease measurement and a lack of standardisation of how the healing outcome was defined and measured. Proteases may have a role in defining the status of a chronic wound, but the limitations in study reporting mean that it is impossible to draw a robust conclusion about the role of proteases as biomarkers for leg ulcer healing. This remains an important question, and there is a need for well-conducted, further research. Therefore, we propose a large prognostic factor research study that employs an appropriate study design and analytical approach, uses advanced methods for measuring protease activity, and takes account of confounding factors and treatments in its analysis. The following elements are important: study design, protease measurement and appropriate analysis.

\section{Study design}

A large prospective cohort study with adequate follow-up times to measure complete healing as time-to-event is a minimum requirement for new primary prognosis studies in this field.

\section{Protease measurement}

The type of proteases should be selected carefully and advanced protease activity measurement methods should be used to allow investigation of specific proteases and focus on the active form of the enzymes, rather than protease bound to other molecules or surfaces.

The measurement of proteases has evolved over time and continues to evolve, and the studies in this review used numerous techniques ranging from radiolabelled collagen breakdown, to zymograms, ELISAs, Western blots and fluorogenic substrates. These tests have now been superseded by more advanced protein evaluations, which should be used in future research.

It is also important to consider the type of proteases that would be measured in future research. Proteases have many different biological functions and activity of one protease does not necessarily provide a complete wound signature that relates to the wound phenotype. For example, specific MMPs such as MMP-2 and MMP-9 have a particular role in type IV and V collagen proteolysis, but this varies according to the study or clinical context. In addition, the different temporal and spatial location of proteases in the wound will depend on which phase of healing (coagulation, inflammation, proliferation, synthesis, remodelling) or how inflamed or infected the tissue is, hence the value of proteases as simple biomarkers may be limited. This would suggest a whole-system approach to future research, that, as a minimum, takes into account combinations of proteases and time-dependent effects, but preferably also considers demographics, comorbidities, wound duration, location and bioburden as possible confounding or interacting factors, which in turn could allow investigation of mechanisms of wound healing.

\section{Appropriate analysis}

A future study should use multivariable analysis of survival data, with continuous factors analysed on their continuous scale, and potential non-linear relationships also considered. The study 
should be sufficiently powered to take account of adjusting factors (Knofczynski 2008). IPD meta-analyses may be needed to standardise definitions and reduce heterogeneity across studies.

Finally, there may be interactions between protease levels and protease-modulating treatments, which distort any associations being studied. Future studies should take interactions into consideration in the analyses.

\section{Considerations for prognosis reviews in wound care}

In the context of systematic reviews of biomarker prognostic factor studies in wounds, serious consideration should be given to restricting the reviews to well-conducted studies with multivariable analyses, and identifying the ensuing evidence gaps separately.

\section{Current clinical context}

In the current clinical context, a number of protease-modulating dressings have been marketed and are used, based on very limited research that postulates that reducing protease activity could promote healing and that timing may also be important (Harding 2011; McCarty 2013). We have shown in this review that the evidence for protease biomarkers being prognostic for ulcer healing is of very low certainty. We have also shown in our PMM intervention review that it is unclear whether PMM dressings are more effective than other dressings in healing VLUs (Westby 2016). There is currently no study evidence on the effectiveness of a test- and-treat strategy, in which VLUs with elevated levels of protease are selectively treated with PMM dressings (Norman 2016).

\section{AUTHORS' CONCLUSIONS}

This review of protease activity as a prognostic factor for wound healing in VLUs has demonstrated the very low validity of the evidence, which means that no reliance can be placed on the findings beyond the conclusion of total uncertainty. The review can inform future research and give pointers on the methodology of systematic reviews of biomarkers as prognostic factors for wound healing. With modern protein assessment tools and validation using an 'Omics' approach, future complex wound studies should be able to highlight the significance of many of the proteases in chronic venous leg ulcers.

\section{ACKN OWLEDGEMENTS}

We are grateful to peer reviewers Anne-Marie Glenny (Editor), Carolina Weller, Janet Yarrow and Luis Nakano for their comments and feedback and we thank the Prognosis Methods Group, especially Carl Moons, for guidance and feedback. We would like to thank Deirdre Walshe for copy editing the protocol and Anne Lawson for copy editing the review, Su Golder for devising the searches, Amber Rithalia for helping with data extraction and Zhenmi Liu for helping with the risk of bias assessment. 


\section{R E F E R E N C E S}

\section{References to studies included in this review}

Ahmad 2015 \{published data only\}

Ahmad A, Saha P, Evans C, Thurison T, Hoyer-Hansen G, Patel A, et al. The soluble urokinase plasminogen activator receptor and its fragments in venous ulcers. Journal of Vascular Surgery: Venous and Lymphatic Disorders 2015;3(2):190-7.

\section{Cullen 2012 \{published data only\}}

Cullen B, Gibson M, Nisbet L. Targeted use of collagen/ORC improves clinical outcomes. Wound Repair and Regeneration 2012;20(5):A93.

\section{Frankova 2013 \{published data only\}}

Frankova J, Diamantova D, Vrbkova J, Ulrichova J. Influence of hydrogencalcium salts of oxidized cellulose on MMP-2, MMP-9 and TNF-alpha production and wound healing in non-healing wounds. Acta Dermatovenerologica Croatica 2013;21(4):219-23.

\section{Gohel 2008 \{published data only\}}

Gohel MS, Windhaber RA, Tarlton JF, Whyman MR, Poskitt KR. The relationship between cytokine concentrations and wound healing in chronic venous ulceration. Journal of Vascular Surgery 2008;48(5):1272-7.

\section{Grzela 2014 \{published data only\}}

Grzela T, Niderla-Bielinska J, Litwiniuk M, White R. The direct inhibition of MMP-2 and MMP-9 by an enzyme alginogel: a possible mechanism of healing support for venous leg ulcers. Journal of Wound Care 2014;23(5):278, 280-2, 284.

\section{Harris 1995 \{published data only\}}

Harris IR, Yee KC, Walters CE, Cunliffe WJ, Kearney JN, Wood EJ, et al. Cytokine and protease levels in healing and nonhealing chronic venous leg ulcers. Experimental Dermatology 1995;4(6):342-9.

\section{Hoffman 1999 \{published data only\}}

Hoffman R, Noble J, Eagle M. The use of proteases as prognostic markers for the healing of venous leg ulcers. Journal of Wound Care 1999;8(6):273-6.

\section{James 2003 \{published data only\}}

James TJ, Hughes MA, Cherry GW, Taylor RP. Evidence of oxidative stress in chronic venous ulcers. Wound Repair and Regeneration 2003;11(3):172-6.

\section{Litwiniuk 2012 \{published data only\}}

Litwiniuk M, Bikowska B, Niderla-Bielinska J, Jozwiak J, Kaminski A, Skopinski P, et al. Potential role of metalloproteinase inhibitors from radiation-sterilized amnion dressings in the healing of venous leg ulcers. Molecular Medicine Reports 2012;6(4):723-8.

\section{McDaniel 2017 \{published data only\}}

McDaniel JC, Szalacha L, Sales M, Roy S, Chafee S, Parinandi N. $\mathrm{EPA}+\mathrm{DHA}$ supplementation reduces PMN activation in microenvironment of chronic venous leg ulcers: a randomized, double-blind, controlled study. Wound Repair and Regeneration 2017;25(4):680-90.

\section{Moffatt 2014a \{published data only\}}

Moffatt CJ, Stanton J, Murray S, Doody V, Davis PJ, Franks PJ. A randomised trial to compare the performance of Oxyzyme and lodozyme with standard care in the treatment of patients with venous and mixed venous/arterial ulceration. Wound Medicine 2014;6:1-10.

\section{Moffatt 2014b \{published data only\}}

Moffatt CJ, Stanton J, Murray S, Doody V, Davis PJ, Franks PJ. A randomised trial to compare the performance of Oxyzyme and lodozyme with standard care in the treatment of patients with venous and mixed venous/arterial ulceration. Wound Medicine 2014;6:1-10.

\section{Mwaura 2006 \{published data only\}}

Mwaura B, Mahendran B, Hynes N, Defreitas D, Avalos G, Adegbola T, et al. The impact of differential expression of extracellular matrix metalloproteinase inducer, matrix metalloproteinase-2, tissue inhibitor of matrix metalloproteinase-2 and PDGF-AA on the chronicity of venous leg ulcers. European Journal of Vascular and Endovascular Surgery 2006;31(3):306-10.

\section{Raffetto 2015 \{published data only\}}

Raffetto JD, Mosti G, Santi M, Ligi D, Mannello F. Matrix metalloproteinase profiles in chronic venous ulcer wound fluid of inflammatory and granulating venous leg ulcers. Journal of Vascular Surgery: Venous and Lymphatic Disorders 2015;3(1):119-20.

\section{Serra 2013 \{published data only\}}

Serra R, Buffone G, Falcone D, Molinari V, Scaramuzzino M, Gallelli L, et al. Chronic venous leg ulcers are associated with high levels of metalloproteinases- 9 and neutrophil gelatinase-associated lipocalin. Wound Repair and Regeneration 2013;21(3):395-401.

\section{Serra 2015a \{published data only\}}

Serra R, Gallelli L, Buffone G, Molinari V, Stillitano DM, Palmieri C, et al. Doxycycline speeds up healing of chronic venous ulcers. International Wound Journal 2015;12(2):179-84.

\section{Serra 2015b \{published data only\}}

Serra R, Gallelli L, Buffone G, Molinari V, Stillitano DM, Palmieri C, et al. Doxycycline speeds up healing of chronic venous ulcers. International Wound Journal 2015;12(2):179-84.

\section{Smeets 2008 \{published data only\}}

Smeets R, Ulrich D, Unglaub F, Woltje M, Pallua N. Effect of oxidised regenerated cellulose/collagen matrix on proteases in wound exudate of patients with chronic venous ulceration. International Wound Journal 2008;5(2):195-203.

\section{Trengove 1999 \{published data only\}}

Trengove NJ, Stacey MC, Macauley S, Bennett N, Gibson J, Burslem F, et al. Analysis of the acute and chronic would 
environments: the role of proteases and their inhibitors. Wound Repair and Regeneration 1999;7(6):442-52.

Trøstrup 2011 \{published data only\}

* Trøstrup H, Lundquist R, Christensen LH, Jorgensen LN, Karlsmark T, Haab BB, et al. S100A8/A9 deficiency in nonhealing venous leg ulcers uncovered by multiplexed antibody microarray profiling. British Journal of Dermatology 2011;165(2):292-301.

Trøstrup H, Lundquist R, Jorgensen L, Karlmark T, Haab B, Agren MS. Antibody microarray profiling uncovers molecular anomalies in chronic venous leg ulcers. Wound Repair and Regeneration 2010;18(2):A14.

Trøstrup H, Lundquist R, Jorgensen L, Karlsmark T, Haab B, Agren M. Antibody-based microarray profiling of acute and chronic wound fluids. Wound Repair and Regeneration 2010;18(6):A95.

\section{Wysocki 1999 \{published data only\}}

Wysocki AB, Kusakabe AO, Chang S, Tuan TL. Temporal expression of urokinase plasminogen activator, plasminogen activator inhibitor and gelatinase-B in chronic wound fluid switches from a chronic to acute wound profile with progression to healing. Wound Repair and Regeneration 1999;7(3):154-65.

\section{References to studies excluded from this review}

\section{Ahmad 2011 \{published data only\}}

Ahmad A, Waltham M, Hooyer-Hansen G, Soorensen TT, Mattock K, Saha P, et al. Reduced expression of soluble urokinase receptor fragment DII-III predicts venous ulcers that fail to heal. Journal of Vascular Surgery 2011;53(1):256.

\section{Alexewicz 2007 \{published data only\}}

Alexewicz P, Gosk-Bierska I, Malecki R, Adamiec R. Plasma protein $S$ level in patients with venous ulcers secondary to postthrombotic syndrome. Przeglad Flebologiczny 2007;15(3):117-9.

\section{Amato 2015 \{published data only\}}

Amato B, Coretti G, Compagna R, Amato M, Buffone G, Gigliotti $D$, et al. Role of matrix metalloproteinases in non-healing venous ulcers. International Wound Journal 2015;12(6):641-5.

\section{Anon 2008 \{published data only\}}

Anonymous. A stimulating approach to hard-to-heal wounds. Wounds UK 2008;4(1 Suppl):1-5.

\section{Ayuk 2016 \{published data only\}}

Ayuk SM, Abrahamse $\mathrm{H}$, Houreld NN. The role of matrix metalloproteinases in diabetic wound healing in relation to photobiomodulation. Journal of Diabetes Research 2016;2016:2897656.

\section{Barros 2012 \{published data only\}}

Barros SC, Martins JA, Marcos JC, Cavaco-Paulo A. Influence of secretory leukocyte protease inhibitor-based peptides on elastase activity and their incorporation in hyaluronic acid hydrogels for chronic wound therapy. Biopolymers 2012;98(6):576-90.

Bernatchez 2012 \{published data only\}

Bernatchez SF, Stoffel JJ, Walters SH, Lindroos WE, Crossland MC, Shawler LG, et al. Nitric oxide levels in wound fluid may reflect the healing trajectory. Wound Repair and Regeneration 2012;20(2):A15

Bigliardi 1955 \{published data only\}

Bigliardi P. Enzymatic wound treatment with a new chemotherapeutic trypsin-containing preparation with special reference to the treatment of ulcus cruris. Therapeutische Umschau. Revue Therapeutique 1955;12(4-5):70-3.

Bogaczewicz 2004 \{published data only\}

Bogaczewicz J, Chodorowska G, Krasowska D. The role of matrix metalloproteinases and tissue inhibitors of metalloproteinases in cutaneous wound healing. Przeglad Dermatologiczny 2004;91(3):253-61.

Bohórquez-Sierra 2006 \{published data only\}

Bohórquez-Sierra JC. Matrix metalloproteases: their involvement in peripheral vascular diseases [Metaloproteinasas de matriz: su implicación en las enfermedades vasculares periféricas]. Angiologia 2006;58(4):269-77.

\section{Budzyn-Napierala 2016 \{published data only\}}

Budzyn-Napierala M, Iskra M, Krasinski Z, Turkiewicz W, Gryszczynska B, Kasprzak M, et al. Altered elastase-alpha1antitrypsin balance in the blood of patients with chronic venous disease. Phlebology 2016;31(2):125-32.

\section{Caimi 2015 \{published data only\}}

Caimi G, Ferrara F, Montana M, Muratori I, Amato C, Canino B, et al. Behaviour of the plasma concentration of gelatinases and their tissue inhibitors in subjects with venous leg ulcers. Clinical Hemorheology and Microcirculation 2015;60(3):309-16.

\section{Clark 2001 \{published data only\}}

Clark RA. Fibrin and wound healing. Annals of the New York Academy of Sciences 2001;936:355-67.

\section{Cook 2000 \{published data only\}}

Cook H, Stephens P, Davies KJ, Harding KG, Thomas DW. Defective extracellular matrix reorganization by chronic wound fibroblasts is associated with alterations in TIMP-1, TIMP-2, and MMP-2 activity. Journal of Investigative Dermatology 2000;115(2):225-33.

\section{Cook 2009 \{published data only\}}

Cook H, Stephens P, Davies KJ, Harding KG, Thomas DW. Phenotypic differences in wound healing responses are reflected by differences in ECM reorganisation and MMP-2 activation. Journal of Gastroenterology and Hepatology 2009;24:A88.

Cullen 2002b \{published data only\}

Cullen B, Watt PW, Lundqvist C, Silcock D, Schmidt RJ, Bogan D, et al. The role of oxidised regenerated cellulose/collagen in chronic wound repair and its potential mechanism of 
action. International Journal of Biochemistry \& Cell Biology 2002;34(12):1544-56.

\section{Dalton 2005 \{published data only\}}

Dalton SJ, Mitchell DC, Whiting CV, Tarlton JF. Abnormal extracellular matrix metabolism in chronically ischemic skin: a mechanism for dermal failure in leg ulcers. Journal of Investigative Dermatology 2005;125(2):373-9.

\section{Da Silva 2014 \{published data only\}}

Da Silva FS, Araujo DN, Lima JP, De Rezende AA, Da Graca Azevedo Abreu BJ, Dias FA. Enzymatic activity analysis of MMP-2 and 9 collected by swab from lower limb venous ulcers. Jornal Vascular Brasileiro 2014;13(3):229-34.

\section{Derbyshire 2003 \{published data only\}}

Derbyshire A. A case study to demonstrate the role of proteases in wound healing. Professional Nurse 2003;19(2):108-11.

\section{Duffy 2005 \{published data only\}}

Duffy D. Serum iron and matrix metalloproteinase- 9 variations in limbs affected by chronic venous disease and venous leg ulcers: commentary. Dermatologic Surgery 2005;31(6):649.

\section{Eming 2006 \{published data only\}}

Eming SA, Smola-Hess S, Kurschat P, Hirche D, Krieg T, Smola H. A novel property of povidon-iodine: inhibition of excessive protease levels in chronic non-healing wounds. Journal of Investigative Dermatology 2006;126(12):2731-3.

\section{Eming 2008 \{published data only\}}

Eming S, Smola H, Hartmann B, Malchau G, Wegner R, Krieg T, et al. The inhibition of matrix metalloproteinase activity in chronic wounds by a polyacrylate superabsorber. Biomaterials 2008;29(19):2932-40.

\section{Failla 2008 \{published data only\}}

Failla G, Campo S, Ardita G, Finocchiaro P, Mugno F, Attanasio L, et al. Proteases and chronic leg ulcers. Minerva Cardioangiologica 2008;56(4):409-15.

\section{Fernandez 2008 \{published data only\}}

Fernandez ML, Broadbent JA, Shooter GK, Malda J, Upton Z. Development of an enhanced proteomic method to detect prognostic and diagnostic markers of healing in chronic wound fluid. British Journal of Dermatology 2008;158(2):281-90.

\section{Fisher 1998 \{published data only\}}

Fisher DA, Grossman D, Heald PW, Rinder HM. Activated protein $C$ resistance and anticardiolipin antibodies in patients with venous leg ulcers. Journal of the American Academy of Dermatology 1998;39(2 Pt 1):299-300.

\section{Fray 2003 \{published data only\}}

Fray MJ, Dickinson RP, Huggins JP, Occleston NL. A potent, selective inhibitor of matrix metalloproteinase-3 for the topical treatment of chronic dermal ulcers. Journal of Medicinal Chemistry 2003;46(16):3514-25.

\section{Gacka 2004 \{published data only\}}

Gacka M, Mastej K, Adamiec R. Thrombotic and fibrinolitic activity in patients with venous ulcer during sulodexide treatment. Przeglad Flebologiczny 2004;12(3):97-100.

\section{Gordon 1975 \{published data only\}}

Gordon B. The use of topical proteolytic enzymes in the treatment of post-thrombotic leg ulcers. British Journal of Clinical Practice 1975;29(6):143-6.

Grinnell 1992 \{published data only\}

Grinnell F, Ho CH, Wysocki A. Degradation of fibronectin and vitronectin in chronic wound fluid: analysis by cell blotting, immunoblotting, and cell adhesion assays. Journal of Investigative Dermatology 1992;98(4):410-6.

\section{Grinnell 1998 \{published data only\}}

Grinnell F, Zhu M, Parks WC. Collagenase-1 complexes with alpha2-macroglobulin in the acute and chronic wound environments. Journal of Investigative Dermatology 1998;110(5):771-6

\section{Hasmann 2011 \{published data only\}}

Hasmann A, Gewessler U, Hulla E, Schneider KP, Binder B, Francesko A, et al. Sensor materials for the detection of human neutrophil elastase and cathepsin $\mathrm{G}$ activity in wound fluid. Experimental Dermatology 2011;20(6):508-13.

\section{He 1999 \{published data only\}}

He C, Hughes MA, Cherry GW, Arnold F. Effects of chronic wound fluid on the bioactivity of platelet-derived growth factor in serum-free medium and its direct effect on fibroblast growth. Wound Repair and Regeneration 1999;7(2):97-105.

Herouy 2000a \{published data only\}

Herouy Y, Trefzer D, Hellstern MO, Stark GB, Vanscheidt W, Schopf $E$, et al. Plasminogen activation in venous leg ulcers. British Journal of Dermatology 2000;143(5):930-6.

Herouy 2000b \{published data only\} Herouy Y, Trefzer D, Zimpfer U, Schopf E, Wanscheidt W, Norgauer J. Matrix metalloproteinases and venous leg ulceration. European Journal of Dermatology 2000;10(3):173-80.

Herouy 2004 \{published data only\}

Herouy Y, Kahle B, Idzko M, Hildenbrand T, Ali MY, Clement J, et al. Venous leg ulcers and apoptosis: a TIMP-3mediated pathway?. Journal of Investigative Dermatology 2004;123(6):1210-2.

\section{Herrick 1997 \{published data only\}}

Herrick S, Ashcroft G, Ireland G, Horan M, McCollum C, Ferguson M. Up-regulation of elastase in acute wounds of healthy aged humans and chronic venous leg ulcers are associated with matrix degradation. Laboratory Investigation $1997 ; 77(3): 281-8$

Hoffman 1998 \{published data only\}

Hoffman R, Starkey S, Coad J. Wound fluid from venous leg ulcers degrades plasminogen and reduces plasmin generation 
by keratinocytes. Journal of Investigative Dermatology 1998;111(6):1140-4.

\section{Honda 2011 \{published data only\}}

Honda K, Okamoto K, Mochida Y, Ishioka K, Oka M, Maesato K, et al. A novel mechanism in maggot debridement therapy: protease in excretion/secretion promotes hepatocyte growth factor production. American Journal of Physiology: Cell Physiology 2011;301(6):C1423-30.

\section{Huttunen 2000 \{published data only\}}

Huttunen M, Aalto ML, Harvima RJ, Horsmanheimo M, Harvima IT. Alterations in mast cells showing tryptase and chymase activity in epithelializating and chronic wounds. Experimental Dermatology 2000;9(4):258-65.

\section{Huttunen 2004 \{published data only\}}

Huttunen M. Mast cells in cutaneous wound healing. Forum for Nordic Dermato-Venerology 2004;9(2):37-8.

\section{Huttunen 2005 \{published data only\}}

Huttunen M, Harvima IT. Mast cell tryptase and chymase in chronic leg ulcers: chymase is potentially destructive to epithelium and is controlled by proteinase inhibitors. British Journal of Dermatology 2005;152(6):1149-60.

\section{Ibbotson 1994 \{published data only\}}

Ibbotson SH, Layton AM, Davies JA, Goodfield MJ. Plasminogen activator inhibitor 1 (PAI-1) levels in patients with chronic venous leg ulceration. British Journal of Dermatology 1994;131(5):738-9.

\section{Impola 2005 \{published data only\}}

Impola U, Jeskanen L, Ravanti L, Syrjanen S, Baldursson B, Kahari VM, et al. Expression of matrix metalloproteinase (MMP)-7 and MMP-13 and loss of MMP-19 and p16 are associated with malignant progression in chronic wounds. British Journal of Dermatology 2005;152(4):720-6.

\section{Ivins 2014 \{published data only\}}

Ivins N. Evaluation of the mode of action of a new gel wound dressing. Wounds UK 2014;10(2):86-95.

\section{Karatepe 2010 \{published data only\}}

Karatepe O, Unal O, Ugurlucan M, Kemik A, Karahan S, Aksoy M, et al. The impact of valvular oxidative stress on the development of venous stasis ulcer valvular oxidative stress and venous ulcers. Angiology 2010;61(3):283-8.

\section{Karim 2006 \{published data only\}}

Karim RB, Brito BL, Dutrieux RP, Lassance FP, Hage JJ. MMP-2 assessment as an indicator of wound healing: a feasibility study. Advances in Skin \& Wound Care 2006;19(6):324-7.

\section{Körber 2006 \{published data only\}}

Körber A, Freise J, Grabbe S, Dissemond J. Reduction of $\mathrm{pH}$ values in chronic leg ulcers by cadesorb. Zeitschrift fur Wundheilung 2006;11(5):230-4.
Kucharzewski 2005 \{published data only\}

Kucharzewski M. Matrix metalloproteinases and venous leg ulcer. Przeglad Flebologiczny 2005;13(6):269-74.

Kucukguven 2013 \{published data only\}

Kucukguven A, Khalil RA. Matrix metalloproteinases as potential targets in the venous dilation associated with varicose veins. Current Drug Targets 2013;14(3):287-324.

\section{Lantis 2011 \{published data only\}}

Lantis J 2nd, Theoharides T, Fuller A, Gendics C. Analysis of mast cell tryptase in hard to heal venous leg ulcers. Wound Repair and Regeneration 2011;19(5):A76.

Ligi 2016 \{published data only\}

Ligi D, Mosti G, Croce L, Raffetto JD, Mannello F. Chronic venous disease - part II: proteolytic biomarkers in wound healing. Biochimica et Biophysica Acta 2016;1862(10):1900-8.

\section{Lim 2010 \{published data only\}}

Lim CS, Shalhoub J, Gohel MS, Shepherd AC, Davies AH. Matrix metalloproteinases in vascular disease: a potential therapeutic target?. Current Vascular Pharmacology 2010;8(1):75-85.

Lotti 1995 \{published data only\} Lotti T, Benci M. Plasminogen activators, venous leg ulcers and reepithelialization. International Journal of Dermatology 1995;34(10):696-9.

\section{McCarty 2012 \{published data only\}}

McCarty SM, Cochrane CA, Clegg PD, Percival SL. The role of endogenous and exogenous enzymes in chronic wounds: a focus on the implications of aberrant levels of both host and bacterial proteases in wound healing. Wound Repair and Regeneration 2012;20(2):125-36.

McCarty 2013 \{published data only\} McCarty SM, Percival SL. Proteases and delayed wound healing. Advances in Wound Care 2013;2(8):438-47.

McInnes 2014 \{published data only\}

McInnes RL, Cullen BM, Hill KE, Price PE, Harding KG, Thomas DW, et al. Contrasting host immuno-inflammatory responses to bacterial challenge within venous and diabetic ulcers. Wound Repair and Regeneration 2014;22(1):58-69.

\section{Mirastschijski 2002 \{published data only\}}

Mirastschijski U, Impola U, Jahkola T, Karlsmark T, Ms AG, Saarialho-Kere U. Ectopic localization of matrix metalloproteinase-9 in chronic cutaneous wounds. Human Pathology 2002;33(3):355-64.

\section{Mirshahi 1995 \{published data only\}}

Mirshahi S, Soria J, Mirshahi M, Soria C, Lenoble M, Vasmant D, et al. Expression of elastase and fibrin in venous leg ulcer biopsies: a pilot study of pentoxifylline versus placebo. Journal of Cardiovascular Pharmacology 1995;25(Suppl 2):S101-5. 
Moor 2009 \{published data only\}

Moor AN, Vachon DJ, Gould LJ. Proteolytic activity in wound fluids and tissues derived from chronic venous leg ulcers. Wound Repair and Regeneration 2009;17(6):832-9.

\section{Moore 2007 \{published data only\}}

Moore K, Huddleston E, Stacey MC, Harding KG. Venous leg ulcers - the search for a prognostic indicator. International Wound Journal 2007;4(2):163-72.

\section{Nielsen 1992 \{published data only\}}

Nielsen JA, Bundgaard D, Schmidt EB. Fibrinolysis in patients with venous ulcers before and after ulcer healing induced by an unelastic bandage. European Journal of Internal Medicine 1992;3(1):23-6.

\section{Norgauer 2002 \{published data only\}}

Norgauer J, Hildenbrand T, Idzko M, Panther E, Bandemir E, Hartmann $M$, et al. Elevated expression of extracellular matrix metalloproteinase inducer (CD147) and membrane-type matrix metalloproteinases in venous leg ulcers. British Journal of Dermatology 2002;147(6):1180-6.

Nwomeh 1999 \{published data only\}

Nwomeh BC, Liang HX, Cohen IK, Yager DR. MMP-8 is the predominant collagenase in healing wounds and nonhealing ulcers. Journal of Surgical Research 1999;81(2):189-95.

\section{Ovington 2001 \{published data only\}}

Ovington LG. Matrix metalloproteases: the newest initials in would healing are MMP. Podiatry Management 2001;20(6):107-12

\section{Palolahti 1993 \{published data only\}}

Palolahti M, Lauharanta J, Stephens RW, Kuusela P, Vaheri A. Proteolytic activity in leg ulcer exudate. Experimental Dermatology 1993;2(1):29-37.

\section{Phillips 2007 \{published data only\}}

Phillips LJ, Sarkar R. Molecular characterization of postthrombotic syndrome. Journal of Vascular Surgery 2007;45(Suppl A):A116-22.

\section{Pirila 2007 \{published data only\}}

Pirila E, Korpi JT, Korkiamaki T, Jahkola T, GutierrezFernandez A, Lopez-Otin C, et al. Collagenase-2 (MMP-8) and matrilysin-2 (MMP-26) expression in human wounds of different etiologies. Wound Repair and Regeneration 2007;15(1):47-57.

\section{Raffetto 2014 \{published data only\}}

Raffetto JD. Which dressings reduce inflammation and improve venous leg ulcer healing. Phlebology 2014;29(1 Suppl):157-64.

\section{Rayment 2008 \{published data only\}}

Rayment EA, Upton, Z, Shooter GK. Increased matrix metalloproteinase-9 (MMP-9) activity observed in chronic wound fluid is related to the clinical severity of the ulcer. Clinical and Laboratory Investigations 2008;158:951-61.
Rayment 2009 \{published data only\}

Rayment EA, Upton Z. Finding the culprit: a review of the influences of proteases on the chronic wound environment. International Journal of Lower Extremity Wounds 2009;8(1):19-27.

\section{Rechardt 2000 \{published data only\}}

Rechardt O, Elomaa O, Vaalamo M, Paakkonen K, Jahkola T, Hook-Nikanne J, et al. Stromelysin-2 is upregulated during normal wound repair and is induced by cytokines. Journal of Investigative Dermatology 2000;115(5):778-87.

\section{Rogers 1999 \{published data only\}}

Rogers AA, Burnett S, Lindholm C, Bjellerup M, Christensen OB, Zederfeldt $B$, et al. Expression of tissue-type and urokinase-type plasminogen activator activities in chronic venous leg ulcers. Vasa 1999;28(2):101-5.

\section{Saarialho-Kere 1998 \{published data only\}}

Saarialho-Kere UK. Patterns of matrix metalloproteinase and TIMP expression in chronic ulcers. Archives of Dermatological Research 1998;290(Suppl):S47-54.

\section{Salgado 2017 \{published data only\}}

Salgado R, Cruz-Castaneda O, Elizondo-Vazquez F, Pat L, De la Garza A, Cano-Colín S, et al. Maltodextrin/ascorbic acid stimulates wound closure by increasing collagen turnover and TGF- $\beta 1$ expression in vitro and changing the stage of inflammation from chronic to acute in vivo. Journal of Tissue Viability 2017;26(2):131-7.

\section{Schmid 1999 \{published data only\}}

Schmid P, Itin P, Cox D. Proteolytic inactivation of transforming growth factor beta3 by elastase in venous leg ulcers: implications for clinical trials using topically-applied peptide growth factors. British Journal of Dermatology 1999;140(6):1170-2.

\section{Schmidtchen 2000 \{published data only\}}

Schmidtchen A. Degradation of antiproteinases, complement and fibronectin in chronic leg ulcers. Acta DermatoVenereologica 2000;80(3):179-84.

\section{Schmidtchen 2003 \{published data only\}}

Schmidtchen A, Wolff H, Rydengard V, Hansson C. Detection of serine proteases secreted by Lucilia sericata in vitro and during treatment of a chronic leg ulcer. Acta Dermato-Venereologica 2003;83(4):310-1.

\section{Schultz 2004 \{published data only\}}

Schultz G. Commentary on mechanism of action of PROMOGRAN, a protease modulating matrix, for the treatment of diabetic foot ulcers. Foot and Ankle Quarterly: the Seminar Journal 2004;16(2):84.

\section{Senet 2003 \{published data only\}}

Senet P, Bon FX, Benbunan M, Bussel A, Traineau R, Calvo F, et al. Randomized trial and local biological effect of autologous platelets used as adjuvant therapy for chronic venous leg ulcers. Journal of Vascular Surgery 2003;38(6):1342-8. 
Serena 2016 \{published data only\}

Serena TE, Cullen B, Bayliff S, Gibson M, DeMarco D, Galbraith J, et al. Protease activity levels associated with nonhealing chronic wounds. Wound Repair and Regeneration 2012;20(5):A93.

* Serena TE, Cullen BM, Bayliff SW, Gibson MC, Carter MJ, Chen $\mathrm{L}$, et al. Defining a new diagnostic assessment parameter for wound care: elevated protease activity, an indicator of nonhealing, for targeted protease-modulating treatment. Wound Repair and Regeneration 2016;24(3):589-95.

\section{Serra 2014 \{published data only\}}

Serra R, Gallelli L, Conti A, De Caridi G, Massara M, Spinelli F, et al. The effects of sulodexide on both clinical and molecular parameters in patients with mixed arterial and venous ulcers of lower limbs. Drug Design, Development and Therapy 2014;8:519-27.

\section{Serra 2015c \{published data only\}}

Serra R, Butrico L, Ruggiero M, Rossi A, Buffone G, Fugetto F, et al. Epidemiology, diagnosis and treatment of chronic leg ulcers: a systematic review. Acta Phlebologica 2015;16(1):9-18.

\section{Serra 2016a \{published data only\}}

Serra R, Grande R, Buffone G, Molinari V, Perri P, Perri A, et al. Extracellular matrix assessment of infected chronic venous leg ulcers: role of metalloproteinases and inflammatory cytokines. International Wound Journal 2016;13(1):53-8.

\section{Serra 2016b \{published data only\}}

Serra R, Grande R, Butrico L, Buffone G, Calio FG, Squillace A, et al. Effects of a new nutraceutical substance on clinical and molecular parameters in patients with chronic venous ulceration. International Wound Journal 2016;13(1):88-96.

\section{Serra 2017 \{published data only\}}

Serra R, Gallelli L, Butrico L, Buffone G, Calio FG, De Caridi G, et al. From varices to venous ulceration: the story of chronic venous disease described by metalloproteinases. International Wound Journal 2017;14(1):233-40.

\section{Shields 1994 \{published data only\}}

Shields DA, Andaz SK, Sarin S, Scurr JH, Coleridge Smith PD. Plasma elastase in venous disease. British Journal of Surgery 1994;81(10):1496-9.

\section{Singh 2010 \{published data only\}}

Singh AV, Subhashree L, Milani P, Gemmati D, Zamboni P. Interplay of iron metallobiology, metalloproteinases, and FXIII, and role of their gene variants in venous leg ulcer. International Journal of Lower Extremity Wounds 2010;9(4):166-79.

\section{Stacey 1993 \{published data only\}}

Stacey MC, Burnand KG, Mahmoud-Alexandroni M, Gaffney PJ, Bhogal BS. Tissue and urokinase plasminogen activators in the environs of venous and ischaemic leg ulcers. British Journal of Surgery 1993;80(5):596-9.
Stacey 2000 \{published data only\}

Stacey MC, Mata SD. Lower levels of PAI-2 may contribute to impaired healing in venous ulcers - a preliminary study. Cardiovascular Surgery 2000;8(5):381-5.

Stojadinovic 2014 \{published data only\}

Stojadinovic O, Ramirez H, Patel S, Yin N, Bollenbach T, Golden P, et al. Genomic insight into molecular mechanisms of action of bilayered living cellular construct nonhealing venous leg ulcers. Wound Repair and Regeneration 2014;22(2):A60.

\section{Tarlton 1999 \{published data only\}}

Tarlton JF, Bailey AJ, Crawford E, Jones D, Moore K, Harding KD. Prognostic value of markers of collagen remodeling in venous ulcers. Wound Repair and Regeneration 1999;7(5):347-55.

Tauzin 2014 \{published data only\}

Tauzin H, Robin S, Humbert P, Viennet C, Saas P, CourderotMasuyer C, et al. Can leg ulcer fibroblasts phenotype be influenced by human amniotic membrane extract?. Cell and Tissue Banking 2014;15(2):251-5.

\section{Turio 2002 \{published data only\}}

Turio E, Avvenente A, Evangelisti L, Panicucci E, Giordani R, Sagripanti A, et al. Measurement of coagulation and fibrinolysis plasma parameters in patients with post-phlebitic and non post-phlebitic venous leg ulcers. Giornale Italiano di Dermatologia e Venereologia 2002;137(1):25-30.

\section{Ulrich 2005 \{published data only\}}

Ulrich D, Lichtenegger F, Unglaub F, Smeets R, Pallua N. Effect of chronic wound exudates and MMP-2/-9 inhibitor on angiogenesis in vitro. Plastic and Reconstructive Surgery 2005;116(2):539-45.

\section{Vaalamo 1996 \{published data only\}}

Vaalamo M, Weckroth M, Puolakkainen P, Kere J, Saarinen P, Lauharanta J, et al. Patterns of matrix metalloproteinase and TIMP-1 expression in chronic and normally healing human cutaneous wounds. British Journal of Dermatology 1996;135(1):52-9.

\section{Vaalamo 1997 \{published data only\}}

Vaalamo M, Mattila L, Johansson N, Kariniemi AL, KarjalainenLindsberg ML, Kahari VM, et al. Distinct populations of stromal cells express collagenase-3 (MMP-13) and collagenase-1 (MMP-1) in chronic ulcers but not in normally healing wounds. Journal of Investigative Dermatology 1997;109(1):96-101.

\section{Vaalamo 1999 \{published data only\}}

Vaalamo M, Leivo T, Saarialho-Kere U. Differential expression of tissue inhibitors of metalloproteinases (TIMP-1, -2, -3, and $-4)$ in normal and aberrant wound healing. Human Pathology 1999;30(7):795-802.

\section{Vahlquist 2000 \{published data only\}}

Vahlquist A. Markers of skin inflammation and wound healing. Acta Dermato-venereologica 2000;80(3):161. 
Van Bergen 1996 \{published data only\}

Van Bergen BH, Andriessen MP, Spruijt KI, Van de Kerkhof PC, Schalkwijk J. Expression of SKALP/elafin during wound healing in human skin. Archives of Dermatological Research 1996;288(8):458-62.

\section{Varelias 2002 \{published data only\}}

Varelias A, Hughes H, Cowin A, Cowled P, Cooter R, Harries R. Detection and modulation of matrix metalloproteinases in patients with chronic leg ulcers treated with whey-derived growth factors. Fourth Australian Wound Management Association Conference; 2002 Mar 7-10; Adelaide, South Australia. 2002:334.

\section{Varelias 2006 \{published data only\}}

Varelias A, Cowin AJ, Adams D, Harries RH Cooter RD, Belford $D$, et al. Mitogenic bovine whey extract modulates matrix metalloproteinase-2, -9 , and tissue inhibitor of matrix metalloproteinase-2 levels in chronic leg ulcers. Wound Repair and Regeneration 2006;14(1):28-37.

\section{Weckroth 1996 \{published data only\}}

Weckroth M, Vaheri A, Lauharanta J, Sorsa T, Konttinen YT. Matrix metalloproteinases, gelatinase and collagenase, in chronic leg ulcers. Journal of Investigative Dermatology 1996;106(5):1119-24.

\section{Weckroth 2004 \{published data only\}}

Weckroth M, Vaheri A, Virolainen S, Saarialho-Kere U, Jahkola T, Siren V. Epithelial tissue-type plasminogen activator expression, unlike that of urokinase, its receptor, and plasminogen activator inhibitor-1, is increased in chronic venous ulcers. British Journal of Dermatology 2004;151(6):1189-96.

\section{Widgerow 2011 \{published data only\}}

Widgerow AD. Chronic wound fluid - thinking outside the box. Wound Repair and Regeneration 2011;19(3):287-91.

\section{Wlaschek 1997 \{published data only\}}

Wlaschek M, Peus D, Achterberg V, Meyer-Ingold W, ScharffetterKochanek K. Protease inhibitors protect growth factor activity in chronic wounds. British Journal of Dermatology 1997;137(4):646.

\section{Wysocki 1993 \{published data only\}}

Wysocki AB, Staiano-Coico L, Grinnell F. Wound fluid from chronic leg ulcers contains elevated levels of metalloproteinases MMP-2 and MMP-9. Journal of Investigative Dermatology 1993;101(1):64-8.

Wysocki 1996 \{published data only\} Wysocki AB. Wound fluids and the pathogenesis of chronic wounds. Journal of Wound, Ostomy \& Continence Nursing 1996;23(6):283-90

\section{Zamboni 2005 \{published data only\}}

Zamboni P, Scapoli G, Lanzara V, Izzo M, Fortini P, Legnaro R, et al. Serum iron and matrix metalloproteinase- 9 variations in limbs affected by chronic venous disease and venous leg ulcers. Dermatologic Surgery 2005;31(6):644-9.

\section{Zeegelaar 1997 \{published data only\}}

Zeegelaar JE, Verheijen JH, Kerckhaert JA, Jankowski I, Faber WR. Local treatment of venous ulcers with tissue type plasminogen activator containing ointment. Vasa 1997;26(2):81-4.

\section{Zillmer 2011 \{published data only\}}

Zillmer R, Trøstrup H, Karlsmark T, Ifversen P, Ågren MS. Duration of wound fluid secretion from chronic venous leg ulcers is critical for interleukin- $1 \alpha$, interleukin- $1 \beta$, interleukin- 8 levels and fibroblast activation. Archives of Dermatological Research 2011;303(8):601-6.

\section{References to studies awaiting assessment}

Cullen 2009 \{published data only\}

Cullen B, Nisbet L, Essler L, Silcock D, Lalikos J, Dunn R. The ability of collagen/ORC to correct biochemical imbalances in venous leg ulcers. Wound Repair and Regeneration 2009;17(4):A55.

\section{Additional references}

\section{Altman 2001}

Altman DG. Systematic reviews of evaluations of prognostic variables. BMJ 2001;323:224-8.

\section{Ashby 2014}

Ashby RL, Gabe R, Ali S, Adderly U, Bland JM, Cullum NA, et al. Clinical and cost-effectiveness of compression hosiery versus compression bandages in treatment of venous leg ulcers (Venous leg Ulcer Study IV, VenUS IV): a randomised controlled trial. Lancet 2014;383(9920):871-9.

\section{Ashcroft 1997}

Ashcroft GS, Horan MA, Herrick SE, Tarnuzzer RW, Schultz GS, Ferguson MW. Age-related differences in the temporal and spatial regulation of matrix metalloproteinases (MMPs) in normal skin and acute cutaneous wounds of healthy humans. Cell and Tissue Research 1997;290(3):581-91.

\section{Augustin 2012}

Augustin M, Brocatti LK, Rustenbach SJ, Schafer I, Herberger K. Cost-of-illness of leg ulcers in the community. International Wound Journal 2012;11(3):283-92.

\section{Austin 2015}

Austin PC, Steyerberg EW. The number of subjects per variable required in linear regression analyses. Journal of Clinical Epidemiology 2015;68(6):627-36.

\section{Barrett 2011}

Barrett S, Davis L, Edwards J, Fletcher J, Harding K, Jack L, et al. Protease diagnostic in wound care: round-table meeting. Wounds UK 2011;7(4 Suppl):3-10.

\section{Barwell 2000}

Barwell JR, Ghauri AS, Taylor M, Deacon J, Wakely C, Poskitt KR, et al. Risk factors for healing and recurrence of chronic venous leg ulcers. Phlebology 2000;15(2):49-52. 


\section{Barwell 2001}

Barwell JR, Taylor M, Deacon J, Davies C, Whyman MR, Poskitt KR. Ankle motility is a risk factor for healing of chronic venous leg ulcers. Phlebology 2001;16(1):38-40.

\section{Beidler 2008}

Beidler SK, Douillet CD, Berndt DF, Keagy BA, Rich PB, Marston WA. Multiplexed analysis of matrix metalloproteinases in leg ulcer tissue of patients with chronic venous insufficiency before and after compression therapy. Wound Repair and Regeneration 2008;16(5):642-8.

\section{Berkey 1995}

Berkey CS, Hoaglin DC, Mosteller F, Colditz GA. A randomeffects regression model for meta-analysis. Statistics in Medicine 1995;14:395-411.

\section{Biomarkers Definitions Working Group 2001}

Biomarkers Definitions Working Group. Biomarkers and surrogate endpoints: preferred definitions and conceptual framework. Clinical Pharmacology and Therapeutics 2001;69(3):89-95.

\section{Callam 1987}

Callam MJ, Harper DR, Dale JJ, Ruckley CV. Chronic ulcer of the leg: clinical history. British Medical Journal 1987;294(6584):1389-91.

\section{Chaby 2013}

Chaby G, Senet P, Ganry O, Caudron A, Thuillier D, Debure C, et al. Prognostic factors associated with healing of venous leg ulcers: a multicentre, prospective, cohort study. British Journal of Dermatology 2013;169(5):1106-13.

\section{Choa 2015}

Choa R, Rayatt S, Mahtani K. Marjolin's ulcer. BMJ 2015;350:h3997.

\section{Cochrane Prognosis Methods Group 2018}

Cochrane Prognosis Methods Group. Review tools. https://methods.cochrane.org/prognosis/sites/ methods.cochrane.org.prognosis/files/public/uploads/ protocol_template_prognosis_reviews.doc (accessed 13 July 2018).

\section{Coleridge Smith 1988}

Coleridge Smith PD, Thomas P, Scurr JH, Dormandy JA. Causes of venous ulceration: a new hypothesis. $B M J$ 1988;296(6638):1726-7.

\section{Cornell 2014}

Cornell JE, Mulrow CD, Localio R, Stack CB, Meibohm AR, Guallar E, et al. Random-effects meta-analysis of inconsistent effects: a time for change. Annals of Internal Medicine 2014;160(4):267-70.

\section{Cullen 2002a}

Cullen B, Smith R, McCulloch E, Silcock D, Morrisson L. Mechanism of action of PROMOGRAN, a protease modulating matrix, for the treatment of diabetic foot ulcers. Wound Repair and Regeneration 2002;10(1):16-25.

\section{Cullen 2006}

Cullen BM, inventor, Ethicon, Inc, assignee. Monitoring of wounds by measurement of protease and protease inhibitor levels in wound fluids. United States patent US 20080132468 March 2006.

\section{Cullum 2016}

Cullum N, Buckley H, Dumville J, Hall J, Lamb K, Madden M, et al. Wounds research for patient benefit: a 5-year programme of research. Programme Grants for Applied Research 2016;4(13):10.3310/pgfar04130.

\section{Debray 2017}

Debray TP, Damen JA, Snell KI, Ensor J, Hooft L, Reitsma JB, et al. A guide to systematic review and meta-analysis of prediction model performance. BMJ 2017;356:i6460.

\section{Debray 2018}

Debray TP, Moons CG, Riley RD. Detecting small-study effects and funnel plot asymmetry in meta-analysis of survival data: a comparison of new and existing tests. Research Synthesis Methods. 2018;9:41-50.

\section{Duffy 2009}

Duffy MJ, McKiernan E, O'Donovan N, McGowan PM. The role of ADAMs in disease pathophysiology. Clinica Chimica Acta 2009;403(1-2):31-6.

\section{Dumville 2009}

Dumville JC, Worthy G, Soares MO, Bland JM, Cullum N, Dowson C, et al. VenUS II: a randomised controlled trial of larval therapy in the management of leg ulcers. Health Technology Assessment 2009;13(55):1-182; iii-iv.

\section{Edwards 2008}

Edwards DR, Handsley MM, Pennington CJ. The ADAM metalloproteinases. Molecular Aspects of Medicine 2008;29(5):258-89.

\section{Fletcher 2013}

Fletcher J, Moffatt C, Partsch H, Vowden K, Vowden P. Principles of compression in venous disease: a practitioner's guide to treatment and prevention of venous leg ulcers. Wounds International 2013. www.woundsinternational.com/media/ issues/672/files/content_10802.pdf (accessed 31 January 2018).

\section{Geersing 2012}

Geersing G-J, Bouwmeester W, Zuithoff P, Spijker R, Leeflang M, Moons K. Search filters for finding prognostic and diagnostic prediction studies in Medline to enhance systematic reviews. PLOS ONE 2012;7(2):e32844.

\section{Ghauri 2010}

Ghauri AS, Nyamekye IK. Leg ulceration: the importance of treating the underlying pathophysiology. Phlebology 2010;25(1 Suppl):42-51.

\section{Gibson 2013}

Gibson M, Serena TE, Bartle C, Bayliff S, Clark J, Cullen B, et al. Testing chronic wounds for EPA. The benefits of testing all wounds, whether assessed as healing or non-healing. 
www.wounds-uk.com/pdf/cases_11013_199.pdf (accessed 31 January 2018).

\section{Gibson 2014}

Gibson M, Bayliff SW, Cullen BM, inventors, Systagenix Wound Management IP Co, assignee. Wound prognosis. United States patent US 20140045761. February 2014.

\section{Gohel 2005}

Gohel MS, Taylor M, Earnshaw JJ, Heather BP, Poskitt KR, Whyman MR. Risk factors for delayed healing and recurrence of chronic venous leg ulcers - an analysis of 1324 legs. European Journal of Vascular and Endovascular Surgery 2005;29(1):74-7.

\section{Graves 2014}

Graves N, Finlayson K, Gibb M, O'Reilly M, Edwards H. Modelling the economic benefits of gold standard care for chronic wounds in a community setting. Wound Practice and Research 2014;22(3):163-8.

\section{Grøndahl-Hansen 1988}

Grøndahl-Hansen J, Lund LR, Ralfkiaer E, Ottevanger V, Danø K. Urokinase- and tissue-type plasminogen activators in keratinocytes during wound reepithelialization in vivo. Journal of Investigative Dermatology 1988;90(6):790-5.

\section{Guyatt 2011a}

Guyatt GH, Oxman AD, Schünemann HJ, Tugwell P, Knottnerus A. GRADE guidelines: a new series of articles in the Journal of Clinical Epidemiology. Journal of Clinical Epidemiology 2011;64(4):380-2.

\section{Guyatt 2011b}

Guyatt GH, Oxman AD, Kunz R, Woodcock J, Brozek J, Helfand M, et al. GRADE guidelines 7: rating the quality of evidence - inconsistency. Journal of Clinical Epidemiology 2011;64(12):1294-302.

\section{Hahm 2011}

Hahm G, Glaser JJ, Elster EA. Biomarkers to predict wound healing: the future of complex war wound management. Plastic and Reconstructive Surgery 2011;127(1 Suppl):21-6S.

\section{Hall 2014}

Hall J, Buckley HL, Lamb KA, Stubbs N, Saramago P, Dumville JC, et al. Point prevalence of complex wounds in a defined United Kingdom population. Wound Repair and Regeneration 2014;22(6):694-700.

\section{Harding 2011}

Harding K, Armstrong DG, Barrett S, Kaufman H, LázaroMartínez JL, Mayer D, et al. International consensus. The role of proteases in wound diagnostics: an expert working group review. Wounds International 2011. woundchek.com/uploads/ downloads/consensus_documents/Role-of-proteases-inwound-diagnostics-International.pdf (accessed 31 January 2018).

\section{Harrison 2011}

Harrison MB, Van den Kerkhof EG, Hopman WM, Graham ID, Carley ME, Nelson EA. The Canadian bandaging trial: evidence-informed leg ulcer care and the effectiveness of two compression technologies. BMC Nursing 2011;10:20.

\section{Hart 2002}

Hart J, Silcock D, Gunnigle S, Cullen B, Light ND, Watt PW. The role of oxidised regenerated cellulose/collagen in wound repair: effects in vitro on fibroblast biology and in vivo in a model of compromised healing. International Journal of Biochemistry and Cell Biology 2002;34(12):1557-70.

\section{Hayden 2008}

Hayden JA, Côté P, Steenstra IA, Bombardier C, for the QUIPSLBP Working Group. Identifying phases of investigation helps planning, appraising, and applying the results of explanatory prognosis studies. Journal of Clinical Epidemiology 2008;61(6):552-60.

\section{Hayden 2013}

Hayden JA, Van der Windt DA, Cartwright JL, Côté P, Bombardier C. Assessing bias in studies of prognostic factors. Annals of Internal Medicine 2013;158(4):280-6.

\section{Hayden 2014}

Hayden JA, Tougas ME, Riley R, Iles R, Pincus T. Individual recovery expectations and prognosis of outcomes in nonspecific low back pain: prognostic factor exemplar review. Cochrane Database of Systematic Reviews 2014, Issue 9. [DOI: 10.1002/14651858.CD011284]

\section{Hemingway 1999}

Hemingway $\mathrm{H}$, Marmot M. Evidence based cardiology: psychosocial factors in the aetiology and prognosis of coronary heart disease: systematic review of prospective cohort studies. BMJ 1999;318(7196):1460-7.

\section{Herber 2007}

Herber OR, Schnepp W, Rieger MA. A systematic review on the impact of leg ulceration on patients' quality of life. Health and Quality of Life Outcomes 2007;5:44.

\section{Higgins 2011}

Higgins JP, Green S, editor(s). Cochrane Handbook for Systematic Reviews of Interventions Version 5.1.0 (updated March 2011). The Cochrane Collaboration, 2011. Available from handbook.cochrane.org.

\section{Hingorani 2013}

Hingorani AD, Van der Windt DA, Riley RD, Abrams K, Moons KG, Steyerberg EW, et al. Prognosis research strategy (PROGRESS) 4: stratified medicine research. BMJ 2013;346:e5793.

\section{Huguet 2013}

Huguet A, Hayden JA, Stinson J, McGrath PJ, Chambers CT, Tougas ME. Judging the quality of evidence in reviews of prognostic factor research: adapting the GRADE framework. Systematic Reviews 2013;2:71.

\section{Iglesias 2004}

Iglesias C, Nelson EA, Cullum NA, Torgerson DJ, VenUS Team. VenUS I: a randomised controlled trial of two types of bandage 
for treating venous leg ulcers. Health Technology Assessment 2004;8(29):iii, 1-105.

\section{Iorio 2015}

Iorio A, Spencer FA, Falavigna M, Alba C, Lang E, Burnand B, et al. Use of GRADE for assessment of evidence about prognosis: rating confidence in estimates of event rates in broad categories of patients. BMJ 2015;350:h870. [DOI: 10.1136/bmj.h870]

\section{Jull 2012}

Jull AB, Arroll B, Parag V, Waters J. Pentoxifylline for treating venous leg ulcers. Cochrane Database of Systematic Reviews 2012, Issue 12. [DOI: 10.1002/14651858.CD001733.pub3]

\section{Kelwick 2015}

Kelwick R, Desanlis I, Wheeler GN, Edwards DR. The ADAMTS (A Disintegrin and Metalloproteinase with Thrombospondin motifs) family. Genome Biology 2015;16:113.

\section{Knofczynski 2008}

Knofczynski GT, Mundfrom D. Sample sizes when using multiple linear regression for prediction. Educational and Psychological Measurement 2008;68(3):431-42.

\section{Ladwig 2002}

Ladwig GP, Robson MC, Liu R, Kuhn MA, Muir DF, Schultz GS. Ratios of activated matrix metalloproteinase- 9 to tissue inhibitor of matrix metalloproteinase-1 in wound fluids are inversely correlated with healing of pressure ulcers. Wound Repair and Regeneration 2002;10(1):26-37.

\section{Lantis 2013}

Lantis JC 2nd, Marston WA, Farber A, Kirsner RS, Zhang Y, Lee TD, et al. The influence of patient and wound variables on healing of venous leg ulcers in a randomized controlled trial of growth-arrested allogeneic keratinocytes and fibroblasts. Journal of Vascular Surgery 2013;58(2):433-9.

\section{Lazaro 2016}

Lazaro JL, Izzo V, Meaume S, Davies AH, Lobmann R, Uccioli L. Elevated levels of matrix metalloproteinases and chronic wound healing: an updated review of clinical evidence. Journal of Wound Care 2016;25(5):277-87.

\section{Liu 2009}

Liu Y, Min D, Bolton T, Nubé V, Twigg SM, Yue DK, et al. Increased matrix metalloproteinase- 9 predicts poor wound healing in diabetic foot ulcers. Diabetes Care 2009;32(1):117-9.

\section{Lowry 2018}

Lowry R. The confidence interval of rho. vassarstats.net/ rho.html (accessed 31 January 2018).

\section{Löffek 2011}

Löffek S, Schilling O, Franzke CW. Series 'matrix metalloproteinases in lung health and disease': biological role of matrix metalloproteinases: a critical balance. European Respiratory Journal 2011;38(1):191-208.

\section{Löffler 2013}

Löffler MW, Schuster H, Bühler S, Beckert S. Wound fluid in diabetic foot ulceration: more than just an undefined soup?. International Journal of Lower Extremity Wounds 2013;12(2):113-29.

\section{Madden 2014}

Madden M. Is research in chronic wound care focusing on the outcomes that matter most to patients?. British Sociological Association Annual Conference: Changing Society; $2014 \mathrm{Apr}$ 23-25; Leeds, UK. 2014:232.

\section{Margolis 1999}

Margolis DJ, Berlin JA, Strom BL. Risk factors associated with the failure of a venous leg ulcer to heal. Archives of Dermatology 1999;135(8):920-6

\section{Margolis 2004}

Margolis DJ, Allen-Taylor L, Hoffstad O, Berlin JA. The accuracy of venous leg ulcer prognostic models in a wound care system. Wound Repair and Regeneration 2004;12(2):163-8.

\section{Marston 2011}

Marston W. Mixed arterial and venous ulcers. Wounds 2011;23(12):351-6.

\section{Milic 2009}

Milic DJ, Zivic SS, Bogdanovic DC, Karanovic ND, Golubovic ZV. Risk factors related to the failure of venous leg ulcers to heal with compression treatment. Journal of Vascular Surgery 2009;49(5):1242-7.

\section{Moffatt 2004}

Moffatt CJ, Franks PJ, Doherty DC, Martin R, Blewett R, Ross F. Prevalence of leg ulceration in a London population. QJM: Monthly Journal of the Association of Physicians 2004;97(7):431-7.

\section{Moffatt 2010}

Moffatt CJ, Doherty DC, Smithdale R, Franks PJ. Clinical predictors of leg ulcer healing. British Journal of Dermatology 2010;162(1):51-8.

\section{Moons 2014}

Moons KG, De Groot JA, Bouwmeester W, Vergouwe Y, Mallett S, Altman DG, et al. Critical appraisal and data extraction for systematic reviews of prediction modelling studies: the CHARMS checklist. PLoS Medicine 2014;11(10):e1001744.

\section{Muller 2008}

Muller M, Trocme C, Lardy B, Morel F, Halimi S, Benhamou PY. Matrix metalloproteinases and diabetic foot ulcers: the ratio of MMP-1 to TIMP-1 is a predictor of wound healing. Diabetic Medicine 2008;25(4):419-26.

\section{Nelzén 1994}

Nelzén O, Berqvist D, Lindhagen A. Venous and non-venous leg ulcers: clinical history and appearance in a population study. British Journal of Surgery 1994;81(2):182-7. 


\section{Nelzén 2008}

Nelzén O. Prevalence of venous leg ulcer: the importance of the data collection method. Phlebolymphology 2008;15(4):143-50.

\section{NICE 2016}

National Institute for Health and Care Excellence (NICE). Woundchek Protease Status for assessing elevated protease status in chronic wounds. Medtech innovation briefing [MIB83]. October 2016. www.nice.org.uk/advice/mib83 (accessed 31 January 2018).

\section{Norman 2016}

Norman G, Westby MJ, Stubbs N, Dumville JC, Cullum N. A 'test and treat' strategy for elevated wound protease activity for healing in venous leg ulcers. Cochrane Database of Systematic Reviews 2016, Issue 1. [DOI: 10.1002/14651858.CD011753]

\section{Nwomeh 1998}

Nwomeh BC, Liang HX, Diegelmann RF, Cohen IK, Yager DR. Dynamics of the matrix metalloproteinases MMP-1 and MMP-8 in acute open human dermal wounds. Wound Repair and Regeneration 1998;6(2):127-34.

\section{O'Meara 2012}

O'Meara S, Cullum N, Nelson EA, Dumville JC. Compression for venous leg ulcers. Cochrane Database of Systematic Reviews 2012, Issue 11. [DOI: 10.1002/14651858.CD000265.pub3]

\section{O'Meara 2014}

O'Meara S, Al-Kurdi D, Ologun Y, Ovington LG, Martyn-St James M, Richardson R. Antibiotics and antiseptics for venous leg ulcers. Cochrane Database of Systematic Reviews 2014, Issue 1. [DOI: 10.1002/14651858.CD003557.pub5]

\section{Patel 2016}

Patel S, Maheshwari A, Chandra A. Biomarkers for wound healing and their evaluation. Journal of Wound Care 2016;25(1):46-55.

\section{Percival 2012}

Percival SL, Hill KE, Williams DW, Hooper SJ, Thomas DW, Costerton JW. A review of the scientific evidence for biofilms in wounds. Wound Repair and Regeneration 2012;20(5):647-57.

\section{Persoon 2004}

Persoon A, Heinen MM, Van der Vleuten CJ, De Rooji MJ, Van de Kerkhof PC, Van Achterberg T. Leg ulcers: a review of their impact on daily life. Journal of Clinical Nursing 2004;13(3):341-54.

\section{Pugliese 2016}

Pugliese DJ. Infection in venous leg ulcers: considerations for optimal management in the elderly. Drugs \& Aging 2016;33(2):87-96.

\section{Quirk 2003}

Quirk S, Tyrell DJ, inventors, Kimberley Clark Worldwide, Inc, assignee. Sensors and methods of detection for proteinase enzymes. United States patent US 20030119073. June 2003.

\section{Raffetto 2016}

Raffetto JD. Pathophysiology of wound healing and alterations in venous leg ulcers - review. Phlebology 2016;31(1S):56-62.

\section{Ragnarson Tennvall 2005}

Ragnarson Tennvall G, Hjelmgren J. Annual costs of treatment for venous leg ulcers in Sweden and the United Kingdom. Wound Repair and Regeneration 2005;13(1):13-8.

\section{Riley 2007}

Riley RD, Ridley G, Williams K, Altman DG, Hayden J, De Vet HC. Prognosis research: toward evidence-based results and a Cochrane methods group. Journal of Clinical Epidemiology 2007;60:863e866.

\section{Riley 2010}

Riley RD, Steyerberg EW. Meta-analysis of a binary outcome using individual participant data and aggregate data. Research Synthesis Methods 2010;1:2-19.

\section{Riley 2011}

Riley RD, Higgins JP, Deeks JJ. Interpretation of random effects meta-analyses. BMJ 2011;342:d549.

\section{Riley 2013}

Riley RD, Hayden JA, Steyerberg EW, Moons KG, Abrams K, Kyzas PA, et al. Prognosis research strategy (PROGRESS) 2: prognostic factor research. PLoS Medicine 2013;10(2):e1001380.

\section{ROBINS-I 2017}

The ROBINS-I tool (Risk Of Bias In Non-randomized Studies - of Interventions). sites.google.com/site/riskofbiastool/welcome/ home (accessed 31 January 2018).

\section{Schünemann 2011a}

Schünemann HJ, Oxman AD, Higgins JP, Vist GE, Glasziou P, Guyatt GH. Chapter 11: Presenting results and 'Summary of findings' tables. In: Higgins JP, Green S, editor(s). Cochrane Handbook for Systematic Reviews of Interventions Version 5.1.0 (updated March 2011). The Cochrane Collaboration, 2011. Available from handbook.cochrane.org.

\section{Schünemann 2011b}

Schünemann HJ, Oxman AD, Higgins JP, Deeks JJ, Glasziou P, Guyatt GH. Chapter 12: Interpreting results and drawing conclusions. In: Higgins JP, Green S, editor(s). Cochrane Handbook for Systematic Reviews of Interventions Version 5.1.0 (updated March 2011). The Cochrane Collaboration, 2011. Available from handbook.cochrane.org.

\section{Scotton 2014}

Scotton MF, Miot HA, Abbade LP. Factors that influence healing of chronic venous leg ulcers: a retrospective cohort. Anais Brasileiros de Dermatologia 2014;89(3):414-22.

\section{Serena 2011}

Serena T, Cullen B, Bayliff S, Gibson M, DeMarco D, Galbraith J, et al. Protease activity levels associated with healing status of chronic wounds. 2011. www.woundchek.com/uploads/ downloads/posters_articles/Protease-Activity-Levels- 
Associated-with-Healing-Status-of-Chronic-Wounds.pdf (accessed 31 January 2018).

\section{Sibbald 2007}

Sibbald RG, Contreras-Ruiz J, Coutts P, Fierheller M, Rothman A, Woo K. Bacteriology, inflammation, and healing: a study of nanocrystalline silver dressings in chronic venous leg ulcers. Advances in Skin \& Wound Care 2007;20(10):549-58.

\section{SIGN 2010}

Scottish Intercollegiate Guidelines Network (SIGN). Management of chronic venous leg ulcers. Clinical guideline 120. August 2010. www.sign.ac.uk/guidelines/fulltext/120/ (accessed 31 January 2018).

\section{Sittampalam 2017}

Sittampalam GS, Coussens NP, Brimacombe K, Grossman A, Arkin M, Auld D, et al. editor(s). Protease assays. Assay guidance manual. Updated 20 November 2017. www.ncbi.nlm.nih.gov/ books/NBK53196/pdf/Bookshelf_NBK53196.pdf (accessed 31 January 2018).

\section{Snyder 2011}

Snyder RJ, Driver V, Fife CE, Lantis J, Peirce B, Serena T, et al. Using a diagnostic tool to identify elevated protease activity levels in chronic and stalled wounds: a consensus panel discussion. Ostomy/Wound Management 2011;57(12):36-46.

\section{Snyder 2013}

Snyder RJ, Cullen B, Nisbet LT. An audit to assess the perspectives of US wound care specialists regarding the importance of proteases in wound healing and wound assessment. International Wound Journal 2013;10(6):653-60.

\section{Srinivasaiah 2007}

Srinivasaiah N, Dugdall H, Barrett S, Drew PJ. A point prevalence survey of wounds in north-east England. Journal of Wound Care 2007;16(10):413-9.

\section{STATA 2013 [Computer program]}

StataCorp LLC. Stata data analysis and statistical software. Version 13. College Station, TX: StataCorp LLC, 2013.

\section{Sterne 2011}

Sterne JA, Egger M, Moher D. Chapter 10: Addressing reporting biases. In: Higgins JP, Green S, editor(s). Cochrane Handbook for Systematic Reviews of Interventions Version 5.1.0 (updated March 2011). The Cochrane Collaboration, 2011. Available from handbook.cochrane.org.

\section{Sterne 2016}

Sterne JA, Hernán MA, Reeves BC, Savović J, Berkman ND, Viswanathan M, et al. ROBINS-I: a tool for assessing risk of bias in non-randomised studies of interventions. BMJ 2016;355:i4919. [DOI: 10.1136/bmj.i4919]

\section{Strimbu 2010}

Strimbu K, Tavel JA. What are biomarkers?. Current Opinion in HIV and AIDS 2010;5(6):463-6.

\section{Suleman 2016}

Suleman L. Extracellular bacterial proteases in chronic wounds: a potential therapeutic target?. Advances in Wound Care 2016;5(10):455-63.

\section{Symons 2002}

Symons MJ, Moore DT. Hazard rate ratio and prospective epidemiological studies. Journal of Clinical Epidemiology 2002;55(9):893-9.

\section{Valencia 2001}

Valencia IC, Falabella A, Kirsner RS, Eaglestein WH. Chronic venous insufficiency and venous leg ulceration. Journal of the American Academy of Dermatology 2001;44:401-21.

\section{Velnar 2009}

Velnar T, Bailey T, Smrkolj V. The wound healing process: an overview of the cellular and molecular mechanisms. Journal of International Medical Research 2009;37(5):1528-42.

\section{Vihinen 2002}

Vihinen P, Kähäri VM. Matrix metalloproteinases in cancer: prognostic markers and therapeutic targets. International Journal of Cancer 2002;99(2):157-66.

\section{Vlajinac 2014}

Vlajinac H, Marinkovic J, Maksimovic M, Radak D. Factors related to venous ulceration: a cross-sectional study. Angiology 2014;65(9):824-30.

\section{Vowden 2009}

Vowden KR, Vowden P. The prevalence, management and outcome for acute wounds identified in a wound care survey within one English health care district. Journal of Tissue Viability 2009;18(1):7-12.

\section{Westby 2016}

Westby MJ, Norman G, Dumville JC, Stubbs N, Cullum N. Protease-modulating matrix treatments for healing venous leg ulcers. Cochrane Database of Systematic Reviews 2016, Issue 12. [DOI: 10.1002/14651858.CD011918.pub2]

\section{Yager 1997}

Yager DR, Chen SM, Ward SI, Olutoye OO, Diegelmann RF, Cohen IK. Ability of chronic wound fluids to degrade peptide growth factors is associated with increased levels of elastase activity and diminished levels of proteinase inhibitors. Wound Repair and Regeneration 1997;5(1):23-32.

\section{Yager 2007}

Yager DR, Kulina RA, Gilman LA. Wound fluids: a window Into the wound environment?. International Journal of Lower Extremity Wounds 2007;6(4):262-72.

\section{References to other published versions of this review Westby 2017 \\ Westby MJ, Dumville JC, Stubbs N, Norman G, Wong JK, Cullum N, et al. Protease activity as a prognostic factor for wound healing in venous leg ulcers. Cochrane}


Database of Systematic Reviews 2017, Issue 10. [DOI:

10.1002/14651858.CD012841]

CHARACTERISTICS OF STUDIES

Characteristics of included studies [ordered by study ID]

Ahmad 2015

\begin{tabular}{|c|c|}
\hline \multirow[t]{5}{*}{ Methods } & Prospective cohort study \\
\hline & Setting: hospital leg ulcer clinic \\
\hline & Country: UK \\
\hline & Duration of follow-up: 6 months \\
\hline & Treatments: compression bandaging (3-layer or 4-layer) \\
\hline \multirow[t]{10}{*}{ Participants } & 30 participants with VLUs (recalcitrant ulcers) \\
\hline & Median age (range): 62 (36-79) years vs 70 (40-92) years (healed vs non-healed) \\
\hline & Sex (M:F): 4:5 vs 10:11 (healed vs non-healed) \\
\hline & Stage of ulcer: not reported \\
\hline & Ulcer duration: median (range): 12 (3-84) months vs 19 (2-180) months (healed vs non-healed) \\
\hline & Ulcer size at baseline: median (range): $6(2-165) \mathrm{cm}^{2}$ vs $9(3-140) \mathrm{cm}^{2}$ (healed vs non-healed) \\
\hline & Wound infection: not reported \\
\hline & Number of wounds: 30 (if bilateral, only 1 limb assessed) \\
\hline & $\begin{array}{l}\text { Inclusion criteria: confirmed VLU; incompetence of superficial veins or thrombosed deep veins on du- } \\
\text { plex scan }\end{array}$ \\
\hline & Exclusion criteria: $\mathrm{ABPI}<0.8$, immunosuppressed, unable to tolerate compression therapy \\
\hline
\end{tabular}

Prognostic factors

Active uPA (continuous data); total uPA (including receptor bound and complexed to PAI-1 and PAI-2). Level of active uPA (quote: "below sensitivity of bioimmunoassay"). Measurement method ELISA: total UPA antigen measurements by ELISA IMUBIND (American Diagnostica). Active uPA measured by bioimmunoassay with the WHO uPA standard. Activity and antigen measurements normalised against soluble protein concentration (Coomassie Plus protein assay).

Time of measurement: collected before start of compression therapy

Wound fluid sampling method: occlusive dressings (exudate collected from under Opsite (Smith \& Nephew) dressing)

Notes
munoassay.

\section{Risk of bias}

\begin{tabular}{lll}
\hline Bias & Authors' judgement & Support for judgement \\
\hline Selection bias & Unclear risk & $\begin{array}{l}\text { Moderate: unclear if consecutive participants, but representative; people at a } \\
\text { dedicated ulcer clinic (but inclusion criterion for review was any with VLU). }\end{array}$ \\
\hline Attrition bias & Low risk & No missing data \\
\hline
\end{tabular}


Ahmad 2015 (Continued)

$\begin{array}{ll}\begin{array}{l}\text { Prognostic factor mea- } \\ \text { surement }\end{array} & \text { High risk } \\ & \begin{array}{l}\text { Inappropriate biomarker measure: ELISA for total uPA (including bound and } \\ \text { complexed uPA); active bioimmunoassay with uPA WHO standard. Activity be- } \\ \text { low sensitivity level }\end{array}\end{array}$

\begin{tabular}{lll}
\hline Outcome measurement & Unclear risk & $\begin{array}{l}\text { Moderate: unclear if blinded; defined as complete re-epithelialisation after } 6 \\
\text { months }\end{array}$ \\
\hline Adjustment factors & High risk & $\begin{array}{l}\text { None of the key adjustment factors taken into account in the design or analy- } \\
\text { sis }\end{array}$ \\
\hline Analysis and reporting & High risk & Results reported only for total uPA \\
\hline Overall risk of bias & High risk & \\
\hline
\end{tabular}

Cullen 2012

\begin{tabular}{ll}
\hline Methods & RCT \\
Setting: not reported \\
Country: UK \\
Duration of follow-up: 4 weeks \\
Treatments: collagen/ORC/silver treatment and collagen/ORC (randomised); and compression
\end{tabular}

Participants
Age: not reported
Sex: not reported
Stage of ulcer: not reported
Ulcer duration: not reported
Ulcer size at baseline: not reported
Wound infection: not reported
Number of wounds: 64 (inferred)
Inclusion criteria: VLUs (no further details)
Exclusion criteria: not reported

Prognostic factors Human neutrophil elastase (dichotomous data); 'elastase activity.' Measurement method fluorogenic substrate assay: cut-off point based on Serena $2011(>25 \mathrm{mU} / 110 \mu \mathrm{L})$

Time of measurement: baseline and then every 2 weeks for 4 weeks

Wound fluid sampling method: not stated

Notes Conference abstract. Authors worked for Systagenix and were involved in developing a diagnostic test
based on elevated protease levels.

\section{Risk of bias}


Cullen 2012 (Continued)

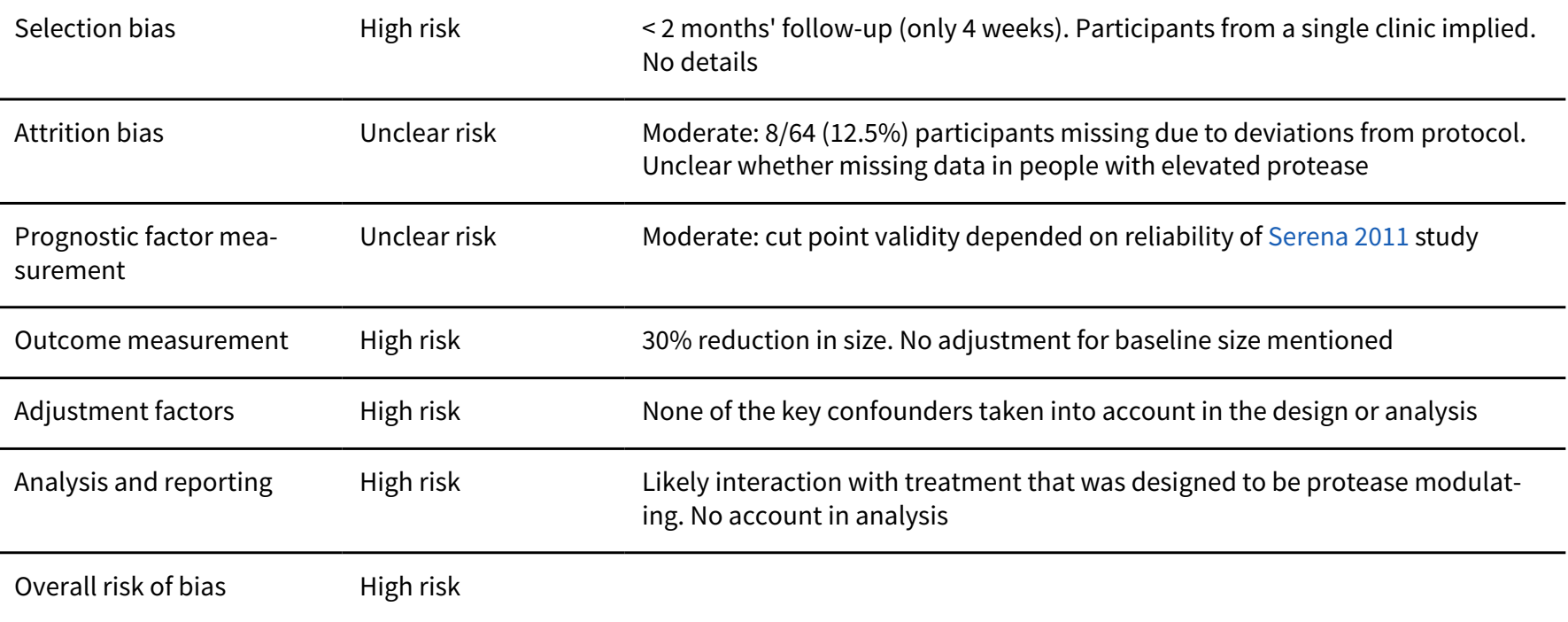

Frankova 2013

\begin{tabular}{|c|c|}
\hline \multirow[t]{5}{*}{ Methods } & Prospective cohort study \\
\hline & Setting: not reported \\
\hline & Country: Czech Republic \\
\hline & Duration of follow-up: 6 weeks \\
\hline & Treatments: gauze hydrogen calcium salts of oxidised cellulose \\
\hline \multirow[t]{3}{*}{ Participants } & $\begin{array}{l}20 \text { participants with VLU and other wounds (VLU 15, A-V leg ulcers 3, decubitus ulcer 1, trophic leg ulcer } \\
\text { 1) }\end{array}$ \\
\hline & Median age: 65.7 (SD 7.1) years \\
\hline & Sex (M:F): 10:10 \\
\hline \multirow[t]{3}{*}{ Prognostic factors } & $\begin{array}{l}\text { MMP-2 and MMP-9 (continuous data); total MMP (pro-, active- and TIMP complexed) median (IQR as- } \\
\text { sumed) reported but not linked to outcome. Measurement method sandwich ELISA }\end{array}$ \\
\hline & Time of measurement: baseline and every 2 weeks \\
\hline & Wound fluid sampling method: entrapment in dressings \\
\hline Notes & Minimal data collection; no results. Risk of bias assessments available on request \\
\hline
\end{tabular}

\section{Gohel 2008}

Methods
Setting: nurse-led specialist leg ulcer service
Country: UK
Duration of follow-up: 5 weeks


Gohel 2008 (Continued)

Treatments: non-adhesive dressings and compression bandaging

Participants participants with VLUS (ABPI $\geq 0.85$ open ulceration; chronic ulcers)
Median age (range): 75 (40-93) years
Sex (M:F): $43: 37$
Stage of ulcer: CEAP grades (level II) C6sEp in 68 and C6sEs in 12
Ulcer duration: chronicity median (range) $3(1-180)$ months
Ulcer size at baseline: median (range) $4.7(0.1-142.4) \mathrm{cm}^{2}$
Wound infection: 0 participants had signs of soft tissue infection
Number of wounds: 80 (for participants with bilateral areas, largest was studied)
Inclusion criteria: new and follow-up participants with open ulceration between the ankle and knee
and an ABPI $\geq 0.85$. Duplex evidence of venous reflux
Exclusion criteria: not stated

Prognostic factors MMP-2 and MMP-9 (continuous data); pro-MMP only. Measurement method gelatin zymography: MMP concentrations expressed as a percentage of an MMP-2 standard sample used for all assays

Time of measurement: baseline and 5 weeks measured. No results given for correlations with baseline, but with change from baseline

Wound fluid sampling method: occlusive dressings. Only 34/74 people had wound fluid

\section{Notes}

\section{Risk of bias}

\begin{tabular}{|c|c|c|}
\hline Bias & Authors' judgement & Support for judgement \\
\hline Selection bias & High risk & $\begin{array}{l}<2 \text { months' follow-up ( } 5 \text { weeks). Otherwise representative (consecutive new } \\
\text { and follow-up patients with open ulceration between the ankle and knee and } \\
\text { an ABPI } \geq 0.85 \text { were targeted) }\end{array}$ \\
\hline Attrition bias & Unclear risk & $\begin{array}{l}\text { Moderate: assessments were attended by } 74 / 80(93 \%) \text { participants; unclear } \\
\text { whether this is likely to affect the results }\end{array}$ \\
\hline $\begin{array}{l}\text { Prognostic factor mea- } \\
\text { surement }\end{array}$ & High risk & $\begin{array}{l}\text { Inappropriate biomarker measure: all assays performed using a sandwich } \\
\text { ELISA technique. Only pro-MMP reported and not cleaved to give an active } \\
\text { form. Wound fluid collection 52/80 (65\%) at baseline }\end{array}$ \\
\hline Outcome measurement & Unclear risk & $\begin{array}{l}\text { Moderate: unclear if blinded. 'Complete ulcer healing' reported, but only use- } \\
\text { able results were change in ulcer size. No details on assessment }\end{array}$ \\
\hline Adjustment factors & Unclear risk & $\begin{array}{l}\text { Moderate: partial, at least half, but not all, key adjustment factors taken into } \\
\text { account in design or analysis (no symptoms of infection in soft tissues) }\end{array}$ \\
\hline Analysis and reporting & High risk & $\begin{array}{l}\text { Analysis concerned correlations between changes in ulcer healing and } \\
\text { changes in pro-MMP levels. Baseline MMP levels not reported. Change in size } \\
\text { not adjusted for baseline }\end{array}$ \\
\hline Overall risk of bias & High risk & \\
\hline
\end{tabular}


Grzela 2014

\begin{tabular}{|c|c|}
\hline Methods & $\begin{array}{l}\text { RCT (within person) } \\
\text { Duration of follow-up: } 4 \text { weeks } \\
\text { Treatments: Flaminal Forte and hydrocolloid (F) or hydrocolloid alone }(H) \text { (1 leg randomised to each), } \\
\text { plus 4-layer compression }\end{array}$ \\
\hline Participants & $\begin{array}{l}8 \text { participants with VLUs } \\
\text { Mean age: } 68.3 \text { (SD 9.3) years } \\
\text { Sex (M:F): } 3: 5 \\
\text { Number of wounds: } 16\end{array}$ \\
\hline Prognostic factors & $\begin{array}{l}\text { MMP-2 and MMP-9 (continuous data); gelatinolytic activity, due to activated MMPs- } 2 \text { and }-9 \text {. Measure- } \\
\text { ment method gelatin/SDS zymography and fluorescent real-time zymography } \\
\text { Time of measurement: baseline, } 14 \text { days, } 28 \text { days }\end{array}$ \\
\hline Notes & Minimal data collection, no results. Risk of bias assessments available on request \\
\hline
\end{tabular}

\section{Harris 1995}

Methods
granulating/epithelialising and non-granulating phases
Setting: not reported
Country: UK
Duration of follow-up: none, case-control
Treatments: not reported

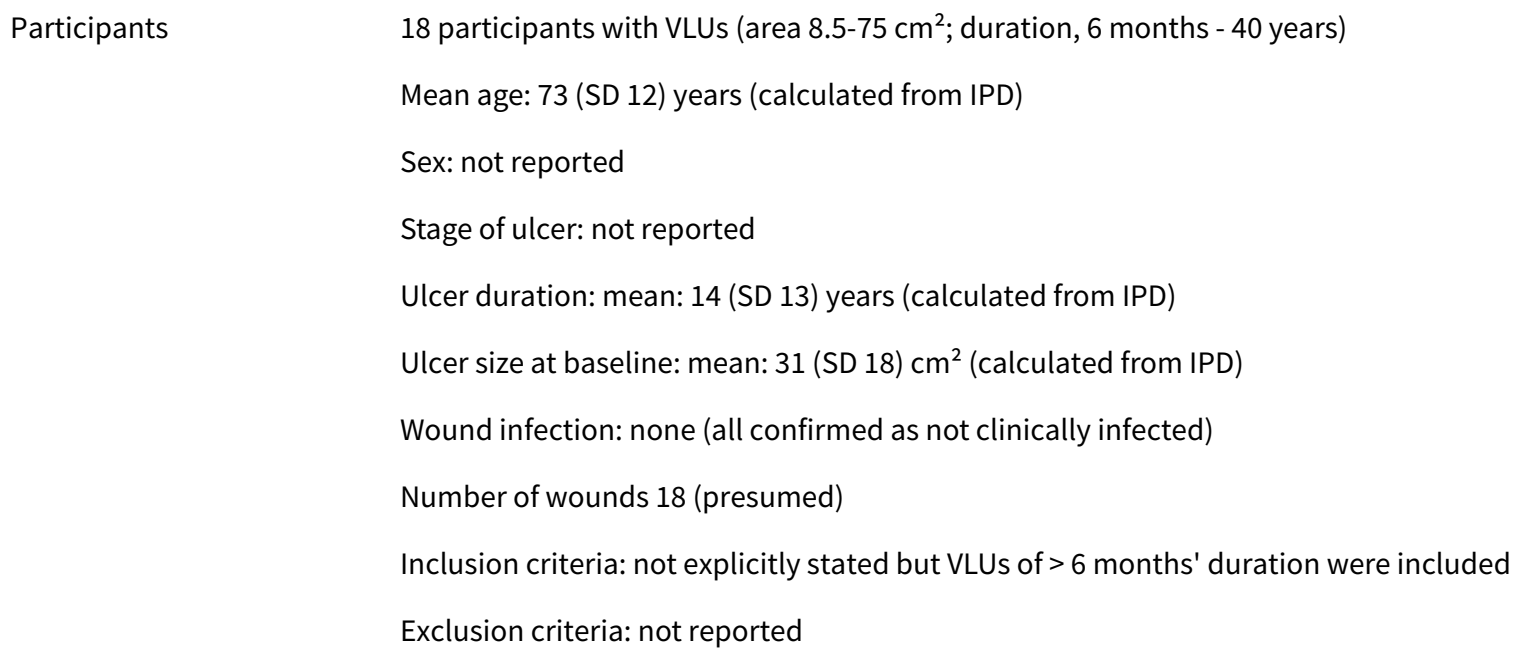

Participants $\quad 18$ participants with VLUs (area $8.5-75 \mathrm{~cm}^{2}$; duration, 6 months -40 years)

Mean age: 73 (SD 12) years (calculated from IPD)

Sex: not reported

Stage of ulcer: not reported

Ulcer duration: mean: 14 (SD 13) years (calculated from IPD)

Ulcer size at baseline: mean: 31 (SD 18) $\mathrm{cm}^{2}$ (calculated from IPD)

Wound infection: none (all confirmed as not clinically infected)

Number of wounds 18 (presumed)

Inclusion criteria: not explicitly stated but VLUs of $>6$ months' duration were included

Exclusion criteria: not reported
Prognostic factors
MMP (unspecified) (continuous data); collagenases (unspecified); total activity ( $\mu$ g collagen degrad- $\mathrm{ed} /$ hour/mg protein in fluid); also reported separately for latent and active. Measurement method was ${ }^{3} \mathrm{H}$-labelled type 1 collagen assay: trypsin was added (to cleave latent MMP to active MMP) and the net total activity measured, endogenous inhibitors of collagenase not removed (active collagenase was al- so measured without trypsin treatment)


Harris 1995 (Continued)

Time of measurement: baseline

Wound fluid sampling method: occlusive dressings (Tegaderm dressing, 4-6 hours (foam))

\section{Notes}

\section{Risk of bias}

\begin{tabular}{lll}
\hline Bias & Authors' judgement & Support for judgement \\
\hline Selection bias & High risk & $\begin{array}{l}\text { No details on selection; wounds were classified into healing and non-healing } \\
\text { within a cohort of participants; not matched and longitudinal features not re- } \\
\text { ported. }\end{array}$ \\
\hline Attrition bias & Unclear risk & $\begin{array}{l}\text { Moderate: 2/12 participants in non-healing group missing. Unclear if this was } \\
\text { important }\end{array}$ \\
\hline $\begin{array}{l}\text { Prognostic factor mea- } \\
\text { surement }\end{array}$ & Unclear risk & $\begin{array}{l}\text { Moderate: MMP type not specified. } 1995 \text { study; unclear if measurement appro- } \\
\text { priate and insufficient details }\end{array}$ \\
\hline Outcome measurement & High risk & $\begin{array}{l}\text { Type of case-control study; healing and non-healing identified, but not } \\
\text { matched at the outset }\end{array}$ \\
\hline Adjustment factors & Unclear risk & $\begin{array}{l}\text { Moderate: at least half, but not all, key adjustment factors taken into account } \\
\text { in design or analysis (ulcers judged not to be "clinically" infected and con- } \\
\text { firmed in microbiology; infection taken into account in design) }\end{array}$ \\
\hline Analysis and reporting & Unclear risk & \begin{tabular}{l} 
Moderate: data had to be extracted from graph \\
\hline Overall risk of bias
\end{tabular} \\
\hline
\end{tabular}

\section{Hoffman 1999}

\begin{tabular}{|c|c|}
\hline \multirow[t]{5}{*}{ Methods } & Prospective cohort study/case series \\
\hline & Setting: community wound clinic \\
\hline & Country: UK \\
\hline & Duration of follow-up: 36 weeks \\
\hline & $\begin{array}{l}\text { Treatments: various dressings (NA ultra (4), wool padding (5), Zipzoc (2), Coltapaste), and compression } \\
\text { bandages (Litepress/Co-plus/crepe (2), Tensopress (2), Tubigrip, Elastocrepe) }\end{array}$ \\
\hline \multirow[t]{8}{*}{ Participants } & 7 participants with VLUs (no further details) \\
\hline & Age: not reported \\
\hline & Sex: not reported \\
\hline & Stage of ulcer: not reported \\
\hline & Ulcer duration: median (range): 3 years (13 months-8 years) (from IPD) \\
\hline & Ulcer size at baseline: not reported \\
\hline & Wound infection: not reported \\
\hline & Number of wounds: 7 \\
\hline
\end{tabular}


Hoffman 1999 (Continued)

Inclusion criteria: VLUs

Exclusion criteria: not reported

\section{Prognostic factors}

Human neutrophil elastase (continuous data); from graph IPD. All participants had data at 4 weeks, so this was selected as the baseline time; variability over time within participants. Measurement method activity assay using selective substrate and measuring change in optical density.

Elastase activity determined using a standard curve generated with pure human neutrophil elastase (Sigma, UK). Total elastase activities determined by correcting for total volume of wound fluid and phosphate-buffered saline recovered from the bandage.

Time of measurement: baseline and weekly for 6 weeks

Wound fluid sampling method: entrapment in dressings (fluid harvested weekly from compression bandages on dressing change)

Notes

\section{Risk of bias}

\begin{tabular}{|c|c|c|}
\hline Bias & Authors' judgement & Support for judgement \\
\hline Selection bias & High risk & $\begin{array}{l}\text { Too few participants to be representative ( } 7 \text { participants with VLUs at } 1 \text { centre } \\
\text { were recruited into the study; study design changed so that measured healing } \\
\text { after } 9 \text { months rather than } 6 \text { weeks) }\end{array}$ \\
\hline Attrition bias & Low risk & No missing data \\
\hline $\begin{array}{l}\text { Prognostic factor mea- } \\
\text { surement }\end{array}$ & High risk & $\begin{array}{l}\text { Moderate: protease levels recorded from bandages when dressings changed. } \\
\text { Protease levels will be influenced by how much remains on the dressings }\end{array}$ \\
\hline Outcome measurement & Unclear risk & Moderate: unclear if blinded \\
\hline Adjustment factors & High risk & $\begin{array}{l}\text { None of the key adjustment factors taken into account in the design or analy- } \\
\text { sis }\end{array}$ \\
\hline Analysis and reporting & High risk & $\begin{array}{l}\text { IPD given for outcome and individual protease levels given graphically. Not } \\
\text { all participants had protease levels at baseline, but results for all for week } 4 \text {; } \\
\text { therefore, we selected this time of prognostic factor measurement }\end{array}$ \\
\hline
\end{tabular}

Overall risk of bias High risk

James 2003

$\begin{array}{ll}\text { Methods } & \text { Prospective cohort study/case series } \\ \text { Setting: leg ulcer clinic } \\ \text { Country: UK } \\ \text { Duration of follow-up: } 12 \text { weeks } \\ \text { Treatments: not reported }\end{array}$

Participants

10 participants with VLU and other wounds ( 7 VLU, 2 mixed A-V, 1 venous and diabetes)

Mean age: 72 (SD 9) years (calculated from IPD) 
James 2003 (Continued)

\author{
Sex: not reported \\ Stage of ulcer: not reported \\ Ulcer duration: 45 (32) months (from IPD) \\ Ulcer size at baseline: 69 (73) $\mathrm{cm}^{2}$ (from IPD) \\ Wound infection: not reported \\ Number of wounds: 10 \\ Inclusion criteria: chronic wound of lower leg \\ Exclusion criteria: not reported
}

Prognostic factors

Human neutrophil elastase (continuous data). Measurement method ELISA: Merck kit. Diluted sample in antibody-coated cuvette and second conjugate with alkaline phosphatase antibodies. Then p-nitrophenol phosphate substrate added, and absorbance measured in spectrophotometer. Likely to be in an active form of protease.

Time of measurement: baseline

Wound fluid sampling method: occlusive dressings (Opsite (Smith \& Nephew) 30-40 minutes)

Notes Minimal data collection because no direct results. Risk of bias assessments available on request

\title{
Litwiniuk 2012
}

Prospective cohort study
Setting: attending outpatient phlebology clinic
Country: Poland
Duration of follow-up: 4 weeks
Treatments: all participants had amnion foetal membrane treatment (plus hydrocolloid and compres-
sion), shown to be an inhibitor of MMP activity (i.e. potential confounder)

Participants

25 participants with VLUs (CVLU; venous insufficiency aetiology, further confirmed by a duplex-Doppler
ultrasound examination)

Mean age: 76.3 (SD 12) years

$\operatorname{Sex}(M: F): 9: 16$

Stage of ulcer: $\mathrm{C} 6$ according to the CEAP classification

Wound infection: excluded if evident signs of infection (odorous, purulent exudates, wound necrosis and significant pain)

Number of wounds: not reported

Inclusion criteria: chronic wound (> 6 months); surface area $10-100 \mathrm{~cm}^{2}$; delayed healing (healing rate < $10 \% /$ week) regardless of $\geq 2$ weeks' treatment (screening period) of hydrocolloid dressing and effective compression

Exclusion criteria: evident signs of wound infection (odorous, purulent exudates, wound necrosis and significant pain), active DVT, leg ischaemia with ankle/brachial index $<0.8$, poor tolerance of compres- 
Litwiniuk 2012 (Continued)

sion, pregnancy, diabetes and other systemic diseases (particularly significant heart insufficiency) in unstable stage and malignancy

Prognostic factors

MMP-2 (continuous data); activity (ng/mL). Measurement method quantitative gelatin/SDS zymography

Time of measurement: baseline and day 28

Wound fluid sampling method: not stated

\section{McDaniel 2017}

\begin{tabular}{|c|c|}
\hline \multirow[t]{5}{*}{ Methods } & $\mathrm{RCT}$ \\
\hline & Setting: clinical research centre associated with large university \\
\hline & Country: USA \\
\hline & Duration of follow-up: 8 weeks \\
\hline & $\begin{array}{l}\text { Treatments: oral EPA + DHA vs placebo; all participants had silver-coated dressing beneath a 4-layer } \\
\text { compression dressing }\end{array}$ \\
\hline \multirow[t]{10}{*}{ Participants } & 40 participants with VLUs (5 with missing data) \\
\hline & Mean age: 60.3 (SD 12.6) years vs 60.9 (SD 11.8) years (EPA + DHA vs placebo) \\
\hline & Sex (M:F): 10:6 vs 11:8 (EPA + DHA vs placebo) \\
\hline & Stage of ulcer: not reported \\
\hline & $\begin{array}{l}\text { Ulcer duration: EPA + DHA: }<6 \text { months: } 8 \text { participants }(50 \%) \text { and }>6 \text { months: } 8 \text { participants }(50 \%) ; \text { vs } \\
\text { placebo: }<6 \text { months: } 7 \text { participants }(37 \%) \text { and }>6 \text { months: } 12 \text { participants }(63 \%)\end{array}$ \\
\hline & Ulcer size at baseline: 15.6 (SD 34.4) $\mathrm{cm}^{2}$ vs 19.7 (SD 23.2) $\mathrm{cm}^{2}$ (EPA + DHA vs placebo) \\
\hline & Wound infection: not reported \\
\hline & $\begin{array}{l}\text { Inclusion criteria: aged } 18-81 \text { years; } \geq 1 \text { existing VLU between the ankle and knee for } 3 \text { months; pre- } \\
\text { scribed compression therapy; ABPI of } 0.8 \text {; target wound } \geq 5 \mathrm{~cm}^{2}\end{array}$ \\
\hline & $\begin{array}{l}\text { Exclusion criteria: allergic to fish or seafood; immunological-related conditions or chronic inflammato- } \\
\text { ry skin diseases; receiving blood thinning therapy or corticosteroids; required to take anti-inflammato- } \\
\text { ry drugs such as corticosteroids or ibuprofen more than twice a week }\end{array}$ \\
\hline & Group 1 received oral EPA + DHA; group 2 received placebo \\
\hline \multirow[t]{4}{*}{ Prognostic factors } & $\begin{array}{l}\text { MMP-8 (continuous data). Measurement method ELISA: MMP-8, neutrophil collagenase, Biotrak ELISA } \\
\text { kit; optical density against a purified MMP-8 standard }\end{array}$ \\
\hline & $\begin{array}{l}\text { Human neutrophil elastase (data). Measurement method activity assay: InnoZyme Human Neutrophil } \\
\text { Elastase Immunocapture Activity Assay Kit }\end{array}$ \\
\hline & Time of measurement: baseline, 28 weeks and 56 weeks \\
\hline & Wound fluid sampling method: occlusive dressings (Opsite (Smith \& Nephew) 1-1.5 hours) \\
\hline
\end{tabular}

Notes 
McDaniel 2017 (Continued)

Risk of bias

\begin{tabular}{|c|c|c|}
\hline Bias & Authors' judgement & Support for judgement \\
\hline Selection bias & Unclear risk & $\begin{array}{l}\text { Participants were those scheduled to begin receiving CVLU treatment. RCT } \\
\text { population. Unclear whether this was representative. }\end{array}$ \\
\hline Attrition bias & Unclear risk & $\begin{array}{l}\text { Group 1: } 5 / 21 \text { participants missing ( } 1 \text { with health issues, } 1 \text { withdrew; } 3 \text { not } \\
\text { analysed); group 2: } 0 / 19 \text { participants missing }\end{array}$ \\
\hline $\begin{array}{l}\text { Prognostic factor mea- } \\
\text { surement }\end{array}$ & Unclear risk & Unclear if active protease measured \\
\hline Outcome measurement & High risk & Ulcer size stated to be measured by principal investigator \\
\hline Adjustment factors & High risk & $\begin{array}{l}\text { Inadequate: none of the key confounders taken into account in the design or } \\
\text { analysis }\end{array}$ \\
\hline Analysis and reporting & High risk & $\begin{array}{l}\text { Analysis as correlation used protease measurements at } 4 \text { weeks and } 8 \text { weeks } \\
\text { only (even though measured at baseline). Results not given separately for in- } \\
\text { tervention groups, even though intervention was designed to address pro- } \\
\text { tease levels }\end{array}$ \\
\hline Overall risk of bias & High risk & \\
\hline
\end{tabular}

\section{Moffatt 2014a}

\section{Methods}

Cohort comprised participants in the intervention arm of an RCT of oxyzyme/iodozyme vs control (usual treatment)

Setting: community leg ulcer service

Country: UK

Duration of follow-up: 12 weeks

Treatments: oxyzyme/iodozyme plus secondary dressing (film, surgipad/thin foam according to exudate level). All used appropriate compression

Participants

47 participants with VLU or arterial leg ulcers ( $26 \mathrm{VLU}, 21$ mixed A-V)

Mean age: 69.7 (SD 13.2) years; similar for both groups

$\operatorname{Sex}(M: F): 23: 24$

Stage of ulcer: not reported

Ulcer duration: mean: 17.6 (SD 40.3) months

Ulcer size at baseline: mean $8.1($ SD 10.2$) \mathrm{cm}^{2}$

Wound infection: no cellulitis (exclusion criteria), but wound infection not mentioned

Number of wounds: unclear (1 limb per participant but (overall) 13 noted as having ulcer on contralateral limb so possibly 113 wounds)

Inclusion criteria: aged $\geq 18$ years, venous ( $A B P I>0.8$ ) or mixed (ABPI $>0.6)$ ulcer $2-50 \mathrm{~cm}^{2}$, mild or moderate exudate, healthy peri-wound skin 
Exclusion criteria: pregnancy, breastfeeding, acute DVT within 3 months, surgery for chronic venous insufficiency within 2 months, surgery for peripheral arterial occlusive disease within 3 months, cellulitis, thyroid treatment, known hypersensitivity to components of new dressings; peri-wound maceration or uncontrolled varicose eczema around the ulceration

Prognostic factors MMP (unspecified) (dichotomous data); MMP activity. Measurement method enzyme detection device
for detecting or measuring the presence in a test sample of the activity of an enzyme capable of cleaving a substrate: reverse ELTABA (Mologic Ltd.)

Time of measurement: baseline

Wound fluid sampling method: swabs (taken at dressing change)

Notes Results reported separately for the 2 randomised groups because oxyzyme/iodozyme suggested to be protease modulating

\section{Risk of bias}

\begin{tabular}{|c|c|c|}
\hline Bias & Authors' judgement & Support for judgement \\
\hline Selection bias & Low risk & All participants considered who met the inclusion criteria \\
\hline Attrition bias & Unclear risk & $\begin{array}{l}\text { Moderate: } 6 / 47 \text { (13\%) participants discontinued in intervention group; unclear } \\
\text { if important }\end{array}$ \\
\hline $\begin{array}{l}\text { Prognostic factor mea- } \\
\text { surement }\end{array}$ & Unclear risk & $\begin{array}{l}\text { Moderate: cut-off defined on } 0 \text { - } 10 \text { scale; unclear if validated: score of } \geq 5 \text { con- } \\
\text { sidered to be high protease activity }\end{array}$ \\
\hline Outcome measurement & High risk & Not blinded, investigator present at all times and assessed the outcome \\
\hline Adjustment factors & High risk & $\begin{array}{l}\text { None of the key adjustment factors taken into account in the design or analy- } \\
\text { sis }\end{array}$ \\
\hline Analysis and reporting & High risk & $\begin{array}{l}\text { Possible interaction with treatment (which proposed to be protease modulat- } \\
\text { ing); not taken into account in analysis }\end{array}$ \\
\hline Overall risk of bias & High risk & \\
\hline
\end{tabular}

Moffatt 2014b

\begin{tabular}{|c|c|}
\hline \multirow[t]{5}{*}{ Methods } & $\begin{array}{l}\text { Cohort comprised participants in the control arm of an RCT of oxyzyme/iodozyme vs control (usual } \\
\text { treatment) }\end{array}$ \\
\hline & Setting: community leg ulcer service \\
\hline & Country: UK \\
\hline & Duration of follow-up: 12 weeks \\
\hline & $\begin{array}{l}\text { Treatment: "standard care" + secondary dressing (film, surgipad/thin foam according to exudate level). } \\
\text { All used appropriate compression }\end{array}$ \\
\hline \multirow[t]{4}{*}{ Participants } & 53 participants with VLU or arterial leg ulcers ( $30 \mathrm{VLU}, 23$ mixed A-V) \\
\hline & Mean age: 69.4 (SD 13.35) years; similar for both groups \\
\hline & Sex (M:F): 29:24 \\
\hline & Stage of ulcer: not reported \\
\hline
\end{tabular}


Ulcer duration: mean 20.0 (SD 56.5) months

Ulcer size at baseline: mean $7.1($ SD 10.0$) \mathrm{cm}^{2}$

Wound infection: no cellulitis (exclusion criteria), but wound infection not mentioned

Number of wounds: unclear (1 limb per participant but (overall) 13 noted as having ulcer on contralateral limb so possibly 113 wounds)

Inclusion criteria: aged $\geq 18$ years, venous ( $A B P I>0.8$ ) or mixed (ABPI $>0.6)$ ulcer $2-50 \mathrm{~cm}^{2}$, mild or moderate exudate, healthy peri-wound skin

Exclusion criteria: pregnancy, breastfeeding, acute DVT within 3 months, surgery for chronic venous insufficiency within 2 months, surgery for peripheral arterial occlusive disease within 3 months, cellulitis, thyroid treatment, known hypersensitivity to components of new dressings; peri-wound maceration or uncontrolled varicose eczema around the ulceration

Prognostic factors

MMP (unspecified) (dichotomous data); MMP activity. Measurement method enzyme detection device for detecting or measuring the presence in a test sample of the activity of an enzyme capable of cleaving a substrate: reverse ELTABA (Mologic Ltd.)

Time of measurement: baseline

Wound fluid sampling method: swabs (taken at dressing change)

Notes

Results reported separately for the 2 randomised groups because oxyzyme/iodozyme suggested to be protease modulating

\section{Risk of bias}

\begin{tabular}{lll}
\hline Bias & Authors' judgement & Support for judgement \\
\hline Selection bias & Low risk & All participants considered who met the inclusion criteria \\
\hline Attrition bias & Low risk & $2 / 53$ participants discontinued in control group \\
\hline $\begin{array}{l}\text { Prognostic factor mea- } \\
\text { surement }\end{array}$ & Unclear risk & $\begin{array}{l}\text { Moderate: cut-off defined on 0-10 scale; unclear if validated: score of } \geq 5 \text { con- } \\
\text { sidered to be high protease activity }\end{array}$ \\
\hline Outcome measurement & High risk & Not blinded - investigator present at all times and assessed the outcome \\
\hline Adjustment factors & High risk & $\begin{array}{l}\text { None of the key adjustment factors taken into account in the design or analy- } \\
\text { sis }\end{array}$ \\
\hline Analysis and reporting & Low risk & Unlikely to be interaction with treatment \\
\hline Overall risk of bias & High risk & \\
\hline
\end{tabular}

\section{Mwaura 2006}

Methods
Setting: hospital venous unit
Country: Ireland
Duration of follow-up: 8 weeks
Treatments: Profore (Smith \& Nephew) graduated compression bandaging


Mwaura 2006 (Continued)
Participants
40 participants with VLUs
Mean age: 60 years
$\operatorname{Sex}(M: F): 11: 29$
Stage of ulcer: CEAP stage 6
Ulcer duration: not reported
Ulcer size at baseline: not reported
Wound infection: not reported
Number of wounds: 40
Inclusion criteria: aged $\geq 50$ years, VLU duration $\geq 8$ weeks, ABPI $>0.9$
Exclusion criteria: deep venous reflux, history of DVT, rheumatoid arthritis, diabetes, use of steroids, im- munosuppression, chronic renal or liver disease, smoker

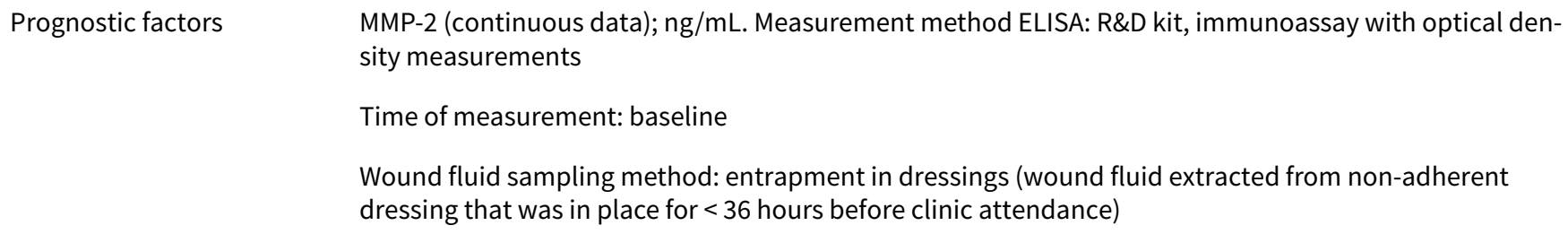

Notes

\section{Risk of bias}

\begin{tabular}{lll}
\hline Bias & Authors' judgement & Support for judgement \\
\hline Selection bias & Unclear risk & $\begin{array}{l}\text { Moderate: participants attending the venous unit were recruited; no further } \\
\text { details. Unclear whether representative }\end{array}$ \\
\hline Attrition bias & Low risk & No missing data \\
\hline $\begin{array}{l}\text { Prognostic factor mea- } \\
\text { surement }\end{array}$ & Unclear risk & $\begin{array}{l}\text { Moderate: wound fluid extracted from dressings used for treatment; unclear if } \\
\text { this is reasonable }\end{array}$ \\
\hline Outcome measurement & Unclear risk & Moderate: unclear if blinded \\
\hline Adjustment factors & High risk & $\begin{array}{l}\text { None of the key adjustment factors taken into account in the design or analy- } \\
\text { sis }\end{array}$ \\
\hline Analysis and reporting & Low risk & \\
\hline Overall risk of bias & Unclear risk & Moderate overall \\
\hline
\end{tabular}

\section{Raffetto 2015}

Methods

Nested case-control design in a cross-sectional study, divided on clinical grounds into granulating and inflammatory phases

Setting: not reported 
Raffetto 2015 (Continued)

\section{Country: not reported}

Duration of follow-up: none, case-control

Participants participants with VLUs
Mean age: 69.1 (SD 14.8) years vs 77.8 (SD 6.5) years (inflammatory
$43-91$ years
Sex: not reported
Stage of ulcer: 32 in inflammatory phase, 16 in granulating phase
Ulcer duration: not reported
Ulcer size at baseline: not reported
Wound infection: not reported
Number of wounds: unclear
Inclusion criteria: quote: "patients with VLU"
Exclusion criteria: not reported

Prognostic factors

MMP-1, MMP-2, MMP-3, MMP-7, MMP-8, MMP-9, MMP-10, MMP-12, MMP-13 (continuous data); concentration $\mathrm{pg} / \mathrm{mL}$. Measurement method multiplex ELISA: wound fluid transferred in collecting tube without additives or antiproteases. Centrifuged and supernatant frozen then concentration from multiplex ELISA

Time of measurement: baseline

Wound fluid sampling method: entrapment in dressings (cotton gauze applied to wound bed until saturated)

\begin{tabular}{|c|c|c|}
\hline Notes & Conference abstract & \\
\hline \multicolumn{3}{|l|}{ Risk of bias } \\
\hline Bias & Authors' judgement & Support for judgement \\
\hline Selection bias & High risk & $\begin{array}{l}\text { Participants subdivided into those with granulating and inflammatory phase } \\
\text { wounds. Not matched and longitudinal features not reported }\end{array}$ \\
\hline Attrition bias & Low risk & No missing data \\
\hline $\begin{array}{l}\text { Prognostic factor mea- } \\
\text { surement }\end{array}$ & Unclear risk & $\begin{array}{l}\text { Moderate: unclear if ELISA was adequate method and unclear if active or la- } \\
\text { tent protease }\end{array}$ \\
\hline Outcome measurement & High risk & $\begin{array}{l}\text { Type of case-control study; granulating and non-granulating identified, but } \\
\text { not matched at the outset. Not validated measure of healing }\end{array}$ \\
\hline Adjustment factors & High risk & $\begin{array}{l}\text { None of the key adjustment factors taken into account in the design or analy- } \\
\text { sis. Significant association of age with the outcome }\end{array}$ \\
\hline Analysis and reporting & High risk & $\begin{array}{l}\text { Results reported only for significant proteases (MMP-3, MMP-8, MMP-10 report- } \\
\text { ed as "non-significant") }\end{array}$ \\
\hline
\end{tabular}

Overall risk of bias

High risk 
Serra 2013

\begin{tabular}{|c|c|c|}
\hline \multirow[t]{5}{*}{ Methods } & \multirow{2}{*}{\multicolumn{2}{|c|}{$\begin{array}{l}\text { Prospective cohort } \\
\text { Setting: single centre }\end{array}$}} \\
\hline & & \\
\hline & \multicolumn{2}{|l|}{ Country: Italy } \\
\hline & \multicolumn{2}{|c|}{ Duration of follow-up: 8 weeks } \\
\hline & \multicolumn{2}{|c|}{ Treatments: all participants treated with appropriate surgery and compression $(30-40 \mathrm{mmHg})$} \\
\hline \multirow[t]{10}{*}{ Participants } & \multicolumn{2}{|c|}{31 participants with VLUs (study additionally reported on a group without ulcers) } \\
\hline & \multicolumn{2}{|c|}{ Mean age: 51.5 (SD 9) years, range $42-61$ years } \\
\hline & \multicolumn{2}{|l|}{$\operatorname{Sex}(M: F): 9: 22$} \\
\hline & \multicolumn{2}{|c|}{ Stage of ulcer: class 6 of CEAP (inclusion criterion) } \\
\hline & \multicolumn{2}{|c|}{ Ulcer duration: $>6$ weeks (inclusion criterion) } \\
\hline & \multicolumn{2}{|c|}{ Ulcer size at baseline: median (range) $10.7(2.1-17.5) \mathrm{cm}^{2}$} \\
\hline & \multicolumn{2}{|c|}{ Wound infection: no infection within 6 weeks (exclusion criterion) } \\
\hline & \multicolumn{2}{|l|}{ Number of wounds: 31} \\
\hline & \multicolumn{2}{|c|}{ Inclusion criteria: aged 20-70 years, VLU (class 6 CEAP), duration > 6 weeks, ABPI > 0.9} \\
\hline & \multicolumn{2}{|c|}{$\begin{array}{l}\text { Exclusion criteria: arterial disease, infection within } 6 \text { weeks, connective tissue disorder, blood disorder, } \\
\text { cancer }\end{array}$} \\
\hline Prognostic factors & \multicolumn{2}{|c|}{$\begin{array}{l}\text { MMP-9 (continuous data); ng/total sample protein }(\mu \mathrm{g}) \text {. Measurement method ELISA: substrate and op- } \\
\text { tical density measurements. Reported as ng per total sample protein }(\mu \mathrm{g})\end{array}$} \\
\hline & \multicolumn{2}{|c|}{ Time of measurement: baseline, within 24 hours of surgery at 4 weeks, 8 weeks } \\
\hline & \multicolumn{2}{|c|}{ Wound fluid sampling method: occlusive dressings (fluid collected after 4 hours) } \\
\hline \multicolumn{3}{|l|}{ Notes } \\
\hline \multicolumn{3}{|l|}{ Risk of bias } \\
\hline Bias & Authors' judgement & Support for judgement \\
\hline Selection bias & Unclear risk & Moderate: sample selection not stated \\
\hline Attrition bias & Low risk & No missing data \\
\hline $\begin{array}{l}\text { Prognostic factor mea- } \\
\text { surement }\end{array}$ & Unclear risk & $\begin{array}{l}\text { Moderate: unclear if ELISA is adequate method and unclear if active or latent } \\
\text { protease }\end{array}$ \\
\hline Outcome measurement & High risk & Not adjusted for baseline; unclear if blinded \\
\hline Adjustment factors & High risk & $\begin{array}{l}\text { None of the key adjustment factors taken into account in the design or analy- } \\
\text { sis }\end{array}$ \\
\hline Analysis and reporting & Unclear risk & Moderate: data extracted from graph \\
\hline Overall risk of bias & High risk & \\
\hline
\end{tabular}


Serra 2015a

Methods
Setting: single clinical centre
Country: Italy
Duration of follow-up: 5 months
Treatments: all participants had basic treatment, including vein surgery if appropriate and compres-
sion stockings. Randomised to receive 3 months' course of doxycycline or standard care

\begin{tabular}{|c|c|c|}
\hline Participants & $\begin{array}{l}32 \text { participants with V } \\
\text { Mean age: } 50.5 \text { (SD 8) } \\
\text { Sex (M:F): 9:23 } \\
\text { Stage of ulcer: class } 6 \\
\text { Ulcer duration: } \geq 6 \text { we } \\
\text { Ulcer size at baseline } \\
\text { Wound infection: no ir } \\
\text { Number of wounds: u } \\
\text { Inclusion criteria: age } \\
\text { Exclusion criteria: arte } \\
\text { cancer, gastroenteriti }\end{array}$ & $\begin{array}{l}\text { CEAP (inclusion criterion) } \\
\text { «S (inclusion criterion) } \\
\text { edian (range): } 12.9 \text { (2.9-19.5) } \mathrm{cm}^{2} \\
\text { ection within } 6 \text { weeks (inclusion criterion) } \\
\text { lear } \\
\text { 20-70 years, VLU (class } 6 \text { CEAP), duration at least weeks, ABPI > } 0.9 \\
\text { allergy to tetracyclines }\end{array}$ \\
\hline Prognostic factors & $\begin{array}{l}\text { MMP-9 (continuous da } \\
\text { approach as Serra } 201 \\
\text { Time of measurement } \\
\text { Wound fluid sampling }\end{array}$ & $\begin{array}{l}\text { a). Measurement method ELISA: kit from Amersham Pharmacia Biotech; same } \\
\text { baseline, } 4 \text { weeks, } 3 \text { months, } 5 \text { months } \\
\text { hethod: not stated }\end{array}$ \\
\hline \multicolumn{3}{|l|}{ Notes } \\
\hline \multicolumn{3}{|l|}{ Risk of bias } \\
\hline Bias & Authors' judgement & Support for judgement \\
\hline Selection bias & Unclear risk & $\begin{array}{l}\text { Moderate: insufficient information to assess this domain. RCT, so may be less } \\
\text { representative }\end{array}$ \\
\hline Attrition bias & Low risk & No missing data \\
\hline $\begin{array}{l}\text { Prognostic factor mea- } \\
\text { surement }\end{array}$ & Unclear risk & $\begin{array}{l}\text { Moderate: unclear if ELISA was adequate method and unclear if active or la- } \\
\text { tent protease }\end{array}$ \\
\hline Outcome measurement & High risk & Not adjusted for baseline; unclear if blinded \\
\hline Adjustment factors & High risk & $\begin{array}{l}\text { None of the key adjustment factors taken into account in the design or analy- } \\
\text { sis }\end{array}$ \\
\hline
\end{tabular}


Serra 2015a (Continued)

Analysis and reporting High risk Experimental arm may have interacted with protease levels. Not taken into account. Number of participants healing not reported, so SMD could not be applied

Overall risk of bias High risk

Serra 2015b

Methods
Setting: single clinical centre
Country: Italy
Duration of follow-up: 5 months
Treatments: all participants had basic treatment, including vein surgery if appropriate and compres-
sion stockings. Randomised to receive a 3-month course of doxycycline or standard care

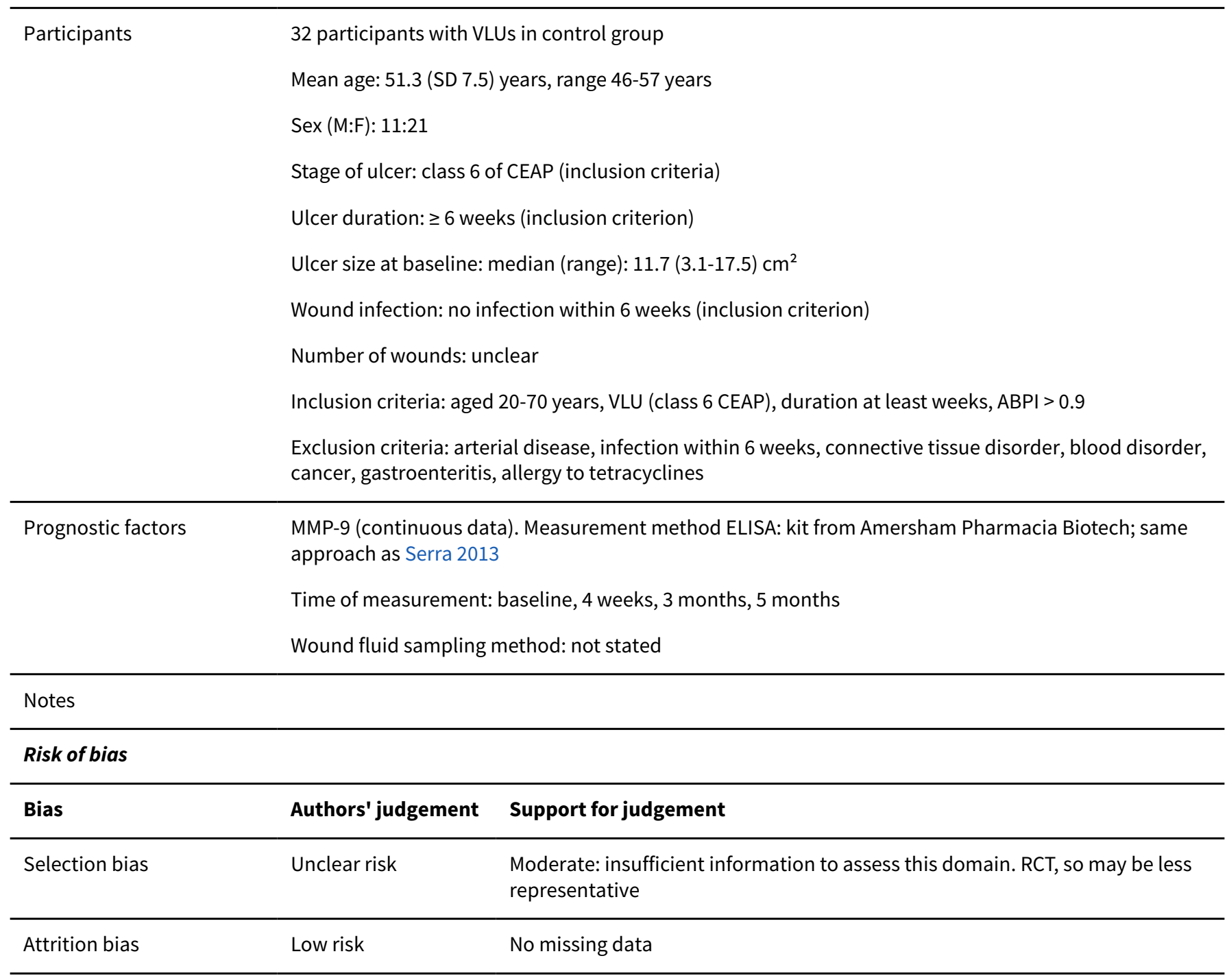


Serra 2015b (Continued)

$\begin{array}{ll}\begin{array}{l}\text { Prognostic factor mea- } \\ \text { surement }\end{array} & \begin{array}{l}\text { Moderate: unclear if ELISA is adequate method and unclear if active or latent } \\ \text { protease }\end{array}\end{array}$

\begin{tabular}{lll}
\hline Outcome measurement & High risk & Not adjusted for baseline; unclear if blinded \\
\hline Adjustment factors & High risk & $\begin{array}{l}\text { None of the key adjustment factors taken into account in the design or analy- } \\
\text { sis }\end{array}$ \\
\hline Analysis and reporting & Unclear risk & $\begin{array}{l}\text { Moderate: number of participants healing not reported, so SMD could not be } \\
\text { applied. Treatment unlikely to interact with protease levels }\end{array}$ \\
\hline
\end{tabular}

Overall risk of bias High risk

Smeets 2008

\begin{tabular}{ll} 
Methods & RCT \\
Setting: single clinical centre \\
Country: Germany \\
Duration of follow-up: 12 weeks \\
Treatments: participants randomised to collagen/ORC matrix (protease modulating) and hydrocolloid \\
\hline Participants \\
27 participants with VLUs \\
Mean age: 63 (SD 8) years \\
Sex: quote: "majority female"
\end{tabular}

Prognostic factors

MMP-2 (continuous data); concentration. Measurement method ELISA and fluorogenic substrate assay: sandwich ELISA for MMP-2, fluorogenic substrate assay for elastase and substrate/optical density measurement for gelatinase (Gelatinase Activity Assay kit from Chemicon)

Time of measurement: baseline and 5, 14, 28, 42 and 56 days

Wound fluid sampling method: occlusive dressings (RELEASE dressing on wound then covered with occlusive dressing (BIOCCLUSIVE) and left for 6 hours)

Notes Limited data collection; no results. Risk of bias assessments available on request

\section{Trengove 1999}

\begin{tabular}{ll}
\hline Methods & Prospective cohort study \\
Setting: inpatients in hospital \\
Country: Australia \\
Duration of follow-up: 2 weeks \\
Treatments: bedrest \\
\hline $\begin{array}{l}15 \text { participants with VLUs or A-V mixed aetiology (7 VLU; } 8 \text { venous with minor arterial disease (Dopplers } \\
\text { Participants }\end{array}$
\end{tabular}


Trengove 1999 (Continued)

Mean age: 77 (range 55-91) years

$\operatorname{Sex}(M: F): 10: 5$

Stage of ulcer: not reported

Ulcer duration: $\geq 3$ months

Wound infection: not reported

Number of wounds: 15 (inferred)

Inclusion criteria: chronic leg ulcers in the gaiter region excluding the foot (all had venous disease and had been treated as outpatients with compression to improve venous function; in all cases, ulcers had failed to respond to treatment as defined by no reduction in size in $>3$ months or a continued increase in size of ulcer); arterial disease by ankle-brachial ratio $<0.9$

Exclusion criteria: not reported

Prognostic factors

MMP (unspecified); MMP-2, MMP-9 (implied) and elastase. Measurement method gelatin zymography and fluorogenic substrate assay: Azcoll assay with spectrophotometer and compared to standard curve for collagenase. $\mu \mathrm{g}$ protease equivalents/mL fluid; gelatin zymography; incubation with Illomostat for specific MMP activity. Fluorogenic substrate assay: $\mu$ g elastase $/ \mathrm{mL}$ fluid (elastase)

Time of measurement: within 24 hours admission and after 2 weeks' bedrest

Wound fluid sampling method: occlusive dressings (transparent occlusive film (Opsite) placed over wound in morning; fluid aspirated from beneath dressing after 1 hour)

Notes Limited data collection; no results. Risk of bias assessments available on request

Trøstrup 2011

\begin{tabular}{ll}
\hline Methods & Prospective cohort study, VLU group (also group with acute wounds) \\
& Setting: not reported \\
& Country: Denmark \\
& Duration of follow-up: 4 weeks \\
\hline Participants & 8 participants with VLUs (and 25 acute wounds) \\
& Mean age: 82 (SD 20) years \\
& Sex (M:F): $4: 4$ \\
\hline Prognostic factors & MMP-9 (continuous data) \\
\hline Time of measurement: baseline, 2 weeks, 4 weeks \\
\hline Minimal data collection because no results. Risk of bias assessments available on request
\end{tabular}

Methods Prospective cohort study


Wysocki 1999 (Continued)

Setting: inpatients and outpatients in a large metropolitan university hospital and a Veterans Affairs hospital

Country: USA

Duration of follow-up: 27 months

Participants
Mean age: 63.5 (SD 16.2) years
Sex (M:F): 8:3
Exclusion criteria: fluid collected only from ulcers with no sign or symptom of clinical wound infection

Prognostic factors UPA and MMP-9 (continuous data); protein expression. Measurement method: fluorogenic substrate assay and fibrin overlap assay (UPA) and gelatin zymography (MMP-9): Spectrozyme PL assay, with bovine plasminogen and 6 -aminohexanoic acid to increase sensitivity; plasmin-specific amidolytic chromogenic substrate, free $\mathrm{p}$-nitroaniline from the substrate measured spectophotometrically. Also fibrin overlap assay to distinguish active UPA

Time of measurement: baseline, and 3, 5, 16, 26, 27 months (data/gel image for 1 participant)

Wound fluid sampling method: occlusive dressings (semiocclusive polyurethane film dressing placed over wound for 4-12 hours (but usually 1-3 hours sufficient))

Notes

Minimal data collection because no results. Risk of bias assessments available on request

ABPI: ankle-brachial pressure index; AUR: allantoin to uric acid ratio; A-V: arterial-venous; CEAP: classification system for venous disorders based on their clinical, aetiological, anatomical and pathophysiological characteristics; $\mathrm{Cl}$ : confidence interval; CVLU: chronic venous leg ulcer; DHA: docosahexaenoic acid; DVT: deep vein thrombosis; ELISA: enzyme-linked immunosorbent assay; ELTABA: enzyme activity assay; EPA: n-3 eicosapentaenoic acid; F: female; HR: hazard ratio; IPD: individual participant data; IQR: interquartile range; ORC: oxidised regenerated cellulose; M: male; MMP: matrix metalloproteinase; PAI-1: plasminogen activator inhibitor-1; PAI-2: plasminogen activator inhibitor-2; RCT: randomised controlled trial; RR: risk ratio; SD: standard deviation; SDS: sodium dodecyl sulphate; SE: standard error; SMD: standardised mean difference; TIMP: tissue inhibitors of metalloproteinases; uPA: urokinase-type plasminogen activator; VLU: venous leg ulcer; WHO: World Health Organization.

Characteristics of excluded studies [ordered by study ID]

\begin{tabular}{ll}
\hline Study & Reason for exclusion \\
\hline Ahmad 2011 & Ineligible study design \\
\hline Alexewicz 2007 & Sample or analysis technique were not eligible \\
\hline Amato 2015 & Ineligible study design \\
\hline Anon 2008 & Ineligible study design \\
\hline Ayuk 2016 & Ineligible study design \\
\hline Barros 2012 & Sample or analysis technique were not eligible \\
\hline Bernatchez 2012 & Ineligible outcome \\
\hline Bigliardi 1955 & Study conducted before relevant techniques available \\
\hline Bogaczewicz 2004 & Ineligible study design \\
\hline
\end{tabular}




\begin{tabular}{|c|c|}
\hline Study & Reason for exclusion \\
\hline Bohórquez-Sierra 2006 & Ineligible study design \\
\hline Budzyn-Napierala 2016 & Ineligible population; not people with venous leg ulcer \\
\hline Caimi 2015 & Sample or analysis technique were not eligible \\
\hline Clark 2001 & Ineligible study design \\
\hline Cook 2000 & Ineligible study design \\
\hline Cook 2009 & Ineligible prognostic factor \\
\hline Cullen 2002b & Ineligible population \\
\hline Da Silva 2014 & Ineligible study design \\
\hline Dalton 2005 & Ineligible outcome \\
\hline Derbyshire 2003 & Ineligible study design \\
\hline Duffy 2005 & Ineligible study design \\
\hline Eming 2006 & Sample or analysis technique were not eligible \\
\hline Eming 2008 & Ineligible outcome \\
\hline Failla 2008 & Ineligible study design \\
\hline Fernandez 2008 & Sample or analysis technique were not eligible \\
\hline Fisher 1998 & Ineligible study design \\
\hline Fray 2003 & Preclinical animal study \\
\hline Gacka 2004 & Sample or analysis technique were not eligible \\
\hline Gordon 1975 & Ineligible study design; used as intervention \\
\hline Grinnell 1992 & Sample or analysis technique were not eligible \\
\hline Grinnell 1998 & Ineligible outcome \\
\hline Hasmann 2011 & Sample or analysis technique were not eligible \\
\hline He 1999 & Sample or analysis technique were not eligible \\
\hline Herouy $2000 a$ & Ineligible study design; used as intervention \\
\hline Herouy 2000b & Ineligible study design \\
\hline Herouy 2004 & Sample or analysis technique were not eligible \\
\hline Herrick 1997 & Sample or analysis technique were not eligible \\
\hline Hoffman 1998 & Sample or analysis technique were not eligible \\
\hline
\end{tabular}




\begin{tabular}{|c|c|}
\hline Study & Reason for exclusion \\
\hline Honda 2011 & Ineligible population \\
\hline Huttunen 2000 & Ineligible outcomes \\
\hline Huttunen 2004 & Ineligible outcomes \\
\hline Huttunen 2005 & Ineligible participants \\
\hline Ibbotson 1994 & Ineligible prognostic factor \\
\hline Impola 2005 & Ineligible outcomes \\
\hline Ivins 2014 & Ineligible study design \\
\hline Karatepe 2010 & Ineligible participants \\
\hline Karim 2006 & Ineligible outcomes \\
\hline Kucharzewski 2005 & Ineligible study design \\
\hline Kucukguven 2013 & Ineligible population \\
\hline Körber 2006 & Ineligible study design \\
\hline Lantis 2011 & Sample or analysis technique were not eligible \\
\hline Ligi 2016 & Ineligible study design \\
\hline Lim 2010 & Ineligible study design \\
\hline Lotti 1995 & Sample or analysis technique were not eligible \\
\hline McCarty 2012 & Ineligible study design \\
\hline McCarty 2013 & Ineligible study design \\
\hline Mclnnes 2014 & Ineligible outcome \\
\hline Mirastschijski 2002 & Ineligible population \\
\hline Mirshahi 1995 & Sample or analysis technique were not eligible \\
\hline Moor 2009 & Ineligible outcome \\
\hline Moore 2007 & Ineligible study design \\
\hline Nielsen 1992 & Sample or analysis technique were not eligible \\
\hline Norgauer 2002 & Sample or analysis technique were not eligible \\
\hline Nwomeh 1999 & Ineligible study design \\
\hline Ovington 2001 & Ineligible study design \\
\hline Palolahti 1993 & Ineligible outcome \\
\hline
\end{tabular}




\begin{tabular}{|c|c|}
\hline Study & Reason for exclusion \\
\hline Phillips 2007 & Ineligible study design \\
\hline Pirila 2007 & Sample or analysis technique were not eligible \\
\hline Raffetto 2014 & Ineligible study design \\
\hline Rayment 2008 & Ineligible outcome \\
\hline Rayment 2009 & Ineligible study design \\
\hline Rechardt 2000 & Sample or analysis technique were not eligible \\
\hline Rogers 1999 & Ineligible study design \\
\hline Saarialho-Kere 1998 & Sample or analysis technique were not eligible \\
\hline Salgado 2017 & Wound biopsy and proteases not investigated for clinical part of the study \\
\hline Schmid 1999 & Ineligible outcome \\
\hline Schmidtchen 2000 & Ineligible outcome \\
\hline Schmidtchen 2003 & Ineligible study design \\
\hline Schultz 2004 & Ineligible population \\
\hline Senet 2003 & Ineligible prognostic factor \\
\hline Serena 2016 & Healing rate measured before the start of the study; so cross-sectional design \\
\hline Serra 2014 & Ineligible population \\
\hline Serra $2015 c$ & Ineligible study design \\
\hline Serra 2016a & Ineligible study design \\
\hline Serra 2016b & Sample or analysis technique were not eligible \\
\hline Serra 2017 & Sample or analysis technique were not eligible \\
\hline Shields 1994 & Ineligible population \\
\hline Singh 2010 & Ineligible study design \\
\hline Stacey 1993 & Sample or analysis technique were not eligible \\
\hline Stacey 2000 & Sample or analysis technique were not eligible \\
\hline Stojadinovic 2014 & Ineligible prognostic factor \\
\hline Tarlton 1999 & Ineligible study design \\
\hline Tauzin 2014 & Sample or analysis technique were not eligible \\
\hline Turio 2002 & Sample or analysis technique were not eligible \\
\hline
\end{tabular}




\begin{tabular}{|c|c|}
\hline Study & Reason for exclusion \\
\hline Ulrich 2005 & Sample or analysis technique were not eligible \\
\hline Vaalamo 1996 & Sample or analysis technique were not eligible \\
\hline Vaalamo 1997 & Sample or analysis technique were not eligible \\
\hline Vaalamo 1999 & Sample or analysis technique were not eligible \\
\hline Vahlquist 2000 & Ineligible study design \\
\hline Van Bergen 1996 & Sample or analysis technique were not eligible \\
\hline Varelias 2002 & Ineligible population \\
\hline Varelias 2006 & Ineligible population \\
\hline Weckroth 1996 & Ineligible study design \\
\hline Weckroth 2004 & Sample or analysis technique were not eligible \\
\hline Widgerow 2011 & Ineligible study design \\
\hline Wlaschek 1997 & Ineligible prognostic factor \\
\hline Wysocki 1993 & Ineligible outcome \\
\hline Wysocki 1996 & Ineligible outcome \\
\hline Zamboni 2005 & Ineligible population \\
\hline Zeegelaar 1997 & Sample or analysis technique were not eligible \\
\hline Zillmer 2011 & Ineligible outcome \\
\hline
\end{tabular}

Characteristics of studies awaiting assessment [ordered by study ID]

Cullen 2009

Notes Conference abstract. Participants with venous leg ulcers treated with collagen/oxidised regenerated cellulose for 4 weeks and elastase levels measured. Outcome was response to treatment (unclear how this was measured). Few details

\section{DATA AND ANALYSES}


Comparison 1. Protease activity continuous

\begin{tabular}{|c|c|c|c|c|}
\hline Outcome or subgroup title & No. of studies & $\begin{array}{l}\text { No. of partici- } \\
\text { pants }\end{array}$ & Statistical method & Effect size \\
\hline $\begin{array}{l}1 \text { t-test assocation of protease level and } \\
\text { healing (dichotomous) }\end{array}$ & 6 & & $\begin{array}{l}\text { Std. Mean Difference (IV, } \\
\text { Fixed, } 95 \% \mathrm{CI} \text { ) }\end{array}$ & $\begin{array}{l}\text { Totals not select- } \\
\text { ed }\end{array}$ \\
\hline 1.1 Completely healed vs non-healed & 2 & & $\begin{array}{l}\text { Std. Mean Difference (IV, } \\
\text { Fixed, } 95 \% \mathrm{CI} \text { ) }\end{array}$ & $0.0[0.0,0.0]$ \\
\hline $\begin{array}{l}\text { 1.2 Degrading MMPs: (gelatinases/met- } \\
\text { alloelastase) healing vs non-healing }\end{array}$ & 3 & & $\begin{array}{l}\text { Std. Mean Difference (IV, } \\
\text { Fixed, } 95 \% \mathrm{CI} \text { ) }\end{array}$ & $0.0[0.0,0.0]$ \\
\hline $\begin{array}{l}\text { 1.3 Reparative MMPs: (collagenases/ma- } \\
\text { trilysin) healing vs non-healing }\end{array}$ & 2 & & $\begin{array}{l}\text { Std. Mean Difference (IV, } \\
\text { Fixed, } 95 \% \mathrm{CI} \text { ) }\end{array}$ & $0.0[0.0,0.0]$ \\
\hline $\begin{array}{l}2 \mathrm{t} \text {-test association of protease level and } \\
\text { healing: high }\left(\geq 1 \mathrm{~cm}^{2} / \text { week }\right) \text { vs low }(<1 \\
\mathrm{cm}^{2} / \text { week) healing }\end{array}$ & 3 & & $\begin{array}{l}\text { Mean Difference (Fixed, 95\% } \\
\mathrm{Cl} \text { ) }\end{array}$ & $\begin{array}{l}\text { Totals not select- } \\
\text { ed }\end{array}$ \\
\hline 2.1 With doxycycline treatment & 1 & & $\begin{array}{l}\text { Mean Difference (Fixed, 95\% } \\
\mathrm{Cl} \text { ) }\end{array}$ & $0.0[0.0,0.0]$ \\
\hline 2.2 With standard care treatment & 1 & & $\begin{array}{l}\text { Mean Difference (Fixed, 95\% } \\
\mathrm{Cl} \text { ) }\end{array}$ & $0.0[0.0,0.0]$ \\
\hline $\begin{array}{l}\text { 2.3 Treatment not reported (other than } \\
\text { compression) }\end{array}$ & 1 & & $\begin{array}{l}\text { Mean Difference (Fixed, 95\% } \\
\mathrm{Cl} \text { ) }\end{array}$ & $0.0[0.0,0.0]$ \\
\hline $\begin{array}{l}3 \text { Correlation coefficients: protease lev- } \\
\text { els and change in size }\end{array}$ & 3 & & $\begin{array}{l}\text { Correlation coefficient } \\
\text { (Fixed, } 95 \% \mathrm{Cl} \text { ) }\end{array}$ & $\begin{array}{l}\text { Totals not select- } \\
\text { ed }\end{array}$ \\
\hline $\begin{array}{l}\text { 3.1 Change in MMP-2 level vs reduction } \\
\text { in ulcer size }\end{array}$ & 1 & & $\begin{array}{l}\text { Correlation coefficient } \\
\text { (Fixed, 95\% Cl) }\end{array}$ & $0.0[0.0,0.0]$ \\
\hline $\begin{array}{l}3.2 \text { Change in MMP-9 level vs reduction } \\
\text { in ulcer size }\end{array}$ & 1 & & $\begin{array}{l}\text { Correlation coefficient } \\
\text { (Fixed, } 95 \% \mathrm{Cl} \text { ) }\end{array}$ & $0.0[0.0,0.0]$ \\
\hline $\begin{array}{l}3.3 \mathrm{MMP}-8 \text { level at } 4 \text { weeks vs } \% \text { reduc- } \\
\text { tion in size at } 8 \text { weeks }\end{array}$ & 1 & & $\begin{array}{l}\text { Correlation coefficient } \\
\text { (Fixed, } 95 \% \mathrm{Cl} \text { ) }\end{array}$ & $0.0[0.0,0.0]$ \\
\hline $\begin{array}{l}3.4 \text { Elastase level at } 4 \text { weeks vs } \% \text { reduc- } \\
\text { tion in size at } 8 \text { weeks }\end{array}$ & 1 & & $\begin{array}{l}\text { Correlation coefficient } \\
\text { (Fixed, 95\% Cl) }\end{array}$ & $0.0[0.0,0.0]$ \\
\hline $\begin{array}{l}3.5 \text { Elastase at } 4 \text { weeks vs } \% \text { change in } \\
\text { size at } 9 \text { months }\end{array}$ & 1 & & $\begin{array}{l}\text { Correlation coefficient } \\
\text { (Fixed, } 95 \% \mathrm{Cl} \text { ) }\end{array}$ & $0.0[0.0,0.0]$ \\
\hline
\end{tabular}

\section{Analysis 1.1. Comparison 1 Protease activity continuous, Outcome $1 \mathrm{t}$-test assocation of protease level and healing (dichotomous).}

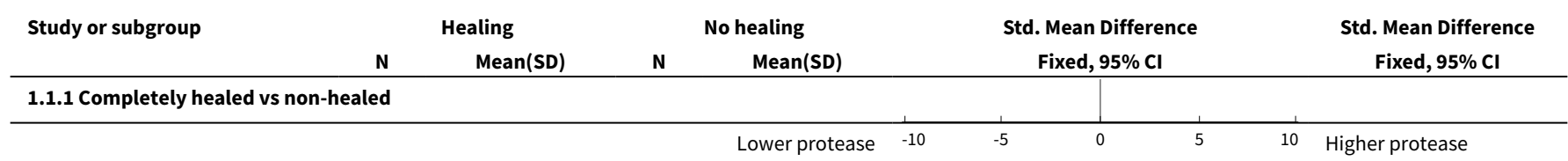




\begin{tabular}{|c|c|c|c|c|c|c|c|}
\hline \multirow[t]{2}{*}{ Study or subgroup } & \multicolumn{2}{|c|}{ Healing } & \multicolumn{2}{|c|}{ No healing } & \multirow{2}{*}{\multicolumn{2}{|c|}{$\begin{array}{c}\text { Std. Mean Difference } \\
\text { Fixed, } 95 \% \mathrm{Cl}\end{array}$}} & \multirow{2}{*}{$\begin{array}{c}\text { Std. Mean Difference } \\
\text { Fixed, } 95 \% \mathrm{Cl}\end{array}$} \\
\hline & $\mathbf{N}$ & $\operatorname{Mean}(S D)$ & $\mathbf{N}$ & $\operatorname{Mean}(S D)$ & & & \\
\hline Ahmad 2015 & 9 & $0.4(0.5)$ & 21 & $0.2(0.1)$ & & + & $0.72[-0.08,1.53]$ \\
\hline Hoffman 1999 & 3 & $9.5(7.1)$ & 4 & $53(54.3)$ & & 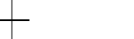 & $-0.87[-2.51,0.78]$ \\
\hline \multicolumn{8}{|c|}{ 1.1.2 Degrading MMPs: (gelatinases/metalloelastase) healing vs non-healing } \\
\hline Mwaura 2006 & 20 & $117(61)$ & 20 & $133(12)$ & & & $-0.36[-0.98,0.27]$ \\
\hline Raffetto 2015 & 16 & $173900(47170)$ & 32 & $483100(68190)$ & $千$ & & $-4.9[-6.08,-3.71]$ \\
\hline Raffetto 2015 & 16 & $22780(7478)$ & 32 & $67550(12350)$ & 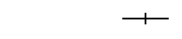 & & $-4[-5.03,-2.97]$ \\
\hline Raffetto 2015 & 16 & $14700(65300)$ & 32 & 943900 (119600) & + & & $-8.7[-10.62,-6.79]$ \\
\hline Serra 2013 & 13 & $240.2(41.5)$ & 7 & 249.1 (33.9) & & - & $-0.22[-1.14,0.7]$ \\
\hline Serra 2013 & 11 & $247.8(42.5)$ & 7 & $249.1(33.9)$ & & - & $-0.03[-0.98,0.92]$ \\
\hline \multicolumn{8}{|c|}{ 1.1.3 Reparative MMPs: (collagenases/matrilysin) healing vs non-healing } \\
\hline Harris 1995 & 6 & $0.6(0.8)$ & 12 & $0.4(0.4)$ & & + & $0.3[-0.69,1.28]$ \\
\hline Raffetto 2015 & 16 & $3072(1076)$ & 32 & $1212(609)$ & & + & $2.31[1.54,3.08]$ \\
\hline Raffetto 2015 & 16 & $10290(3775)$ & 32 & $3093(930)$ & & + & $3.1[2.21,3.98]$ \\
\hline Raffetto 2015 & 16 & $142800(26730)$ & 32 & $79460(26370)$ & & + & $2.35[1.58,3.13]$ \\
\hline
\end{tabular}

Analysis 1.2. Comparison 1 Protease activity continuous, Outcome $2 \mathrm{t}$-test association of protease level and healing: high ( $\geq 1 \mathrm{~cm}^{2} /$ week) vs low $\left(<1 \mathrm{~cm}^{2} /\right.$ week) healing.

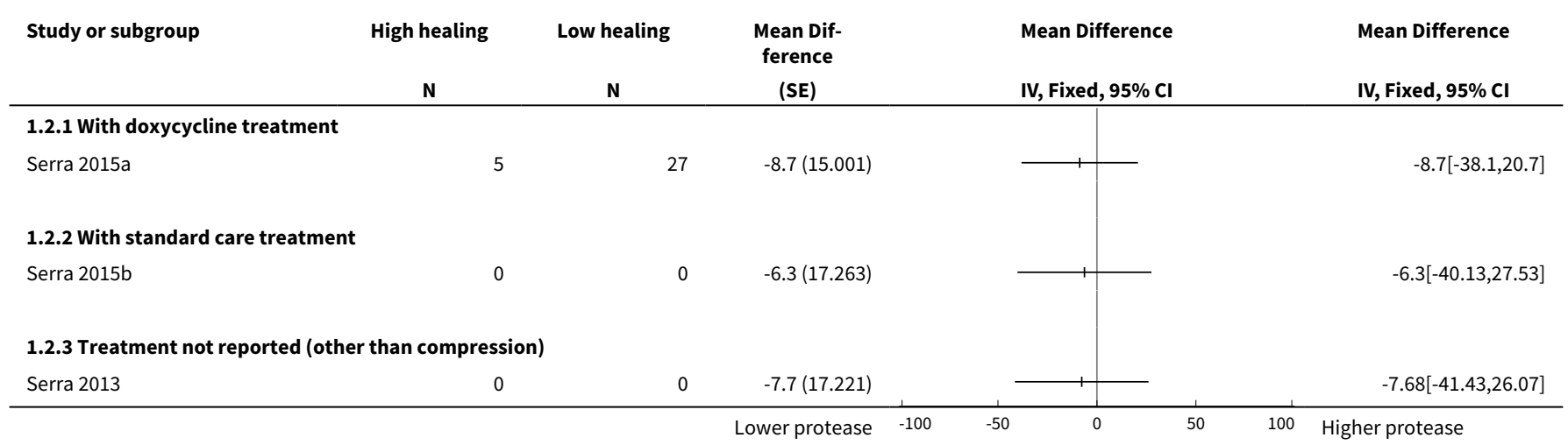

Analysis 1.3. Comparison 1 Protease activity continuous, Outcome 3 Correlation coefficients: protease levels and change in size.

\begin{tabular}{|c|c|c|c|c|c|}
\hline Study or subgroup & $\begin{array}{c}\text { not applicable } \\
\text { N } \\
\end{array}$ & not applicable & $\begin{array}{c}\text { Correlation } \\
\text { coefficient } \\
\text { (SE) }\end{array}$ & $\begin{array}{c}\text { Correlation coefficient } \\
\text { IV, Fixed, } 95 \% \mathrm{Cl} \\
\end{array}$ & $\begin{array}{l}\text { Correlation coefficient } \\
\qquad \text { IV, Fixed, } 95 \% \mathrm{Cl} \\
\end{array}$ \\
\hline \multicolumn{6}{|c|}{ 1.3.1 Change in MMP-2 level vs reduction in ulcer size } \\
\hline Gohel 2008 & 0 & 0 & $0(0)$ & & Not estimable \\
\hline \multicolumn{6}{|c|}{ 1.3.2 Change in MMP-9 level vs reduction in ulcer size } \\
\hline \multicolumn{6}{|c|}{ 1.3.3 MMP-8 level at 4 weeks vs $\%$ reduction in size at 8 weeks } \\
\hline & & & Less healing $\quad-1$ & -0.5 & More healing \\
\hline
\end{tabular}




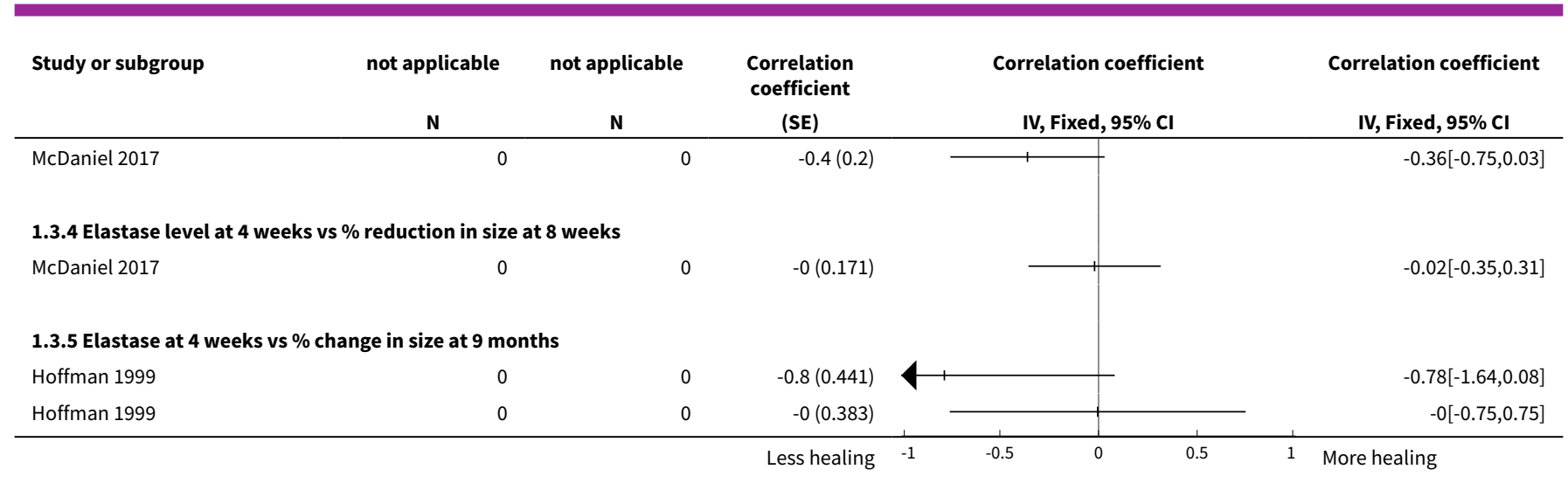

\section{Comparison 2. Protease activity dichotomous}

\begin{tabular}{|c|c|c|c|c|}
\hline Outcome or subgroup title & No. of studies & $\begin{array}{l}\text { No. of partici- } \\
\text { pants }\end{array}$ & Statistical method & Effect size \\
\hline $\begin{array}{l}1 \text { Association of healing with elevated protease } \\
\text { level; by protease modulating (PM) interven- } \\
\text { tion }\end{array}$ & 3 & & $\begin{array}{l}\text { Risk Ratio (Fixed, } \\
95 \% \mathrm{Cl} \text { ) }\end{array}$ & $\begin{array}{l}\text { Totals not select- } \\
\text { ed }\end{array}$ \\
\hline $\begin{array}{l}1.1 \text { Elastase }>25 \mathrm{mU} / 100 \mu \mathrm{L} \text { vs } \leq 25 \mathrm{mU} / 100 \mu \mathrm{L} \\
+ \text { PM intervention }\end{array}$ & 1 & & $\begin{array}{l}\text { Risk Ratio (Fixed, } \\
95 \% \mathrm{Cl} \text { ) }\end{array}$ & $0.0[0.0,0.0]$ \\
\hline $\begin{array}{l}1.2 \mathrm{MMP} \text { (unspecified) level } \geq 5 \text { ( } 0-10 \text { scale) vs }< \\
5+\text { possible PM intervention }\end{array}$ & 1 & & $\begin{array}{l}\text { Risk Ratio (Fixed, } \\
95 \% \mathrm{Cl} \text { ) }\end{array}$ & $0.0[0.0,0.0]$ \\
\hline $\begin{array}{l}1.3 \mathrm{MMP} \text { (unspecified) level } \geq 5 \text { ( } 0-10 \text { scale) vs }< \\
5+\text { non-PM intervention }\end{array}$ & 1 & & $\begin{array}{l}\text { Risk Ratio (Fixed, } \\
95 \% \mathrm{Cl} \text { ) }\end{array}$ & $0.0[0.0,0.0]$ \\
\hline
\end{tabular}

Analysis 2.1. Comparison 2 Protease activity dichotomous, Outcome 1 Association of healing with elevated protease level; by protease modulating (PM) intervention.

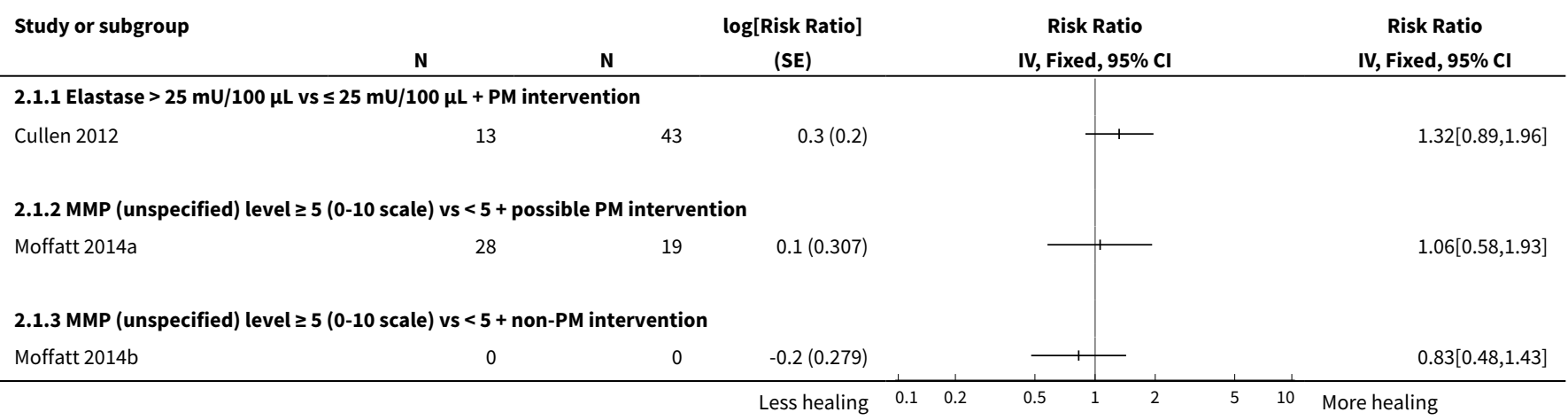




\section{A P P E N D I CES}

\section{Appendix 1. Search strategy}

\section{Cochrane Central Register of Controlled Trials (CENTRAL)(Issue 2 of 12, February 2018)}

\#1 MeSH descriptor: [Leg Ulcer] explode all trees

\#2 (varicose ulcer ${ }^{\star}$ or venous ulcer ${ }^{\star}$ or leg ulcer $^{\star}$ or stasis ulcer $^{\star}$ or crural ulcer ${ }^{\star}$ or ulcus cruris or ulcer cruris or foot ulcer $\left.{ }^{\star}\right): t i, a b, \mathrm{kw}^{2}$ $\# 3$ or \#1-\#2\}

\#4 MeSH descriptor: [Protease Inhibitors] explode all trees \#5 MeSH descriptor: [Peptide Hydrolases] explode all trees

\#6 proteas $^{\star}$ or proteinas ${ }^{\star}$ or metalloproteas ${ }^{\star}$ or metalloproteinas ${ }^{\star}$ or $\mathrm{mmp}$ or timp or gelatinase* or collagenase ${ }^{\star}$ or stromelysin* or metalloelastase ${ }^{\star}$ or matrilysin ${ }^{\star}$ or enamelysin ${ }^{\star}$ or epilysin* or endometase* or hne):ti,ab,kw

\#7 (neutrophil elastase ${ }^{\star}$ or cathepsin* or urokinase type plasminogen activator ${ }^{\star}$ or upa or enzyme* activit* or proteolytic* or

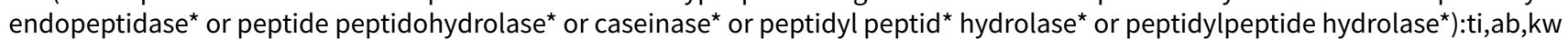

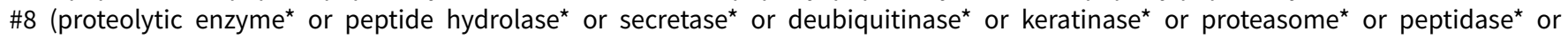
complestatin ${ }^{\star}$ or ecarin ${ }^{\star}$ or rupintrivir ${ }^{\star}$ or Acrosin ${ }^{\star}$ or Aminopeptidase or Ancrod $^{\star}$ or Anistreplase $): t i, a b, k w$ \#9 (Antigen* and CD13):ti,ab,kw

\#10 (Ataxin 3 or Batroxobin* or Botulinum Toxin* or Brinolase* or Bromelain* or Calpain^ or Carboxypeptidase* or Caspase* or Chymase* or Chymopapain* or Chymosin* or Chymotrypsin* or Coagulase* or Complement Factor* or Dipeptidase*):ti,ab,kw

\#11 (Dipeptidyl-Peptidase* or Enteropeptidase* or Esteroprotease* or Exopeptidase* or Factor IXa or Factor VIla or Factor Xa or Factor Xia or Factor XIla or Fibrinolysin* or Ficain* or Furin* or gamma-Glutamyl Hydrolase* or Granzyme* or Insulysin ${ }^{\star}$ :ti,ab,kw

\#12 (Kallikrein* or Lactoferrin* or Lysostaphin* or Metalloexopeptidase* or Myeloblastin* or Neprilysin* or Papain* or Pepsin A or Plasminogen Activator ${ }^{\star}$ or Prekallikrein ${ }^{\star}$ or Pronase ${ }^{\star}$ or Proprotein Convertase ${ }^{\star}$ or Renin ${ }^{\star}$ or Separase ${ }^{\star}$ or Streptodornase* or Streptokinase ${ }^{\star}$ or Subtilisin ${ }^{\star}$ or Thermolysin ${ }^{\star}$ or Thrombin ${ }^{\star}$ or Trypsin ${ }^{\star}$ or Tryptases $\left.{ }^{\star}\right): t i, a b, k w$

$\# 13$ \{or \#4-\#12\}

\#14 \#3 and \#13

\section{Ovid MEDLINE}

(1946 to January week 4 2018)

1 exp Leg Ulcer/ (21282)

2 (varicose ulcer ${ }^{\star}$ or venous ulcer ${ }^{\star}$ or leg ulcer ${ }^{\star}$ or stasis ulcer ${ }^{\star}$ or crural ulcer $^{\star}$ or ulcus cruris or ulcer cruris or foot ulcer $\left.{ }^{\star}\right)$.tw. (13385)

31 or 2 (24989)

4 exp Peptide Hydrolases/ (557476)

5 exp Protease Inhibitors/ (207571)

6 (proteas* or proteinas*).tw. (213317)

7 metalloproteas ${ }^{\star}$. tw. $(10342)$

8 metalloproteinas*.tw. (59177)

9 mmp.tw. (47220)

10 timp.tw. (11539)

11 gelatinase ${ }^{\star} . t w .(8630)$

12 collagenase ${ }^{\star}$. tw. (21223)

13 stromelysin $^{\star}$.tw. (2216)

14 metalloelastase ${ }^{\star} . t w$. (235)

15 matrilysin*.tw. (634)

16 enamelysin*.tw. (129)

17 epilysin ${ }^{\star} . t w$. (30)

18 endometase ${ }^{\star}$. tw. (20)

19 hne.tw. (3945)

20 neutrophil elastase ${ }^{\star} . t w$. (4194)

21 cathepsin $^{\star}$. tw. (21302)

22 urokinase-type plasminogen activator ${ }^{\star}$.tw. (4923)

23 upa.tw. (5755)

24 enzyme ${ }^{\star}$ activit*.tw. (105506)

25 proteolytic ${ }^{\star}$. tw. $(73550)$

26 endopeptidase*.tw. (8884)

27 peptide peptidohydrolase ${ }^{\star}$. tw. (5)

28 caseinase $^{\star}$.tw. (180)

29 peptidyl peptid ${ }^{\star}$ hydrolase ${ }^{\star} . t w .(6)$

30 peptidylpeptide hydrolase*.tw. (2)

31 proteolytic enzyme*.tw. (11483)

Protease activity as a prognostic factor for wound healing in venous leg ulcers (Review)

Copyright (c) 2018 The Cochrane Collaboration. Published by John Wiley \& Sons, Ltd. 
32 peptide hydrolase*.tw. (385)

33 secretase*.tw. (7993)

34 deubiquitinase*.tw. (1176)

35 keratinase $^{\star}$.tw. (331)

36 proteasome ${ }^{\star}$.tw. (34437)

37 peptidase ${ }^{\star} . t w$. (19353)

38 complestatin $^{\star}$. tw. (39)

39 ecarin ${ }^{\star} . t w .(286)$

40 rupintrivir ${ }^{\star} . t w$. (32)

41 Acrosin $^{\star} . t w . ~(916)$

42 Aminopeptidase ${ }^{\star}$.tw. (11845)

43 Ancrod*.tw. (395) $^{*}$

44 Anistreplase*.tw. (198)

45 (Antigen* adj2 CD13).tw. (228)

46 Ataxin-3.tw. (551)

47 Batroxobin*.tw. (279)

48 Botulinum Toxin ${ }^{\star}$. tw. (11872)

49 Brinolase $^{\star}$. tw. (13)

50 Bromelain*.tw. (1336)

51 Calpain*.tw. (9151)

52 Carboxypeptidase ${ }^{\star}$.tw. (8311)

53 Caspase $^{\star}$.tw. (92315)

54 Chymase $^{\star}$. tw. (1980)

55 Chymopapain*.tw. (747)

56 Chymosin*.tw. (514)

57 Chymotrypsin*.tw. (18311)

58 Coagulase ${ }^{\star}$. tw. (11196)

59 Complement Factor ${ }^{\star}$. tw. (4054)

60 Dipeptidase*.tw. (1383)

61 Dipeptidyl-Peptidase*.tw. (6459)

62 Enteropeptidase*.tw. (183)

63 Esteroprotease ${ }^{\star} . t w$. (58)

64 Exopeptidase $^{\star}$.tw. (787)

65 Factor IXa.tw. (730)

66 Factor VIla.tw. (3228)

67 Factor Xa.tw. (7194)

68 Factor Xla.tw. (487)

69 Factor XIla.tw. (525)

70 Fibrinolysin ${ }^{\star}$.tw. (677)

71 Ficain*.tw. (2)

72 Furin*.tw. (2730)

73 gamma-Glutamyl Hydrolase*.tw. (193)

74 Granzyme*.tw. (5802)

75 Insulysin*.tw. (57)

76 Kallikrein ${ }^{\star} . t w .(10812)$

77 Lactoferrin $^{\star}$. tw. (7648)

78 Lysostaphin ${ }^{\star}$. tw. (593)

79 Metalloexopeptidase ${ }^{\star}$.tw. (24)

80 Myeloblastin ${ }^{\star} . t w$. (53)

81 Neprilysin*.tw. (1249)

82 Papain ${ }^{\star} . t w . ~(8656)$

83 Pepsin A.tw. (208)

84 Plasminogen Activator ${ }^{\star}$.tw. (38347)

85 Prekallikrein ${ }^{\star}$.tw. (1609)

86 Pronase $^{\star}$.tw. (5608)

87 Proprotein Convertase ${ }^{\star}$.tw. (2387)

88 Renin $^{\star}$. tw. (53044)

89 Separase $^{\star}$.tw. (450)

90 Streptodornase ${ }^{\star} . t w .(567)$

91 Streptokinase ${ }^{\star} . t w$. (7558)

92 Subtilisin*.tw. (5888)

93 Thermolysin*.tw. (2353)

Protease activity as a prognostic factor for wound healing in venous leg ulcers (Review)

Copyright $\odot 2018$ The Cochrane Collaboration. Published by John Wiley \& Sons, Ltd. 
94 Thrombin*.tw. (47618)

95 Trypsin $^{\star}$.tw. (61663)

96 Tryptases $^{\star}$.tw. (218)

97 or/4-96 (1067636)

983 and 97 (736)

99 exp animals/ not humans.sh. (4861175)

10098 not 99 (718)

\section{Ovid Embase}

(1974 to 2018 February (week 6))

1 leg ulcer/ or foot ulcer/ or leg varicosis/ (20352)

2 (varicose ulcer* ${ }^{*}$ r venous ulcer* or leg ulcer ${ }^{\star}$ or stasis ulcer ${ }^{*}$ or crural ulcer ${ }^{\star}$ or ulcus cruris or ulcer cruris

or foot ulcer $\left.{ }^{\star}\right)$.tw. (15795)

31 or 2 (25225)

4 exp Proteinase/ (669495)

5 exp Proteinase Inhibitor/ (311383)

6 (proteas* or proteinas $\left.{ }^{\star}\right)$.tw. $(213747)$

7 metalloproteas ${ }^{\star}$. tw. (10676)

8 metalloproteinas*.tw. (63056)

9 mmp.tw. (55120)

10 timp.tw. (13502)

11 gelatinase ${ }^{\star}$. tw. (9437)

12 collagenase*.tw. (22992)

13 stromelysin*.tw. (2117)

14 metalloelastase ${ }^{\star}$. tw. (229)

15 matrilysin*.tw. (588)

16 enamelysin ${ }^{*}$.tw. (86)

17 epilysin ${ }^{\star} . t w .(29)$

18 endometase ${ }^{\star} . t w .(19)$

19 hne.tw. (4272)

20 neutrophil elastase ${ }^{\star}$. tw. (4834)

21 cathepsin $^{\star}$. tw. (21650)

22 urokinase-type plasminogen activator ${ }^{\star}$.tw. (4993)

23 upa.tw. (6460)

24 enzyme $^{\star}$ activit*.tw. (105378)

25 proteolytic $^{\star}$. tw. (69113)

26 endopeptidase ${ }^{\star}$. tw. (8538)

27 peptide peptidohydrolase ${ }^{\star} . t w$. (1)

28 caseinase*.tw. (194)

29 peptidyl peptid ${ }^{\star}$ hydrolase ${ }^{\star} . t w . ~(7)$

30 peptidylpeptide hydrolase ${ }^{\star}$. tw. (3)

31 proteolytic enzyme*.tw. (11539)

32 peptide hydrolase ${ }^{\star}$.tw. (333)

33 secretase $^{\star}$.tw. (8796)

34 deubiquitinase ${ }^{\star}$. tw. (1058)

35 keratinase ${ }^{\star}$. tw. (413)

36 proteasome ${ }^{\star}$.tw. (34829)

37 peptidase*.tw. (19823)

38 complestatin ${ }^{\star} . t w$. (42)

39 ecarin $^{\star}$.tw. (421)

40 rupintrivir*.tw. (36)

41 Acrosin $^{\star}$. tw. (954)

42 Aminopeptidase*.tw. (11341)

43 Ancrod $^{\star}$. tw. (443)

44 Anistreplase ${ }^{\star}$. tw. (216)

45 (Antigen ${ }^{\star}$ adj2 CD13).tw. (246)

46 Ataxin-3.tw. (498)

47 Batroxobin $^{\star} . t w .(345)$

48 Botulinum Toxin ${ }^{\star}$. tw. (15575)

49 Brinolase*.tw. (14)

50 Bromelain*.tw. (1401)

Protease activity as a prognostic factor for wound healing in venous leg ulcers (Review)

Copyright $\odot 2018$ The Cochrane Collaboration. Published by John Wiley \& Sons, Ltd. 
51 Calpain*.tw. (9068)

52 Carboxypeptidase ${ }^{\star}$.tw. (7525)

53 Caspase $^{\star} . t w$. (103048)

54 Chymase*.tw. (2100)

55 Chymopapain*.tw. (732)

56 Chymosin $^{\star}$. tw. (507)

57 Chymotrypsin*.tw. (16352)

58 Coagulase ${ }^{\star}$.tw. (13204)

59 Complement Factor*.tw. (4515)

60 Dipeptidase*.tw. (1247)

61 Dipeptidyl-Peptidase ${ }^{\star} . t w . ~(7601)$

62 Enteropeptidase*.tw. (196)

63 Esteroprotease ${ }^{\star} . t w$. (56)

64 Exopeptidase $^{\star} . t w$. (752)

65 Factor IXa.tw. (704)

66 Factor VIla.tw. (3922)

67 Factor Xa.tw. (8476)

68 Factor XIa.tw. (486)

69 Factor XIla.tw. (515)

70 Fibrinolysin ${ }^{\star} . t w .(481)$

71 Ficain ${ }^{*}$.tw. (2)

72 Furin*.tw. (2584)

73 gamma-Glutamyl Hydrolase*.tw. (195)

74 Granzyme*.tw. (7374)

75 Insulysin*.tw. (40)

76 Kallikrein*.tw. (10846)

77 Lactoferrin ${ }^{\star}$. tw. (7803)

78 Lysostaphin*.tw. (565)

79 Metalloexopeptidase ${ }^{\star}$.tw. (21)

80 Myeloblastin*.tw. (61)

81 Neprilysin ${ }^{\star} . t w$. (1442)

82 Papain*.tw. (8141)

83 Pepsin A.tw. (201)

84 Plasminogen Activator ${ }^{\star}$.tw. (41285)

85 Prekallikrein ${ }^{\star}$.tw. (1643)

86 Pronase $^{\star}$.tw. (5204)

87 Proprotein Convertase ${ }^{\star}$.tw. (2469)

88 Renin $^{\star}$. tw. (59567)

89 Separase*.tw. (423)

90 Streptodornase $^{\star}$. tw. (482)

91 Streptokinase*.tw. (8008)

92 Subtilisin*.tw. (5678)

93 Thermolysin $^{\star}$.tw. (2079)

94 Thrombin*.tw. (55364)

95 Trypsin $^{\star}$. tw. (59501)

96 Tryptases $^{\star}$.tw. (211)

97 or/4-96 (1190187)

983 and 97 (1209)

99 exp animals/ or exp invertebrate/ or animal experiment/ or animal model/ or animal tissue/ or animal cell/ or nonhuman/ (24411894)

100 human/ or human cell/ (18421186)

10199 and 100 (18374370)

10299 not $101(6037524)$

10398 not $102(1166)$

\section{EBSCO CINAHL Plus}

(Inception to February 2018)

\section{S1 (MH "Leg Ulcer+")}

S2 TI ( (varicose ulcer* or venous ulcer ${ }^{\star}$ or leg ulcer* or stasis ulcer* or crural ulcer* or ulcus cruris or ulcer cruris or foot ulcer ${ }^{\star}$ ) ) OR AB

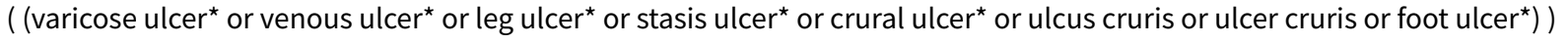

Protease activity as a prognostic factor for wound healing in venous leg ulcers (Review) 
S3 S1 OR S2

S4 (MH "Protease Inhibitors+") OR (MH "Peptide Hydrolases+")

S5 TI ( (proteas ${ }^{\star}$ or proteinas $\left.{ }^{\star}\right)$ ) OR AB ( (proteas ${ }^{\star}$ or proteinas $\left.{ }^{\star}\right)$ )

S6 TI ((metalloproteas* or metalloproteinas $\left.\left.{ }^{\star}\right)\right)$ OR AB ((metalloproteas ${ }^{\star}$ or metalloproteinas $\left.\left.{ }^{\star}\right)\right)$

S7 TI ((mmp or timp)) OR AB ((mmp or timp))

S8 TI ((gelatinase* OR collagenase* OR stromelysin* OR metalloelastase* OR matrilysin*)) OR AB ((gelatinase* OR collagenase ${ }^{\star}$ OR stromelysin* OR metalloelastase* OR matrilysin $\left.{ }^{\star}\right)$ )

S9 TI ((enamelysin* OR epilysin* OR endometase* OR hne OR neutrophil elastase* OR cathepsin*)) OR AB ((enamelysin* OR epilysin* OR endometase* OR hne OR neutrophil elastase* OR cathepsin*))

S10 TI ((urokinase type plasminogen activator* or upa or enzyme ${ }^{\star}$ activit* or proteolytic ${ }^{\star}$ or endopeptidase*)) OR AB ((urokinase type plasminogen activator ${ }^{\star}$ or upa or enzyme ${ }^{\star}$ activit $^{\star}$ or proteolytic* or endopeptidase $\left.{ }^{\star}\right)$ )

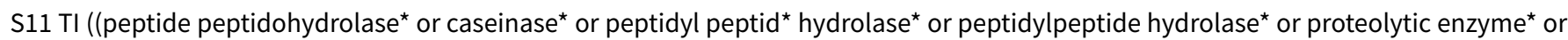

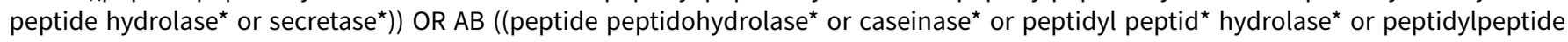
hydrolase ${ }^{\star}$ or proteolytic enzyme ${ }^{\star}$ or peptide hydrolase ${ }^{\star}$ or secretase $\left.{ }^{\star}\right)$ )

S12 $\mathrm{TI}$ ((deubiquitinase* or keratinase* or proteasome* or signal peptidase* or complestatin* or ecarin* or rupintrivir $\left.{ }^{\star}\right)$ ) OR $\mathrm{AB}^{\star}$ ((deubiquitinase ${ }^{\star}$ or keratinase* or proteasome ${ }^{\star}$ or signal peptidase* or complestatin* or ecarin* or rupintrivir $\left.^{\star}\right)$ )

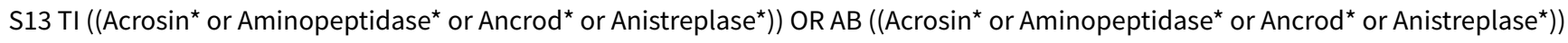

S14 TI (Antigen* and CD13) OR AB (Antigen* and CD13)

S15 TI ((Ataxin 3 or Batroxobin* or Botulinum Toxin* or Brinolase* or Bromelain ${ }^{\star}$ or Calpain* or Carboxypeptidase* or Caspase $\left.{ }^{\star}\right)$ ) OR AB

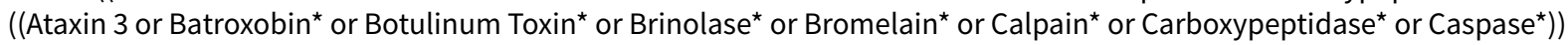

S16 TI ((Chymase* or Chymopapain* or Chymosin* or Chymotrypsin* or Coagulase* or Complement Factor ${ }^{\star}$ or Dipeptidase* or Dipeptidyl Peptidase $\left.{ }^{\star}\right)$ OR AB ((Chymase* or Chymopapain* or Chymosin ${ }^{\star}$ or Chymotrypsin* or Coagulase* or Complement Factor ${ }^{\star}$ or Dipeptidase* or Dipeptidyl Peptidase*))

S17 TI ((Enteropeptidase ${ }^{\star}$ or Esteroprotease* or Exopeptidase* or Factor IXa or Factor VIla or Factor Xa or Factor Xia or Factor XIla or Fibrinolysin $\left.{ }^{\star}\right)$ ) OR AB ((Enteropeptidase* or Esteroprotease* or Exopeptidase* or Factor IXa or Factor VIla or Factor Xa or Factor Xia or Factor XIla or Fibrinolysin $\left.{ }^{\star}\right)$ )

S18 TI ((Ficain* or Furin^ or gamma Glutamyl Hydrolase* or Granzyme* or Insulysin* or Kallikrein* or Lactoferrin* or Lysostaphin* or Metalloexopeptidase or Myeloblastin $\left.^{\star}\right)$ ) OR AB ((Ficain* or Furin* or gamma Glutamyl Hydrolase* or Granzyme* or Insulysin* or Kallikrein* or Lactoferrin* or Lysostaphin* or Metalloexopeptidase* or Myeloblastin*))

S19 TI ((Neprilysin* or Papain* or Pepsin A or Plasminogen Activator* or Prekallikrein* or Pronase* or Proprotein Convertase $\left.{ }^{\star}\right)$ ) OR AB ((Neprilysin ${ }^{\star}$ or Papain* or Pepsin A or Plasminogen Activator ${ }^{\star}$ or Prekallikrein* or Pronase* or Proprotein Convertase $\left.{ }^{\star}\right)$ )

S20 TI ((Renin* or Separase* or Streptodornase* or Streptokinase* or Subtilisin* or Thermolysin* or Thrombin* or Trypsin* or Tryptases $\left.\left.{ }^{\star}\right)\right)$ OR AB ((Renin* or Separase* or Streptodornase* or Streptokinase ${ }^{\star}$ or Subtilisin* or Thermolysin ${ }^{\star}$ or Thrombin* or Trypsin* or Tryptases $\left.{ }^{\star}\right)$ )

S21 (S4 OR S5 OR S6 OR S7 OR S8 OR S9 OR S10 OR S11 OR S12 OR S13 OR S14 OR S15 OR S16 OR S17 OR S18 OR S19 OR S20) S22 S3 and S21

\section{Appendix 2. Quality In Prognosis Studies (QUIPS): risk of bias assessment, modified for this review}

We assessed risk of bias for each study for each prognostic factor-outcome combination, considering each of six domains.

\section{Domain 1. Study participation}

This domain assessed whether the study sample was representative of the population of interest (source population).

\section{Low risk of bias}

The relationship between the prognostic factor and the outcome was unlikely to be different for participating individuals and eligible nonparticipating individuals. We made an assignment of low risk of bias if all the following requirements were met: 
- the study sample was consecutively or randomly recruited from the target population or, for case-control studies, the cases and controls were from similar populations;

- participants were representative of the review population of interest:

- people with venous leg ulcers;

- study follow-up was adequate for healing to occur and reverse association to be avoided; a minimum of two months' follow-up;

- participants were not different from eligible non-participants in terms of the key prognostic factors (Appendix 3);

○ the participation rate was high; review authors' judgement.

\section{High risk of bias}

The relationship between the prognostic factor and the outcome was very likely to be different for participating individuals and eligible non-participating individuals. We noted that prognostic studies based on data from randomised trial evidence would often have selected participants and we considered the RCT inclusion criteria, as appropriate (lorio 2015). We made an assignment of high risk of bias if any of the following statements applied and we considered there was a likely high risk of bias as a consequence:

- the sample was selectively recruited. For case-control studies, cases and controls were not from similar source populations;

- participants were not representative of the review population of interest:

- participants had very different characteristics from eligible non-participants in terms of the key prognostic factors;

- study follow-up was inadequate for events to occur or reverse association was possible (less than two months) (or both);

- the participation rate was low.

\section{Moderate risk of bias}

The relationship between the prognostic factor and the outcome may have been different for participating individuals and eligible nonparticipating individuals, but there was insufficient information to make a judgement of low or high risk of bias, or we were uncertain whether the quality issue was likely to lead to high risk of bias.

\section{Domain 2. Study attrition}

The study attrition domain addressed whether participants completing the study (i.e. with follow-up data) represented the baseline sample.

\section{Low risk of bias}

The relationship between the prognostic factor and the outcome was unlikely to be different for completing and non-completing participants. We made an assignment of low risk of bias if any one of the following was true:

- no missing outcome data or adequate response rate;

- reasons for missing outcome data were unlikely to be related to true outcome (for survival data, censoring was unlikely to be introducing bias), e.g. missing at random;

- missing outcome data were balanced in numbers across categorical prognostic groups, with similar reasons for missing data across groups in terms of the key prognostic factors;

- missing data were imputed using appropriate methods.

\section{High risk of bias}

The relationship between the prognostic factor and the outcome was very likely to be different for completing and non-completing participants. We made an assignment of high risk of bias if any of the following statements applies and we considered there was a likely high risk of bias as a consequence:

- reasons for missing data were likely to be related to the true outcome or the prognostic factor, with either imbalance in numbers or reasons for missing data across categorical prognostic groups in terms of the key prognostic factors;

- high levels of missing data;

- potentially inappropriate application of simple imputation.

\section{Moderate risk of bias}

The relationship between the prognostic factor and the outcome may have been different for completing and non-completing participants, but there was insufficient information to make a judgement of low or high risk of bias, or we were uncertain whether the quality issue was likely to lead to high risk of bias.

\section{Domain 3. Prognostic factor measurement}

The prognostic factor measurement domain addressed adequacy of measurement of the prognostic factor of interest. 


\section{Low risk of bias}

The measurement of the prognostic factor was unlikely to be different for different outcome levels (i.e. healed or not healed). We made an assignment of low risk of bias if all the following requirements were met:

- a clear definition or description of the prognostic factor was given;

- the prognostic factor was measured similarly for all participants (same method and setting);

- a valid and reliable measure was used;

- continuous variables were used or appropriate cut-off points were applied;

- an adequate proportion of the sample had complete data for the prognostic factor;

- appropriate imputation of missing values was done.

\section{High risk of bias}

The measurement of the prognostic factor was very likely to be different for different outcome levels (i.e. healed or not healed). We made an assignment of high risk of bias if any of the following statements applied and we considered there was a likely high risk of bias as a consequence:

- an unreliable or non-validated method was used to measure the prognostic factor (non-differential misclassification bias);

- different approaches to prognostic factor measurement were taken for participants with different outcomes;

- details about the prognostic factor were based on recall or potentially unreliable participant records (reporting bias);

- inappropriate cut-off points were used;

- the proportion of the sample with complete data for the prognostic factor was inadequate.

\section{Moderate risk of bias}

The measurement of the prognostic factor may have been different for different outcome levels (e.g. healed or not healed) or for different risks of the outcome, but there was insufficient information to make a judgement of low or high risk of bias, or we were uncertain whether the quality issue was likely to lead to high risk of bias.

\section{Domain 4. Outcome measurement}

The outcome measurement domain addressed the adequacy of outcome measurement.

\section{Low risk of bias}

The measurement of the outcome was unlikely to be different with respect to different baseline levels of the prognostic factor. We made an assignment of low risk of bias if all the following requirements were met:

- a clear definition or description of the outcome was given (including duration of follow-up);

- the outcome of interest was measured similarly for all participants (same method and setting);

- a valid and reliable outcome measure was used (including blinding and avoidance of recall methods).

\section{High risk of bias}

The measurement of the outcome was very likely to be different with respect to different baseline levels of the prognostic factor. We made an assignment of high risk of bias if any of the following statements applied and we considered there was a likely high risk of bias as a consequence:

- different methods were used for participants with different values of the prognostic factor;

- measurement of the outcome was not blinded;

- an unreliable or non-validated outcome measure was used;

- the outcome measure relied on participant/carer recall;

- measurement error varied according to the prognostic factor level.

\section{Moderate risk of bias}

The measurement of the outcome may have been different for different baseline levels of the prognostic factor, but there was insufficient information to make a judgement of low or high risk of bias, or we were uncertain whether the quality issue was likely to lead to high risk of bias. 


\section{Domain 5. Adjustment}

The adjustment domain addressed potential factors that may have distorted the relationship between prognostic factor and outcome. Considerations in this domain helped the assessor judge whether another factor may have explained the study's reported association (see Appendix 3).

Our literature review provided little evidence to enable us to define key adjustment factors, but in this domain, we considered whether the included studies took into account age and infection (Appendix 3). We reported and compared adjusting factors used across the studies. We also examined whether there were differences between adjusted and unadjusted analyses.

\section{Low risk of bias}

Important key adjustment factors were appropriately accounted for. We made an assignment of low risk of bias if all the following requirements were met:

- key adjustment factors were taken into account in the study design (e.g. matching, stratification) or in the analysis (e.g. multivariable regression) or adjusted and unadjusted analyses were compared and differences identified;

- key adjustment factors were measured adequately;

- measurement of all key adjustment factors was valid and reliable (including blinding);

- methods and settings for measurement of adjustment factors were the same for all participants;

- appropriate imputation methods were used;

- account was taken of treatments in the analysis if appropriate.

\section{High risk of bias}

The observed effect of the prognostic factor on the outcome was very likely to be distorted by another factor related to the prognostic factor and the outcome. We made an assignment of high risk of bias if any of the following statements applied and we considered there was a likely high risk of bias as a consequence:

- key adjustment factors were not taken into account in either the design or in the analysis;

- key adjustment factors were not measured adequately;

- methods or settings for the measurement of adjustment factors were different for different prognostic factor levels or different outcome levels;

- interventions were different for different prognostic factor levels or different outcome levels.

\section{Moderate risk of bias}

The observed effect of the prognostic factor on the outcome may have been distorted by another factor related to the prognostic factor and the outcome, but there was insufficient information to make a judgement of low or high risk of bias, or we were uncertain whether the quality issue was likely to lead to high risk of bias. Alternatively, key adjustment factors considered in the design or analysis were unclear or the analytical procedure was poorly reported.

\section{Domain 6. Statistical analysis and reporting}

The statistical analysis and reporting domain addressed the appropriateness of the study's statistical analysis and completeness of reporting. If there were unit of analysis issues, these should have been analysed appropriately.

The analytical approach and the results should have been reported fully, regardless of their findings or level of significance.

\section{Low risk of bias}

The reported results were unlikely to be biased, either in relation to the analysis or the reporting of results. We made an assignment of low risk of bias if all the following requirements were met:

- there was sufficient presentation of data to assess the adequacy of the analysis;

- the strategy for model building (i.e. inclusion of variables in the statistical model) was appropriate; in practice, this item was not required if an adequately designed and reported phase I study was used;

- the selected statistical model was adequate for the design of the study (e.g. a confirmatory study was correctly analysed, and unit of analysis issues were considered appropriately);

- there was no selective reporting of results.

\section{High risk of bias}

The reported results were very likely to be biased, either related to the analysis or the reporting of results. We made an assignment of high risk of bias if any of the following statements applied and we considered there was a likely high risk of bias as a consequence: 
- there was insufficient detail to assess the adequacy of the analysis approach;

- the selected statistical model was inadequate;

- the analysis approach was inadequate (e.g. in selecting variables for a multivariable analysis or in including mediators in a regression analysis or ignoring important intervention effects);

- results were reported selectively, either on the basis of the findings or statistical significance.

\section{Moderate risk of bias}

The reported results may have been biased, either related to the analysis or the reporting of results, but there was insufficient information to decide.

\section{All-domain risk of bias}

We defined an all-domain risk of bias for each prognostic factor-outcome combination, taking into account all the above domains, but especially focusing on selection bias, study attrition, adjustment, and statistical analysis and reporting. As a guide, we assigned risk of bias as follows: low risk of bias, if all (or all key) domains had low risk of bias; moderate risk of bias, if there was high risk of bias for one key domain or moderate risk of bias for at least two key domains (with the rest as low risk of bias); or high risk of bias, if there was high risk of bias for at least two key domains.

\section{Appendix 3. Key prognostic factors and key adjustment factors for venous leg ulcer healing}

To assess the reliability of reported associations of biomarkers with healing, we needed to know whether confounding factors were taken into account in the analyses of the included studies, and this required us to identify key confounding factors. We identified no evidence on key confounders and did not find reviews of independent prognostic factors for healing VLUs. Therefore, we surveyed the literature for prognostic factor studies that used multivariable analyses, identified likely key prognostic factors and then investigated whether these factors were likely to be associated with the biomarkers, thus determining the key confounding factors.

\section{Prognostic factors}

We identified 13 cohort studies that examined prognostic factors for venous leg ulcer (VLU) healing at 24 or 52 weeks' follow-up and reported results of multivariable analyses (Ashby 2014; Barwell 2000; Barwell 2001; Chaby 2013; Gohel 2005; Harrison 2011; Iglesias 2004; Lantis 2013; Margolis 1999; Margolis 2004; Milic 2009; Moffatt 2010; Scotton 2014). Other than multivariable analysis and the study design, we did not assess the study quality. The prognostic factors investigated were:

- participant characteristics: age (five studies), gender (six studies), weight/BMI (two studies), ethnicity (one study);

- comorbidities: angina (one study), myocardial infarction (one study), hypertension (one study), cerebrovascular accident (one study), deep vein thrombosis (three studies), diabetes mellitus (two studies), thyroid disease (one study), rheumatoid arthritis (one study);

- mobility: mobility (three studies), ankle flexion (three studies), hip/knee replacement surgery (one study);

- ulcer characteristics: wound duration (six studies), wound area (seven studies), depth of VLU (one study), grade of VLU (one study), number of ulcers (two studies), number of previous ulcer episodes (one study), wound covered with fibrin (two studies), wound covered with eschar (one study), wound debrided surgically (two studies), chronicity (two studies);

- limb characteristics: ankle brachial pressure index (one study), lipodermatosclerosis (one study), calf/ankle circumference ratio (one study), venous ligation/stripping (one study), venous reflux of various types and levels (one study);

- Infection (one study), bacterial bioburden (two studies);

- other: public assistance/self-pay healthcare (one study);

- interventions: two studies.

These results were represented on forest plots to determine trends for prognostic factors with more than two studies or showing dose effects (Figure 8; Figure 9; Figure 10; Figure 11; Figure 12; Figure 13). From these results, we identified likely important prognostic factors and possibly important prognostic factors, by taking into account consistency and dose effects. 
Figure 8. Prognostic factors for healing venous leg ulcers: participant characteristics. $H R=$ hazard ratio; $O R=$ odds ratio

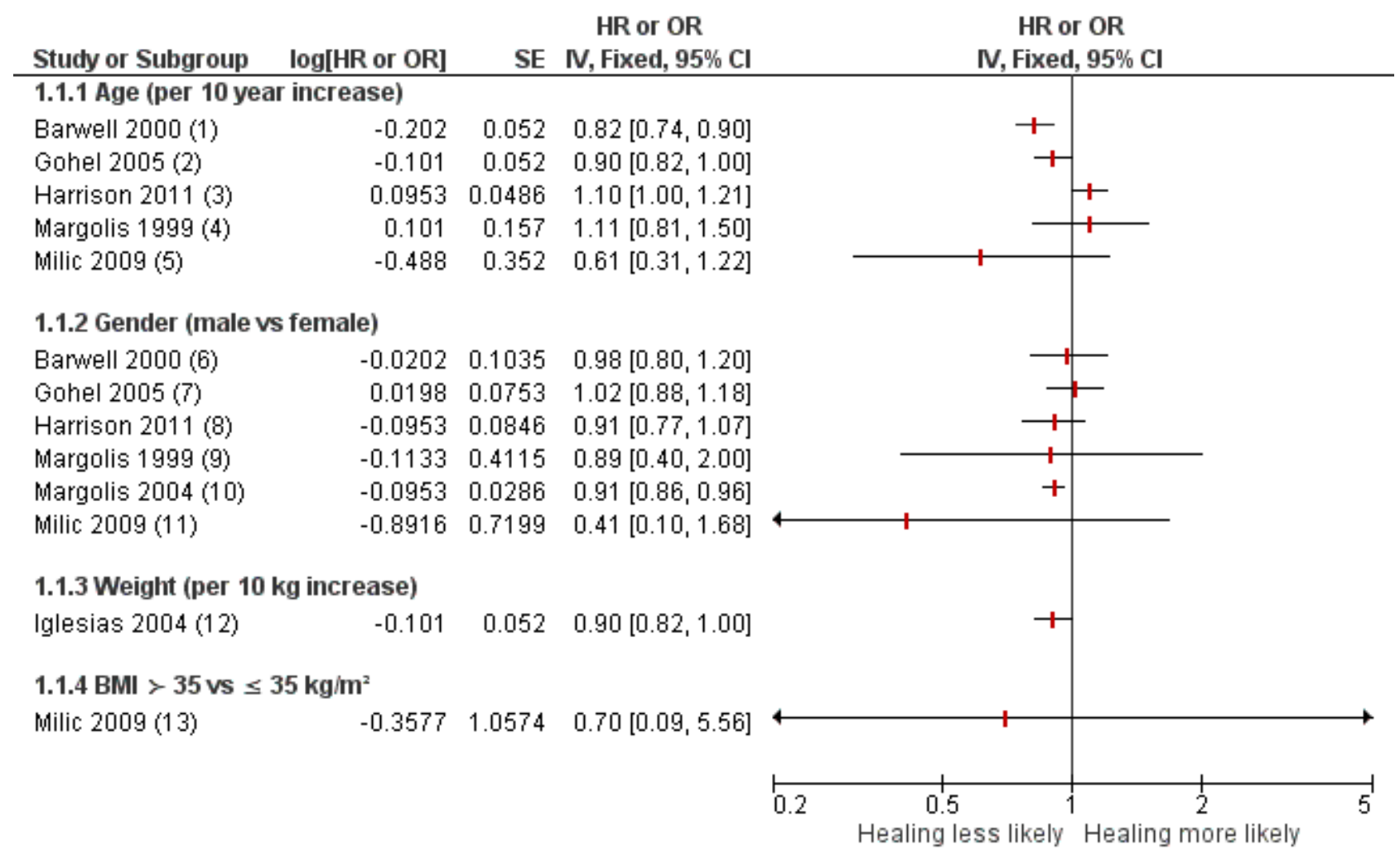

\section{Footnotes}

(1) Hazard ratio (HR); calculated from HR per year

(2) HR; calculated from HR per year

(3) $\mathrm{HR}$

(4) Odds ratio $(O R)$; calculated from OR per year; reversed

(5) 52 weeks; $O R$, reversed results; calculated from $O R$ per year

(6) HR; assumed male vs female

(7) HR

(8) HR

(9) OR; reversed results

(10) OR; reversed results

(11) 52 weeks; OR (female versus male - reversed) and reversed for non-healing

(12) VenUS I; HR: calculated from HR per kg

(13) 52 weeks; OR; reversed results 
Figure 9. Prognostic factors for venous leg ulcer healing: wound characteristics 1. HR = hazard ratio; OR = odds ratio

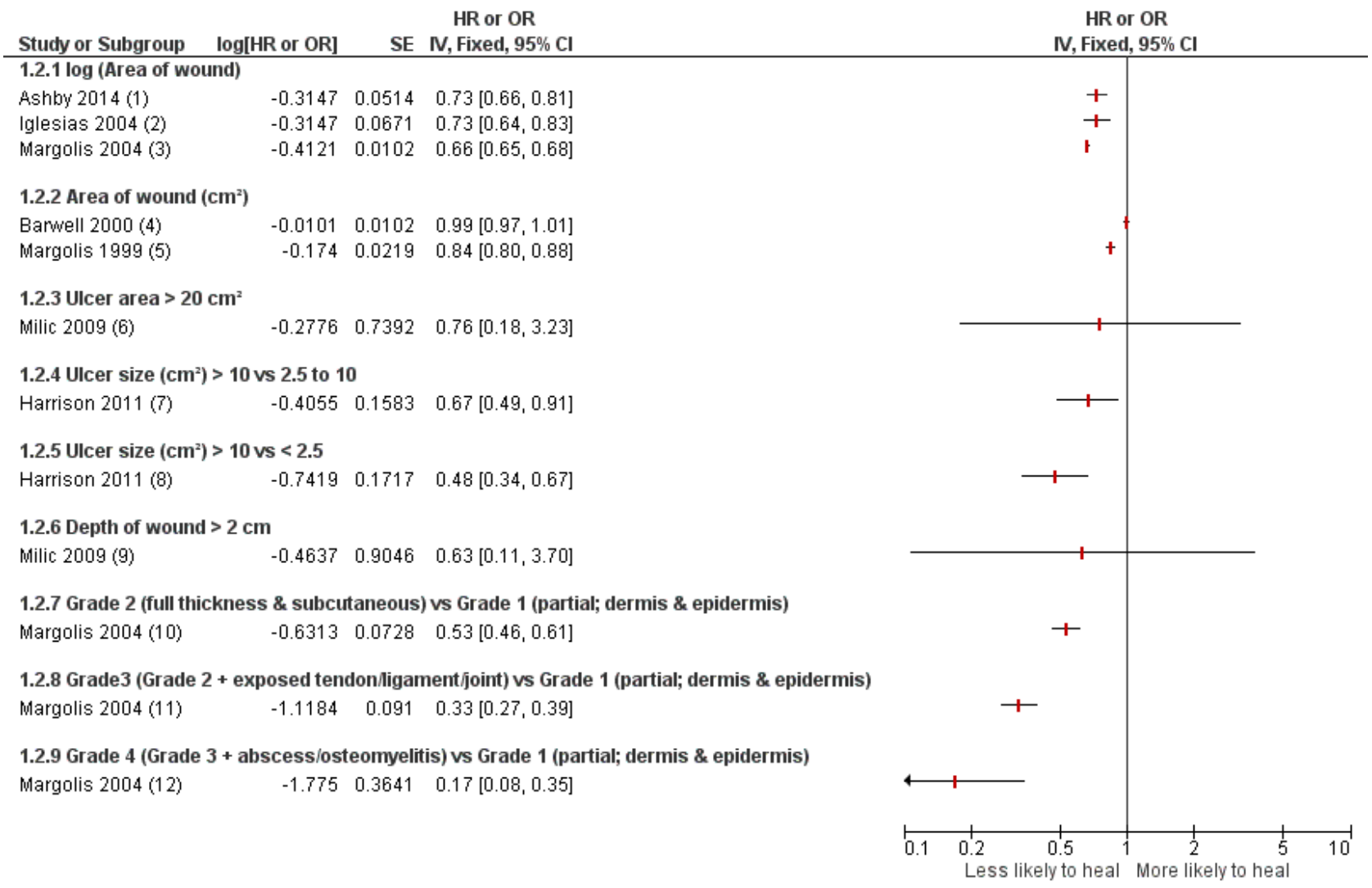

\section{Footnotes}

(1) VenUS IV; hazard ratio (HR)

(2) VenUSI- $\log ($ area of wound at baseline); HR

(3) Odds ratio (OR); $\log \mathrm{mm}^{2}$; reversed results

(4) HR; units unclear

(5) OR; reversed results

(6) 52 weeks; OR; reversed results

(7) HR

(8) $\mathrm{HR}$

(9) 52 weeks; OR; reversed results

(10) OR; reversed results

(11) OR; reversed results

(12) $O R$; reversed results 
Figure 10. Prognostic factors for VLU healing: wound characteristics $2 . H R=$ hazard ratio; $O R=$ odds ratio

\begin{tabular}{lrrr} 
Study or Subgroup & log[HR or OR] & SE & $\begin{array}{c}\text { HR or OR } \\
\text { IV, Fixed, 95\% Cl }\end{array}$ \\
\hline 1.3.1 Duration of ulcer per 6 months & & \\
lglesias 2004 (1) & -0.1212 & 0.0312 & $0.89[0.83,0.94]$ \\
Margolis 1999 (2) & -0.5172 & 0.144 & $0.60[0.45,0.79]$ \\
Margolis 2004 (3) & -0.1188 & 0.03 & $0.89[0.84,0.94]$
\end{tabular}

1.3.2 Duration of ulcer 6-18 months vs $<6$ months

Moffat 2010 (4)

$-0.3857 \quad 0.3105 \quad 0.68[0.37,1.25]$

1.3.3 Duration of ulcer $>18$ months vs $<6$ months

Moffat $2010(5)$

$-1.3093 \quad 0.2069 \quad 0.27[0.18,0.41]$

1.3.4 Log (wound duration)

Ashby 2014 (6)

Margolis $2004(7)$

$\left.\begin{array}{lll}-0.5108 & 0.0633 & 0.60[0.53,0.68\end{array}\right]$

$-0.3221 \quad 0.0112 \quad 0.72[0.71,0.74]$

HR or OR

IV, Fixed, 95\% Cl

1.3.5 Wound duration > 12 months

Milic $2009(8) \quad-0.6523 \quad 0.7754 \quad 0.52[0.11,2.38]$

1.3.7 Ulcer chronicity per 6 months

Bawell $2000(9)$

$\begin{array}{lll}-0.0608 & 0.031 & 0.94[0.89,1.00]\end{array}$

Gohel 2005 (10)

$\left.\begin{array}{lll}-0.024 & 0.009 & 0.98[0.96,0.99\end{array}\right]$

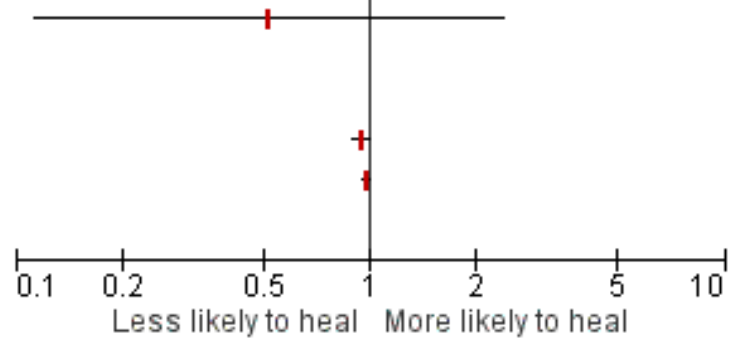

Footnotes

(1) VenUS I; hazard ratio (HR); calculated from HR per month

(2) Odds ratio (OR); reversed results; calculated from OR per month

(3) OR; reversed results; calculated from OR per month

(4) HR; only 43\% VLU (but aetiology not significant factor in MV model)

(5) HR; only $43 \%$ VLU (but aetiology not significant factor in MV model)

(6) VenUS IV; HR

(7) OR; reversed results

(8) 52 weeks; OR; reversed results

(9) HR; calculated from HR per month

(10) HR 
Figure 11. Prognostic factors for VLU healing: number of ulcers

Odds Ratio

Study or Subgroup log[Odds Ratio]

1.4.1 Number of limb ulcers

Margolis 1999 (1)

$-0.174 \quad 0.1963$

SE IV, Fixed, $95 \% \mathrm{Cl}$

1.4.2 Two wounds versus one wound

Margolis 2004 (2)

$-0.3507 \quad 0.0373$

$0.70[0.65,0.76]$

1.4.3 Three wounds versus one wound

Margolis 2004 (3)

$-0.6152 \quad 0.0522 \quad 0.54[0.49,0.60]$

1.4.4 Four wounds versus one wound

Margolis 2004 (4)

$-0.9243 \quad 0.0466$

$0.40[0.36,0.43]$

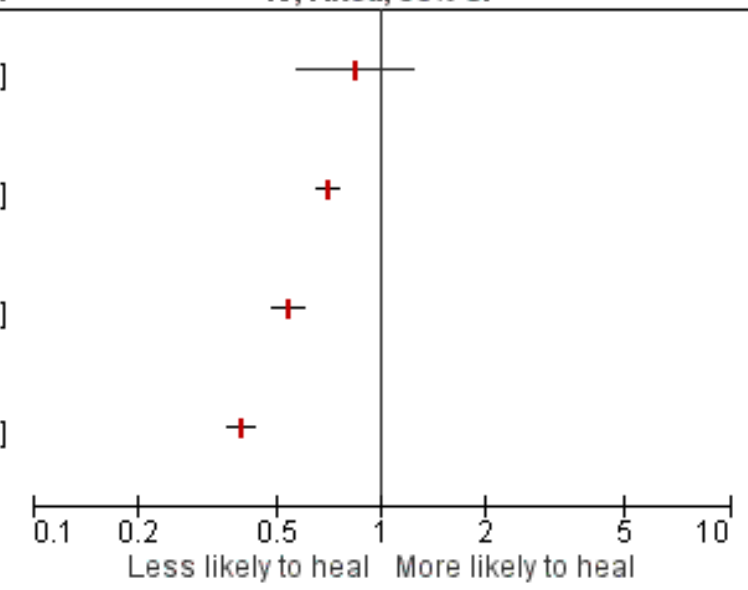

Odds Ratio

IV, Fixed, 95\% Cl

Footnotes

(1) Odds ratio $(O R)$; reversed results

(2) OR; reversed results

(3) $O R$; reversed results

(4) OR; reversed results 
Figure 12. Prognostic factors for venous leg ulcer healing: mobility and ankle flexion. $H R=$ hazard ratio; OR = odds ratio

HR or OR HR or OR

$\begin{array}{llll}\text { Study or Subgroup } & \log [\mathrm{HR} \text { or OR] } & \text { SE } \quad \text { IV, Fixed, 95\% Cl } & \mathrm{N}, \text { Fixed, } 95 \% \mathrm{Cl}\end{array}$

1.5.1 Fixed ankle joint and ROM $<20$ deg

Milic 2009 (1)

$-4.0958 \quad 0.8757 \quad 0.02[0.00,0.09]$

1.5.2 Ankle immobility (impaired vs full mobility)

Iglesias 2004(2) $\quad-0.4187 \quad 0.1423 \quad 0.66[0.50,0.87]$

1.5.3 Lack of ankle motility (< 35 deg motion vs > 35 deg)

Barwell 2001 (3) $\quad-0.077 \quad 0.0242 \quad 0.93[0.88,0.97]$

1.5.4 Unable to walk one block

Margolis $1999(4) \quad-0.4637 \quad 0.4888 \quad 0.63[0.24,1.64]$

1.5.5 Poor mobility score (categorical)

Bawwell $2000(5) \quad-0.0862 \quad 0.0595 \quad 0.92[0.82,1.03]$

1.5.6 Immobility (walks with difficulty vs walks freely)

Ashby $2014(6) \quad-0.1278 \quad 0.1315 \quad 0.88[0.68,1.14]$

1.5.7 Immobility (immobile vs walks freely)

Ashby $2014(7) \quad 0.6678 \quad 0.726 \quad 1.95[0.47,8.09]$

$\longleftarrow$

Footnotes

(1) 52 weeks; odds ratio (OR); reversed

(2) VenUS I (1=full range of motion, 0 = impaired (reduced mobility or fixed)); hazard ratio (HR); reversed for immobility

(3) Ankle motility > 35 deg vs < 35 deg; HR; reversed for motility

(4) OR; reversed results

(5) Score: walks unaided, walks with aid, limited outside home, housebound, chairbound; HR; reversed for mobility

(6) HR

(7) HR 
Figure 13. Prognostic factors for venous leg ulcer healing: bacteria and infection. $H R=$ hazard ratio; $O R=$ odds ratio; $\mathrm{RR}=$ risk ratio

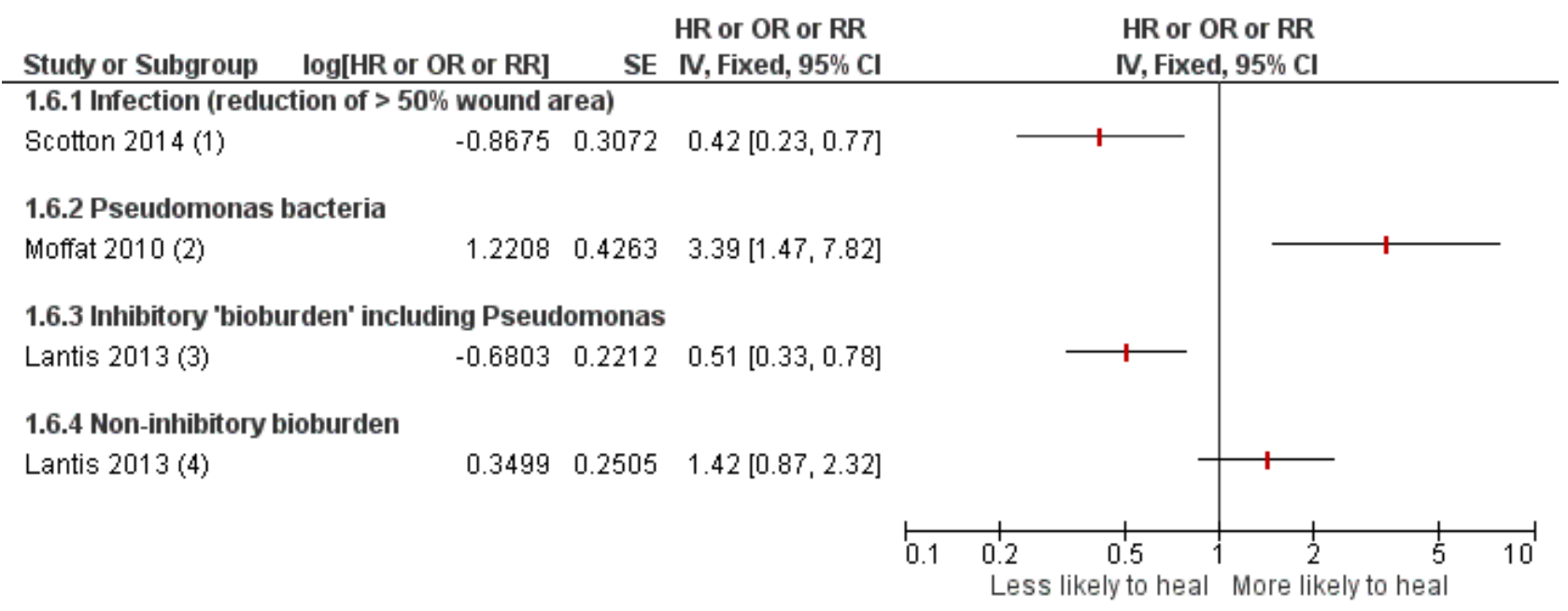

\section{Footnotes}

(1) Outcome: number with $>50 \%$ reduction in area at 6 months; risk ratio (RR)

(2) Hazard ratio (HR); only $43 \%$ VLU (but aetiology not significant factor in MV model)

(3) Odds ratio (OR) (12 weeks follow-up); treatment included in analysis

(4) OR (12 weeks follow-up); treatment included in analysis

- Likely important prognostic factors for healing: smaller wound area (or lower grade or depth of ulcer), shorter duration of ulcer.

- Possible important prognostic factors for healing: younger age, smaller number of wounds, ankle flexion (with individual mobility as a possible surrogate) and lower weight (or BMI).

- The evidence from three studies on the prognostic value of bacterial species in wounds appeared to be contradictory and there may be confounding effects from treatment (Figure 13) (Lantis 2013; Moffatt 2004; Scotton 2014). However, infection itself was likely to be a prognostic factor for a lack of healing/delayed healing.

\section{Key adjustment factors}

To accurately determine the association between a prognostic factor and the outcome, it was important to adjust for key factors that distorted that relationship. Key adjustment factors should be statistically associated with both the outcome and the prognostic factor, and should not lie on a direct pathway between the prognostic factor and the outcome.

We planned to determine key adjustment factors for healing by investigating whether each of the key prognostic factors (KPFs) were associated (in a univariable analysis) with protease activity, on the basis of the evidence, ensuring that the adjustment factor was unlikely to be on the direct pathway. If we identified an association of the KPF with protease activity, we termed the KPF a 'key adjustment factor.' We also discussed possible key adjustment factors with clinicians.

In practice, the evidence was limited. There was some evidence that age could have affected protease activity and may therefore have been a key adjustment factor (Ashcroft 1997). Additionally, we considered infection likely to be a key adjustment factor, but we were unclear regarding the KPFs. We tentatively defined two key adjustment factors a priori (age and infection), but recognised that we may have missed important factors. Therefore, if additional adjustment factors appeared in analyses from several studies, we considered adding these to the set of key factors and reassessing the risk of bias for all the studies.

We reported and compared any adjusting factors used in the studies, and examined whether there were differences between adjusted and unadjusted analyses.

\section{Appendix 4. GRADE for prognostic factors}

Before assessing the GRADE factors for downgrading/upgrading, we assigned an initial GRADE rating as follows (Hayden 2014):

- high for evidence based on phase 2 or phase 3 explanatory/confirmatory studies, i.e. studies aimed at identifying independent associations between prognostic factor and outcome, or those investigating mechanisms;

- moderate for evidence based on phase 1 exploratory studies, i.e. those aimed at investigating all associations, usually in univariable analyses) or other studies reporting univariable associations or having sufficient data to calculate associations. 
Unlike GRADE for intervention studies, we did not initially rate differently the different types of study design (e.g. case-control, retrospective or prospective cohort studies) because we identified quality issues in the risk of bias assessment.

We took into consideration the following GRADE factors, downgrading (or upgrading) the evidence certainty as follows.

\section{Downgrading the evidence certainty}

\section{Risk of bias}

We assigned serious limitations (downgraded once) when most evidence was from studies with moderate all-domain risk of bias. We assigned very serious limitations (downgrade twice) when most evidence was from studies with high all-domain risk of bias.

\section{Indirectness}

Indirectness occurs when any, or all, of the study sample, the prognostic factor and the outcome did not accurately reflect the review question for most of the evidence. We downgraded the evidence certainty accordingly, taking into consideration whether differences were likely to be selection bias or indirectness.

If the evidence was based on RCT data analysed as an observational study, we considered whether the trial's inclusion criteria made the evidence indirect (lorio 2015).

\section{Inconsistency}

The GRADE criteria for judging inconsistency included variability in point estimates, extent of overlap in confidence intervals (Cl), and considering where point estimates lay in relation to decision thresholds. Prognostic studies were often large and so Cls were narrow; this could have meant the overlap was small, leading to large $I^{2}$ statistic values, which could have been misleading (lorio 2015). We will not rely solely on statistical measures of inconsistency, but took these into account alongside assessing variations in effect estimates across studies, considering whether the point estimates lay on either side of the line of no effect, or whether the range of point estimates were consistent with more than one conclusion. We conducted prespecified subgroup analyses if there were sufficient studies before making a judgement on inconsistency (Guyatt 2011b).

\section{Imprecision}

The evidence was considered to be imprecise if we found the following:

- for meta-analysis only:

- there was an insufficient sample size;

- an imprecise estimate of the effect size in the meta-analysis: i.e. the $\mathrm{Cl}$ was wide and overlapped the null and contained values implying that the factor played an important role in protecting or putting the individual at risk;

- there was within-study imprecision: for the majority of the studies, sample size justification was not provided and there were fewer than 10 outcome events for each prognostic variable (for dichotomous outcomes) or there were fewer than 100 cases per regression analysis (Hayden 2014), or as few as two participants per prognostic variable (Austin 2015) (for continuous outcomes);

- we considered whether any Cls were wide because of inconsistency, which could have led to double counting of GRADE factors (Iorio 2015).

- for a narrative summary:

- within-study imprecision: sample size justification was not provided and there were fewer than 10 outcome events for each prognostic variable (for dichotomous outcomes) or there were fewer than 100 cases per regression or two participants per prognostic factor (for continuous outcomes);

- imprecision in the estimation of the effect size within each primary study, and across-study imprecision: there were few studies and a small number of participants across studies.

\section{Publication bias}

We examined funnel plots for asymmetry provided there were at least 10 studies. We also considered downgrading routinely, unless the value of the risk/protective factor in predicting the outcome had been repetitively investigated, ideally by phase 2 and 3 studies.

\section{Upgrading the evidence certainty}

\section{Large effect estimate}

We considered upgrading the evidence certainty if the pooled effect (for meta-analysis) was moderate or large, or if a moderate or large similar effect was reported by most studies (for a narrative summary). An effect estimate was considered moderate if the odds ratio was $\geq$ 1.5 or $\leq 2$, and large if it was $>2$ (Hemingway 1999). We noted that risk of bias may have led to inflated effect estimates. 


\section{Dose effect}

We upgraded the evidence certainty if, for meta-analysis, a gradient was present between analyses for factors measured at different levels (doses). For a narrative review, we considered upgrading if studies seemed similar apart from dose.

\section{CONTRIBUTIONS OFAUTHORS}

Maggie Westby: designed and coordinated the review; extracted data; checked the quality of data extraction; analysed and interpreted data; undertook and checked quality assessment; performed statistical analysis; produced the first draft of the review; contributed to writing and editing the review; approved the final review prior to submission and is the guarantor of the review.

Jo Dumville: conceived, designed and coordinated the review; analysed and interpreted data; checked the quality of the statistical analysis; contributed to writing and editing the review; advised on the review; secured funding; performed previous work that was the foundation of the current review and approved the final review prior to submission.

Nikki Stubbs: contributed to writing and editing the review; advised on the review and approved the final review prior to submission.

Gill Norman: extracted data; checked the quality of data extraction; analysed and interpreted data; undertook and checked quality assessment; contributed to writing and editing the review and approved the final review prior to submission.

Jason Wong: checked the quality of data extraction; contributed to writing or editing the review; advised on the review and approved the final review prior to submission.

Nicky Cullum: conceived the review; analysed or interpreted data; checked the quality of the statistical analysis; contributed to writing and editing the review; advised on the review; secured funding; performed previous work that was the foundation of the current review and approved the final review prior to submission.

Richard Riley: checked the quality of the statistical analysis; contributed to writing or editing the review; advised on the review and approved the final review prior to submission.

\section{Contributions of the editorial base}

Tanya Walsh (Editor): edited the protocol; advised on methodology, interpretation and protocol content; approved the final protocol prior to submission.

Gill Rizzello (Managing Editor): coordinated the editorial process; edited the protocol and the review.

Ursula Gonthier (Editorial Assistant): edited the Plain Language Summary and the reference sections of the review.

\section{DECLARATIONSOF INTEREST}

Maggie Westby: my employment at the University of Manchester while completing this work was funded by a National Institute for Health Research (NIHR)-funded Cochrane programme grant that focused on high-priority Cochrane Reviews in the prevention and treatment of wounds. This research was co-funded by the NIHR Manchester Biomedical Research Centre.

Jo Dumville: received research funding from the NIHR for the production of systematic reviews focusing on high-priority Cochrane Reviews in the prevention and treatment of wounds. This research was co-funded by the NIHR Manchester Biomedical Research Centre, and partly funded by the National Institute for Health Research Collaboration for Leadership in Applied Health Research and Care (NIHR CLAHRC) Greater Manchester.

Nikki Stubbs: I have received payments from Cogora, a healthcare marketing agency and expenses for conference attendance. Funding from pharmaceutical companies supports training and education events in the service and I have received payments for non-productrelated educational sessions. These were unrelated to the subject matter of the systematic review and have never been in support or in pursuit of the promotion of products.

Gill Norman: my employment at the University of Manchester while completing this work was funded by an NIHR-funded Cochrane programme grant that focused on high-priority Cochrane Reviews in the prevention and treatment of wounds. This research was co-funded by the NIHR Manchester Biomedical Research Centre.

Jason Wong: none known.

Nicky Cullum: received research funding for wounds-related research and systematic reviews from the NIHR for the production of systematic reviews focusing on high-priority Cochrane Reviews in the prevention and treatment of wounds. This research was co-funded by the NIHR Manchester Biomedical Research Centre, and partly funded by the National Institute for Health Research Collaboration for Leadership in Applied Health Research and Care (NIHR CLAHRC) Greater Manchester. 
Richard Riley: none known.

\section{SOURCES OF SUPPORT}

\section{Internal sources}

- Division of Nursing, Midwifery and Social Work, School of Health Sciences, Faculty of Biology, Medicine and Health, University of Manchester, UK.

\section{External sources}

- National Institute for Health Research (NIHR), UK.

This project was supported by the NIHR, via Cochrane Infrastructure and Cochrane Programme Grant funding (NIHR Cochrane Programme Grant 13/89/08 - High Priority Cochrane Reviews in Wound Prevention and Treatment) to Cochrane Wounds. The views and opinions expressed herein are those of the authors and do not necessarily reflect those of the Systematic Reviews Programme, the NIHR, the NHS or the Department of Health.

- NIHR Manchester Biomedical Research Centre (BRC), UK.

This research was co-funded by the NIHR Manchester BRC. The views expressed in this publication are those of the authors and not necessarily those of the NHS, the National Institute for Health Research or the Department of Health.

- National Institute for Health Research Collaboration for Leadership in Applied Health Research and Care (NIHR CLAHRC), Greater Manchester, UK.

Nicky Cullum and Jo Dumville's work on this project was partly funded by the NIHR CLAHRC, Greater Manchester. The funder had no role in the decision to publish, or preparation of the manuscript. However, the review may be considered to be affiliated to the work of the NIHR CLAHRC Greater Manchester. The views expressed herein are those of the authors and not necessarily those of the NHS, NIHR or the Department of Health.

\section{DIFFERENCES BETWEEN PROTOCOL AND REVIEW}

The protocol was intended to cover the inclusion of both Phase 1 (exploratory, univariate) and Phase 2 (confirmatory, multivariable) studies, but the search identified no Phase 2 studies and we modified the methods to take account of this. This affected the reporting and analysis of prognostic factor-outcome associations.

- We extracted, where possible, raw data to allow calculation of associations in univariate studies (e.g. proportions with elevated and non-elevated protease levels for healed and unhealed wounds).

- For dichotomous healing outcomes with continuous prognostic factor levels, we conducted univariate regression analyses where IPD were provided, otherwise, we conducted a 'reverse' t-test to obtain an indication of associations between outcome (as an independent variable) and prognostic factor (dependent variable).

- We did not conduct any meta-analyses, but represented the data on forest plots.

- Post-hoc, we modified the QUIPS approach to risk of bias assessment for domain 6 (statistical analysis and reporting) to avoid double counting, both with the GRADE approach and with the QUIPS domain 5 (adjustment factors).

- We did not present formal 'Summary of findings' tables because the vast majority of the evidence was at high risk of bias and this, together with the study design, meant that the evidence was of very low certainty throughout.

We decided pragmatically not contact the authors for further data: in some cases this would have been inappropriate for Phase 1 studies and in other cases, delaying the review to obtain further data would have been unproductive because the overall risk of bias was so high (e.g. the secondary outcome, change in ulcer size, not being adjusted for baseline size). Eight studies did not provide useable results, but some were not intended to investigate associations with healing and others were too poorly conducted to make author contact worthwhile.

\section{N DEX TERMS}

\section{Medical Subject Headings (MeSH)}

*Wound Healing; Case-Control Studies; Peptide Hydrolases [*metabolism]; Prognosis; Prospective Studies; Randomized Controlled Trials as Topic; Regression Analysis; Retrospective Studies; Survival Analysis; Varicose Ulcer [enzymology]

\section{MeSH check words}

Humans 